Business School

University of Navarra
Public-Private

Sector

Research Center
Working Paper

WP-774

November, 2008

Rev. October, 2009

\title{
STRATEGIC SUPPLY FUNCTION COMPETITION WITH PRIVATE INFORMATION
}

\author{
Xavier Vives
}


The Public-Private Center is a Research Center based at IESE Business School. Its mission is to develop research that analyses the relationships between the private and public sectors primarily in the following areas: regulation and competition, innovation, regional economy and industrial politics and health economics.

Research results are disseminated through publications, conferences and colloquia. These activities are aimed to foster cooperation between the private sector and public administrations, as well as the exchange of ideas and initiatives.

The sponsors of the SP-SP Center are the following:

- Accenture

- Ajuntament de Barcelona

- Caixa Manresa

- Cambra Oficial de Comerç, Indústria i Navegació de Barcelona

- Consell de l'Audiovisual de Catalunya

- Departamento de Economía y Finanzas de la Generalitat de Catalunya

- Departamento de Innovación, Universidades y Empresa de la Generalitat de Catalunya

- Diputació de Barcelona

- Fundació AGBAR

- Garrigues

- Mediapro

- Microsoft

- Sanofi Aventis

- VidaCaixa

The contents of this publication reflect the conclusions and findings of the individual authors, and not the opinions of the Center's sponsors. 


\title{
STRATEGIC SUPPLY FUNCTION COMPETITION WITH PRIVATE INFORMATION
}

\author{
Xavier Vives $^{1^{*}}$
}

\begin{abstract}
A finite number of sellers (n) compete in schedules to supply an elastic demand. The costs of the sellers have uncertain common and private value components and there is no exogenous noise in the system. A Bayesian supply function equilibrium is characterized; the equilibrium is privately revealing and the incentives to acquire information are preserved. Price-cost margins and bid shading are affected by the parameters of the information structure: supply functions are steeper with more noise in the private signals or more correlation among the costs parameters. In fact, for large values of noise or correlation supply functions are downward sloping, margins are larger than the Cournot ones, and as we approach the common value case they tend to the collusive level. Private information coupled with strategic behavior induces additional distortionary market power above full information levels and welfare losses which can be counteracted by subsidies. As the market grows large the equilibrium becomes price-taking, bid shading is of the order of $1 / \mathrm{n}$, and the order of magnitude of welfare losses is $21 / \mathrm{n}$. The results extend to demand schedule competition and a range of applications in product and financial markets are presented.
\end{abstract}

Keywords: reverse auction, demand schedule competition, market power, adverse selection, competitiveness, rational expectations, collusion, welfare.

JEL codes: L13, D44, D82, G14, L94, E58, F13

${ }^{1}$ Professor of Economics, Abertis Chair of Regulation, Competition and Public Policy, IESE and UPF.

I am grateful to Carolina Manzano, Natalia Fabra, Juanjo Ganuza, John Moore, Jean Charles Rochet, Marzena Rostek and participants at seminars at Columbia, Harvard-MIT theory seminar, LSE, Yale, the Toulouse 2007 electricity conference, ESSET 2007 at Gerzensee, the Econometric Society Meeting at New Orleans (2008), and the MIT LIDS Conference on Frontiers of Game Theory and Networked Control Systems (2008) for very helpful comments and suggestions, and to Rodrigo Escudero and Vahe Sahakyan for excellent research assistance. The research in this paper is part of the project Information and Competition, European Advanced Grant (no. 230254) of the European Research Council. I also thank the Abertis Chair of Regulation, Competition and Public Policy, project SEJ2005- 08263 at UPF, Project Consolider-Ingenio CSD2006-00016 and project EC02008-05155 of the Spanish Ministry of Education and Science, as well as the Barcelona GSE Research Network for financial support. 


\section{Introduction}

Many markets are characterized by traders competing in demand or supply schedules. This is very common in financial markets and some goods markets like wholesale electricity. Competition in supply functions has been used also to model bidding for government procurement contracts, management consulting, airline pricing reservation systems and provides a reduced form in strategic agency and trade policy models. And, indeed, the jury is still out on whether many markets are best described as being characterized by price or quantity competition and the supply function model appears as an attractive contender. In many situations private information is relevant and uncertainty has both a common and private values components. This is the case, for example, in both Treasury and central bank liquidity auctions as well as in the reverse auctions proposed by the Treasury to extract toxic assets from the balance sheets of banks. In this paper I present a model of strategic competition in schedules with an information structure which allows for private and common values, and does not need exogenous noise (e.g. noise traders or noisy supply), and explore the impact of private information on price-cost margins, bid shading, competitiveness, and welfare.

Competition in supply schedules has been studied in the absence of uncertainty by Grossman (1981) and Hart (1985) showing a great multiplicity of equilibria. ${ }^{1}$ A similar result is obtained by Wilson (1979) in a share auction model. Back and Zender (1993) and Kremer and Nyborg (2004) obtain related results for Treasury auctions. Some of the equilibria can be very collusive. ${ }^{2}$ Klemperer and Meyer (1989) show how adding uncertainty in the supply function model can reduce the range of equilibria and even pin down a unique equilibrium provided the uncertainty has unbounded support. ${ }^{3}$ In this case the supply function equilibrium always is between the Cournot and competitive

1 Grossman thought of firms signing implicit contracts with consumers that committed the firm to a supply function. Hart uncovers the equivalence between choosing a reaction function and a supply function.

2 Back and Zender (2001) and LiCalzi and Pavan (2005) show how the auction can be designed to limit those collusive equilibria.

3 In a linear-quadratic model this is a linear equilibrium. 
(Bertrand) outcomes. This is also the result in Vives (1986) where the slope of the supply function is fixed by technological considerations. The supply function models considered typically do not allow for private information. ${ }^{4}$ Kyle (1989) introduces private information into a double auction for a risky asset of unknown liquidation value and derives a unique symmetric linear Bayesian equilibrium in demand schedules when traders have constant absolute risk aversion, there is noise trading, and uncertainty follows a Gaussian distribution. Exogenous noise is needed to prevent fully revealing prices and the collapse of the market.

Consider a market where $\mathrm{n}$ sellers compete to satisfy a downward sloping demand. Each seller receives a noisy signal of his uncertain private cost. We could consider the symmetric situation where $\mathrm{n}$ buyers with uncertain private valuations compete to fulfill an upward sloping supply schedule. In the paper we stick to the seller convention until we develop applications. The modeling strategy is to consider linear-quadratic payoffs coupled with an affine information structure, which admits common and private value components, that yields a unique symmetric linear Bayesian supply function equilibrium (LBSFE) of the game among the $\mathrm{n}$ sellers. We do not need to introduce noise in the system. The characterization of a linear equilibrium with supply function competition when there is market power and private information needs some careful analysis in order to model the capacity of a seller to influence the market price at the same time that the seller learns from the price. Kyle (1989) pioneered this type of analysis in a financial market context introducing noise trading in order to prevent prices from being fully revealing and the market collapsing. The present paper provides a tractable alternative to the models with an aggregate exogenous shock based on rational traders who are heterogeneous because of idiosyncrasies that translate in their market positions.

It is found that there is a unique LBSFE except in the pure common value case. This equilibrium is privately revealing. That is, the private information of a firm and the price provide a sufficient statistic of the joint information in the market. This means in

4 Exceptions are the empirical papers of Hortaçsu and Puller (2008) and Kühn and Machado (2004) in electricity. 
particular that the incentives to acquire information are preserved despite the fact that the price aggregates information. In fact, this is so even as we approach the common value case as long as the prior is diffuse enough or the marginal cost of acquiring precision at 0 is null. We do not examine possible nonlinear equilibria. Linear equilibria are tractable, in particular in the presence of private information, have desirable properties like simplicity, and have proved very useful as a basis for empirical analysis.

In the linear equilibrium with private information sellers are more cautious when they see a price raise since it may mean that costs are high. The more so, with sellers using steeper schedules, when signals are noisier or costs parameters more correlated. The market looks less competitive in those circumstances as reflected in increased price-cost margins. This is reminiscent of the winner's curse in auctions. Indeed, the price has an informative role on top of its traditional capacity as index of scarcity. In fact, when the first effect is strong enough supply functions slope downwards and margins are larger than the Cournot ones. This is in contrast to the results of Klemperer and Meyer (1989) with symmetric information. More surprisingly perhaps, as we approach the common value case margins tend to the collusive level. Price-cost margins and bid shading increase with more correlation of cost shocks and/or noisier signals. This happens at the unique linear equilibrium only because of information-induced market power and not because of the existence of a vast multiplicity of equilibria. Relaxation of competition due to adverse selection in a common value environment is also obtained in Biais et al. (2000). I find also that price volatility is increasing in the noise of the signals and in the underlying cost volatility.

When sellers face and inelastic demand then the comparative statics results on the information structure parameters hold but supply functions are always upward sloping. Indeed, the linear equilibrium breaks down when supply schedules become too steep. This is akin to the results of Kyle (1989) and Wang and Zender (2002) studying demand schedule competition. Interestingly, in our case the "linkage principle" of the auction literature according to which on average, the cost to the buyer decreases when providing suppliers with more information about the value of the good (Milgrom and Weber 
(1982)), does not hold. In our case more public information enhances the informational role of the price and makes bidders more cautious instead of more aggressive. ${ }^{5}$

A welfare optimal allocation can be implemented by a price-taking Bayesian supply function equilibrium. This is so since at a LBSFE there is a deadweight loss only because of strategic trading since the equilibrium is privately revealing. Sellers at the strategic equilibrium act as if there were price-takers but facing steeper marginal costs than the true ones. The difference in slopes, the distortion induced by private information, is increasing with the correlation of cost shocks and noise in the signals. This means that both aggregate/allocative and distributive/productive inefficiency increase with the size of the distortion implying too low sales and too similar sales among sellers. It is shown that a quadratic subsidy which lowers the perceived slope of marginal costs of sellers may alleviate or eliminate the distortion and improve efficiency. Furthermore, typically, the deadweight loss increases as we approach the common value case and with noisier signals.

The paper considers also the large market case where the number of sellers and demand are replicated ( $\mathrm{n}$ is the number of sellers and the size of the market as well). Then the distortion induced by private information and bid shading are decreasing in $n$, and the incentives to acquire information are preserved even as we approach the common value case as long as the prior is diffuse enough or the marginal cost of acquiring precision at 0 is low enough. Furthermore, bid shading is of the order of $1 / n$, in a large market there is no efficiency loss (in the limit) and the order of magnitude of the deadweight loss is $1 / \mathrm{n}^{2}$. This is also the rate of convergence to efficiency obtained in a double auction context by Cripps and Swinkels (2006).

The welfare evaluation of the LBSFE is in marked contrast with the Cournot equilibrium in the presence of private information. The reason is that the LBSFE aggregates

5 Perry and Reny (1999) show how, for related reasons, the linkage principle may fail in multi-unit auctions. 
information but not the Cournot market. The welfare analysis in the supply function model contrasts thus with the one in models where there is no endogenous public signal such as the Cournot market in Vives (1988), the beauty contest in Morris and Shin (2002), or the general linear-quadratic set up of Angeletos and Pavan (2007). With Cournot competition we have to add a deadweight loss due to lack of information aggregation. A large Cournot market does not aggregate information (i.e. a large Cournot market does not approach a full information competitive outcome) and in the limit there is a welfare loss due to private information.

A leading application of the model to goods markets is to wholesale electricity. The model admits also other interpretations in goods markets. The cost shock could be related to some ex post pollution or emissions damage which is assessed on the firm. Before submitting its supply schedule a firm would receive some private information on this pollution damage. Still another interpretation of the shock would be a random opportunity cost of serving the market which is related to revenue management dynamic considerations.

The plan of the paper is as follows. Section 2 presents the supply function model with strategic firms and characterizes a linear Bayesian supply function equilibrium and its comparative static properties. It includes results with costly information acquisition. Section 3 performs a welfare analysis characterizing the distortion at the LBSFE and deadweight losses, and showing how to implement the efficient allocation with pricetaking equilibria or with subsidy schemes. Section 4 studies replica markets and characterizes the convergence to price-taking behavior as the market grows large and an analysis of the order of magnitude of deadweight losses. Section 5 presents welfare simulations results of the model and includes a comparison with Bayesian Cournot equilibria. Section 6 introduces applications to electricity markets, pollution control, revenue management, strategic agency and trade policy, reverse auctions, and demand schedule competition in financial markets (to legacy loan auction, central bank liquidity and Treasury auctions). Concluding remarks, including potential policy implications, 
close the paper. Most proofs and the analysis of endogenous information acquisition and the Bayesian Cournot model are gathered in the Appendix.

\section{A strategic supply function model}

Consider a market for a homogenous good with $\mathrm{n}$ sellers. Seller i faces a cost

$$
\mathrm{C}\left(\mathrm{x}_{\mathrm{i}} ; \theta_{\mathrm{i}}\right)=\theta_{\mathrm{i}} \mathrm{x}_{\mathrm{i}}+\frac{\lambda}{2} \mathrm{x}_{\mathrm{i}}^{2}
$$

of supplying $x_{i}$ units of the good where $\theta_{i}$ is a random parameter and $\lambda>0 .{ }^{6}$ Demand arises from an aggregate buyer with quasilinear preferences and gross surplus $U(y)=\alpha y-\beta y^{2} / 2$, where $\alpha$ and $\beta$ are positive parameters and $y$ the consumption level. This gives rise to the inverse demand

$$
\mathrm{P}(\mathrm{y})=\alpha-\beta \mathrm{y}
$$

where $\mathrm{y}$ is total consumption. In a reverse auction, for example, the buyer presents the schedule $\mathrm{P}(\mathrm{y})=\alpha-\beta \mathrm{y}$ to the sellers who will bid to supply. We will comment as we go along on how the results specialize to the case of inelastic demand and in Section 6 on how they can be reinterpreted for the case of demand instead of supply bids. Total surplus is therefore given by TS $=\mathrm{U}\left(\sum_{\mathrm{i}} \mathrm{x}_{\mathrm{i}}\right)-\sum_{\mathrm{i}} \mathrm{C}\left(\mathrm{x}_{\mathrm{i}}, \theta_{\mathrm{i}}\right)$.

We assume that $\theta_{i}$ is normally distributed (with mean $\bar{\theta}>0$ and variance $\sigma_{\theta}^{2}$ ). The parameters $\theta_{i}$ and $\theta_{j}, j \neq i$, are correlated with correlation coefficient $\rho \in[0,1]$. So we have $\operatorname{cov}\left[\theta_{i}, \theta_{j}\right]=\rho \sigma_{\theta}^{2}$, for $j \neq i$. Seller i receives a signal $s_{i}=\theta_{i}+\varepsilon_{i}$ and signals are of the same precision with $\varepsilon_{\mathrm{i}}$ normally distributed with $\mathrm{E}\left[\varepsilon_{\mathrm{i}}\right]=0$ and $\operatorname{var}\left[\varepsilon_{\mathrm{i}}\right]=\sigma_{\varepsilon}^{2}$. Error terms in the signals are uncorrelated among themselves and with the $\theta_{\mathrm{i}}$ parameters. All random variables are thus normally distributed.

\footnotetext{
6 We could also deal easily with the case where there the seller faces an adjustment cost of the form $\lambda\left(\mathrm{x}_{\mathrm{i}}-\hat{\mathrm{x}}_{\mathrm{i}}\right)^{2} / 2$ where $\hat{\mathrm{x}}_{\mathrm{i}}$ is a target quantity for agent $\mathrm{i}$.
} 
Ex-ante, before uncertainty is realized, all sellers face the same prospects. It follows that the average parameter $\tilde{\theta} \equiv\left(\sum_{\mathrm{i}=1}^{\mathrm{n}} \theta_{\mathrm{i}}\right) / \mathrm{n}$ is normally distributed with mean $\bar{\theta}$, $\operatorname{var}[\tilde{\theta}]=(1+(\mathrm{n}-1) \rho) \sigma_{\theta}^{2} / \mathrm{n}$, and $\operatorname{cov}\left[\tilde{\theta}, \theta_{\mathrm{i}}\right]=\operatorname{var}[\tilde{\theta}]$.

Our information structure encompasses the cases of "common value" and of "private values". For $\rho=1$ the $\theta$ parameters are perfectly correlated and we are in a common value model. When signals are perfect, $\sigma_{\varepsilon}^{2}=0$ for all $\mathrm{i}$, and $0<\rho<1$, we will say we are in a private values model. Agents receive idiosyncratic shocks, which are imperfectly correlated, and each agent observes his shock with no measurement error. When $\rho=0$, the parameters are independent, and we are in an independent values model.

Let $\xi \equiv \sigma_{\theta}^{2} /\left(\sigma_{\theta}^{2}+\sigma_{\varepsilon}^{2}\right)$, it is not difficult to see that $\mathrm{E}\left[\theta_{\mathrm{i}} \mid \mathrm{s}_{\mathrm{i}}\right]=\xi_{\mathrm{s}_{\mathrm{i}}}+(1-\xi) \bar{\theta}$ and $\mathrm{E}\left[\mathrm{s}_{\mathrm{j}} \mid \mathrm{s}_{\mathrm{i}}\right]=\mathrm{E}\left[\theta_{\mathrm{j}} \mid \mathrm{s}_{\mathrm{i}}\right]=\xi \rho \mathrm{s}_{\mathrm{i}}+(1-\xi \rho) \bar{\theta}$. When signals are perfect, $\xi=1$ and $\mathrm{E}\left[\theta_{\mathrm{i}} \mid \mathrm{s}_{\mathrm{i}}\right]=\mathrm{s}_{\mathrm{i}}$, and $\mathrm{E}\left[\theta_{\mathrm{j}} \mid \mathrm{s}_{\mathrm{i}}\right]=\rho \mathrm{s}_{\mathrm{i}}+(1-\rho) \bar{\theta}$. When they are not informative, $\xi=0$ and $\mathrm{E}\left[\theta_{\mathrm{i}} \mid \mathrm{s}_{\mathrm{i}}\right]=\mathrm{E}\left[\theta_{\mathrm{j}} \mid \mathrm{s}_{\mathrm{i}}\right]=\bar{\theta}$.

Under the normality assumption conditional expectations are affine. There are other families of conjugate prior and likelihood that also yield affine conditional expectations and allow for bounded supports of the distributions. (See Vives (Ch. 2, 1999)). ${ }^{7}$

Sellers compete in supply functions. We will restrict attention to symmetric Linear Bayesian Supply Function Equilibrium (LBSFE). The characterization of an equilibrium with supply function competition when there is market power and private information needs to model the capacity of a seller to influence the market price at the same time that the seller learns from the price.

7 With normal distributions there is positive probability that prices and quantities are negative in equilibrium. This can be controlled by choice of the variances of the distributions and the parameters $\alpha, \beta, \lambda$ and $\bar{\theta}$. 
The strategy for seller $\mathrm{i}$ is a price contingent schedule $\mathrm{X}\left(\mathrm{s}_{\mathrm{i}}, \cdot\right)$. This is a map from the signal space to the space of supply functions. Given the strategies of sellers $X\left(s_{j}, \cdot\right), j=1$, $\ldots, \mathrm{n}$, for given realizations of signals market clearing implies that

$$
\mathrm{p}=\mathrm{P}\left(\sum_{\mathrm{j}=1}^{\mathrm{n}} \mathrm{X}\left(\mathrm{s}_{\mathrm{j}}, \mathrm{p}\right)\right)
$$

Let us assume that there is a unique market clearing price $\hat{\mathrm{p}}\left(\mathrm{X}\left(\mathrm{s}_{1}, \cdot\right), \ldots, \mathrm{X}\left(\mathrm{s}_{\mathrm{n}}, \cdot\right)\right)$ for any realizations of the signals. ${ }^{8}$ Then profits for seller $i$, for any given realization of the signals, are given by

$$
\pi_{\mathrm{i}}\left(\mathrm{X}\left(\mathrm{s}_{1}, \cdot\right), \ldots, \mathrm{X}\left(\mathrm{s}_{\mathrm{n}}, \cdot\right)\right)=\mathrm{pX}\left(\mathrm{s}_{\mathrm{i}}, \mathrm{p}\right)-\mathrm{C}\left(\mathrm{X}\left(\mathrm{s}_{\mathrm{i}}, \mathrm{p}\right)\right)
$$

where $\mathrm{p}=\hat{\mathrm{p}}\left(\mathrm{X}\left(\mathrm{s}_{1}, \cdot\right), \ldots, \mathrm{X}\left(\mathrm{s}_{\mathrm{n}}, \cdot\right)\right)$. This defines a game in supply functions and we want to characterize a symmetric LBSFE.

Given linear strategies of rivals $X\left(s_{j}, p\right)=b-a s_{j}+c p, j \neq i$, seller $i$ faces a residual inverse demand

$$
\mathrm{p}=\alpha-\beta \sum_{\mathrm{j} \neq \mathrm{i}} \mathrm{X}\left(\mathrm{s}_{\mathrm{j}}, \mathrm{p}\right)-\beta \mathrm{x}_{\mathrm{i}}=\alpha-\beta(\mathrm{n}-1)(\mathrm{b}+\mathrm{cp})+\beta \mathrm{a} \sum_{\mathrm{j \neq i}} \mathrm{s}_{\mathrm{j}}-\beta \mathrm{x}_{\mathrm{i}} .
$$

Provided $1+\beta(n-1) c>0$ it follows that

$$
\mathrm{p}=\mathrm{I}_{\mathrm{i}}-\beta(1+\beta(\mathrm{n}-1) \mathrm{c})^{-1} \mathrm{x}_{\mathrm{i}}
$$

where

$$
I_{i}=(1+\beta(n-1) c)^{-1}\left(\alpha-\beta(n-1) b+\beta a \sum_{j \neq i} s_{j}\right)
$$

All the information provided by the price to seller $\mathrm{i}$ about the signals of others is subsumed in the intercept of residual demand $\mathrm{I}_{\mathrm{i}}$. The information available to seller $\mathrm{i}$ is therefore $\left\{s_{i}, p\right\}$ or, equivalently, $\left\{s_{i}, I_{i}\right\}$. Seller $i$ chooses $x_{i}$ to maximize

8 If there is no market clearing price assume the market shuts down and if there are many then the one that maximizes volume is chosen. 
$E\left[\pi_{i} \mid s_{i}, p\right]=x_{i}\left(p-E\left[\theta_{i} \mid s_{i}, p\right]\right)-\frac{\lambda}{2} x_{i}^{2}=x_{i}\left(I_{i}-\beta(1+\beta(n-1) c)^{-1} x_{i}-E\left[\theta_{i} \mid s_{i}, p\right]\right)-\frac{\lambda}{2} x_{i}^{2}$

The F.O.C. is

$$
I_{i}-E\left[\theta_{i} \mid s_{i}, I_{i}\right]-2 \beta(1+\beta(n-1) c)^{-1} x_{i}-\lambda x_{i}=0
$$

or, equivalently,

$$
p-E\left[\theta_{i} \mid s_{i}, p\right]=(d+\lambda) x_{i}
$$

where $d \equiv\left(\beta^{-1}+(n-1) c\right)^{-1}$, yielding a supply function

$$
X\left(s_{i}, p\right)=\frac{p-E\left[\theta_{i} \mid s_{i}, p\right]}{d+\lambda} .
$$

The second order sufficient condition for a maximum is $2 d+\lambda>0$. An equilibrium must fulfill also $1+\beta(n-1) c>0$. It is worth noting that there is strategic complementarity in the slopes of supply functions for given predicted values $t_{i} \equiv E\left[\theta_{i} \mid s_{i}, p\right]$. Indeed, for given $t_{i}$ the slope of $X\left(s_{i}, p\right)$ is $1 /(d+\lambda)$ which is increasing in the slope of the (aggregate) supply function of the rivals $(n-1) c$. The following proposition characterizes the linear equilibrium.

Proposition 1. Let $\rho<1$ and $\sigma_{\varepsilon}^{2} / \sigma_{\theta}^{2}<\infty$, then there is a unique symmetric linear Bayesian supply function equilibrium. It is given by the supply function

$$
X\left(s_{i}, p\right)=\left(p-E\left[\theta_{i} \mid s_{i}, p\right]\right) /(d+\lambda)
$$

with $d=\left(\beta^{-1}+(n-1) c\right)^{-1}, c \equiv \partial X / \partial p$ is the slope of supply and is given by the largest solution to the quadratic equation

$$
\begin{aligned}
& \lambda \beta(n-1)(1+M) c^{2}+\left((\beta+\lambda)(1+M)+\left(\lambda n^{-1} M-\beta\right)(n-1)\right) c \\
& +(\beta+\lambda) \beta^{-1} n^{-1} M-1=0
\end{aligned}
$$

where $M \equiv \frac{\rho \sigma_{\varepsilon}^{2} n}{(1-\rho)\left(\sigma_{\varepsilon}^{2}+(1+(n-1) \rho) \sigma_{\theta}^{2}\right)}$. The sensitivity to private information is $\mathrm{a} \equiv-\partial \mathrm{X} / \partial \mathrm{s}_{\mathrm{i}}$ and $\mathrm{a}=\frac{(1-\rho) \sigma_{\theta}^{2}}{\left(\sigma_{\varepsilon}^{2}+(1-\rho) \sigma_{\theta}^{2}\right)}(\mathrm{d}+\lambda)^{-1}$. In equilibrium we have that 
$1 / \lambda>\mathrm{c}>-\mathrm{M} /(1+\mathrm{M}) \beta \mathrm{n}, \mathrm{a}>0$, and $\mathrm{c}$ decreases with $\mathrm{M}$ and with $\lambda$. When $\mathrm{M}=0$ we have that $c>0$ and $c$ is increasing in $n$. When $c>0$ then $(n-1) c$, and therefore $d^{-1}$ are increasing in $\mathrm{n}$.

Proof: See Appendix I.

Average quantity is given by $\tilde{\mathrm{x}} \equiv\left(\sum_{\mathrm{i}} \mathrm{x}_{\mathrm{i}}\right) / \mathrm{n}=\mathrm{b}-\mathrm{a} \tilde{\mathrm{s}}+\mathrm{cp}, \quad$ where $\tilde{\mathrm{s}} \equiv\left(\sum_{\mathrm{i}} \mathrm{s}_{\mathrm{i}}\right) / \mathrm{n}=\tilde{\theta}+\left(\sum_{\mathrm{i}} \varepsilon_{\mathrm{i}}\right) / \mathrm{n}$. Substituting in the inverse demand $\mathrm{p}=\alpha-\beta n \tilde{\mathrm{x}}$ and solving for $\mathrm{p}$ we obtain

$$
\mathrm{p}=(1+\beta \mathrm{nc})^{-1}(\alpha-\beta \mathrm{nb}+\beta \mathrm{na} \tilde{\mathrm{s}}) .9
$$

The price $\mathrm{p}$ reveals the aggregate information $\tilde{\mathrm{s}}$. The equilibrium is privately revealing (i.e. for seller $i\left(s_{i}, p\right)$ or $\left(s_{i}, \tilde{s}\right)$ is a sufficient statistic of the joint information in the market $\mathrm{s}=\left(\mathrm{s}_{1}, \ldots, \mathrm{s}_{\mathrm{n}}\right)$, see Allen (1981)). In particular, in equilibrium we have that $\mathrm{E}\left[\theta_{\mathrm{i}} \mid \mathrm{s}_{\mathrm{i}}, \mathrm{p}\right]=\mathrm{E}\left[\theta_{\mathrm{i}} \mid \mathrm{s}_{\mathrm{i}}, \tilde{\mathrm{s}}\right]=\mathrm{E}\left[\theta_{\mathrm{i}} \mid \mathrm{s}\right]$. It is worth noting that key to the private revealing property of the equilibrium is that the same signal $s_{i}$ conveys information about the idiosyncratic component $\eta_{i} \equiv \theta_{i}-\tilde{\theta}$ and an aggregate component $\tilde{\theta}$ (average cost parameter). Indeed, an equivalent formulation of the individual cost parameter has $\theta_{i}=\tilde{\theta}+\eta_{i}$, where $\operatorname{cov}\left[\eta_{i}, \tilde{\theta}\right]=0$ and $n^{-1} \sum_{i=1}^{n} \eta_{i}=0$.

Despite the fact that the LBSFE is privately revealing it is distorted in relation to the full information supply function equilibrium where sellers share $s=\left(s_{1}, \ldots, s_{n}\right)$ (denoted by a superscript f). Indeed, following a similar analysis as before it is easy to see that $X^{f}\left(s_{i}, p\right)=\left(p-E\left[\theta_{i} \mid s\right]\right) /\left(d^{f}+\lambda\right)$ where $d^{f}$ corresponds in Proposition 1 to the case

9 Note that since $\mathrm{c}>-\mathrm{M} /(1+\mathrm{M}) \beta \mathrm{n}>-1 / \beta \mathrm{n}$ in equilibrium $1+\beta \mathrm{nc}>0$ (and then $1+\beta(n-1) c=1+\beta n c-\beta c>0$, with either if $c>0$ or $c<0$, as posited to derive $\left.I_{i}\right)$. 
$\mathrm{M}=0$ (in which case $\mathrm{c}=\mathrm{c}^{\mathrm{f}}$, where $\mathrm{c}^{\mathrm{f}}$ is given implicitly by the positive root of $\left.\left(\beta^{-1}+(n-1) c\right)^{-1}+\lambda=c^{-1}\right)$. Whenever there is no correlation between the cost parameters $(\rho=0)$ or signals are perfect (the private values case with $\left.\sigma_{\varepsilon}^{2} / \sigma_{\theta}^{2}=0\right)^{10}, \mathrm{M}=0$, $\mathrm{E}\left[\theta_{\mathrm{i}} \mid \mathrm{s}_{\mathrm{i}}, \mathrm{p}\right]=\mathrm{E}\left[\theta_{\mathrm{i}} \mid \mathrm{s}\right]=\mathrm{E}\left[\theta_{\mathrm{i}} \mid \mathrm{s}_{\mathrm{i}}\right]$ and seller $\mathrm{i}$ does not learn about $\theta_{\mathrm{i}}$ from prices. In these cases the LBSFE coincides with the full information equilibrium. When $\rho>0$ or $\sigma_{\varepsilon}^{2} / \sigma_{\theta}^{2}>0$ sellers learn from prices and supply functions at the LBSFE are steeper: $\mathrm{c}<\mathrm{c}^{\mathrm{f}}$ (and $\mathrm{d}>\mathrm{d}^{\mathrm{f}}$ ). ${ }^{11}$ The price at a LBSFE serves a dual role as index of scarcity and as conveyor of information. This can be seen from the supply function $\mathrm{X}\left(\mathrm{s}_{\mathrm{i}}, \mathrm{p}\right)=\left(\mathrm{p}-\mathrm{E}\left[\theta_{\mathrm{i}} \mid \mathrm{s}_{\mathrm{i}}, \mathrm{p}\right]\right) /(\mathrm{d}+\lambda)$. Indeed, a high price has a direct effect to increase the competitive supply of a seller, but also conveys news that costs are high (since $E\left[\theta_{i} \mid s_{i}, p\right]$ is increasing in $p$ ).

\section{Comparative statics}

If $\rho=0$ or $\sigma_{\varepsilon}^{2} / \sigma_{\theta}^{2}=0$ then the price conveys no extra information on the costs of seller $i$, the equilibrium coincides with the full information equilibrium, and $c>0$. The fact that $\mathrm{c}<\mathrm{c}^{\mathrm{f}}$ is due to adverse selection. As $\rho$ or $\sigma_{\varepsilon}^{2} / \sigma_{\theta}^{2}$ increase then the slope of the supply function becomes steeper ( $\mathrm{c}$ decreases) because of the informational component of the price (i.e. the seller learns more from the price about its cost shock and reacts less to a price change than if the price was only an index of scarcity) and turns negative at some point. Indeed, it is easily checked that $\mathrm{c}$ decreases in $\rho$ and $\sigma_{\varepsilon}^{2} / \sigma_{\theta}^{2}$. This follows from the fact that $\mathrm{c}$ decreases with $\mathrm{M}$ and $\mathrm{M}$ is in turn increasing in $\rho$ and $\sigma_{\varepsilon}^{2} / \sigma_{\theta}^{2}$. Note that as $\sigma_{\varepsilon}^{2}$ increases the private signal of a seller diminishes its precision in a one-to-one fashion while the precision in the price diminishes according to the factor $1 /(\mathrm{n}-1)$. As $\rho$ tends to $1, \mathrm{c}$ becomes negative. There are particular parameter combinations (i.e. when

10 In this case the equilibrium is independent of $\rho$ and it exists even if $\rho=1$.

11 It is worth noting that the equilibrium depends only on the ratio $\sigma_{\varepsilon}^{2} / \sigma_{\theta}^{2}$. 
$\left.\mathrm{M}=\mathrm{n}\left(1+\lambda \beta^{-1}\right)^{-1}\right)$ for which the scarcity and informational effects balance and sellers set a zero weight $(\mathrm{c}=0)$ on public information. In this case sellers do not condition on the price and the model reduces to the Cournot model where sellers compete in quantities. However, in this particular case, when supply functions are allowed, not reacting to the price (public information) is optimal. Figure 1 depicts the change in the equilibrium supply function as $\rho$ goes from 0 to 1 for $s_{i}=\bar{\theta}: X(\bar{\theta}, p)$.

\section{LBSFE}

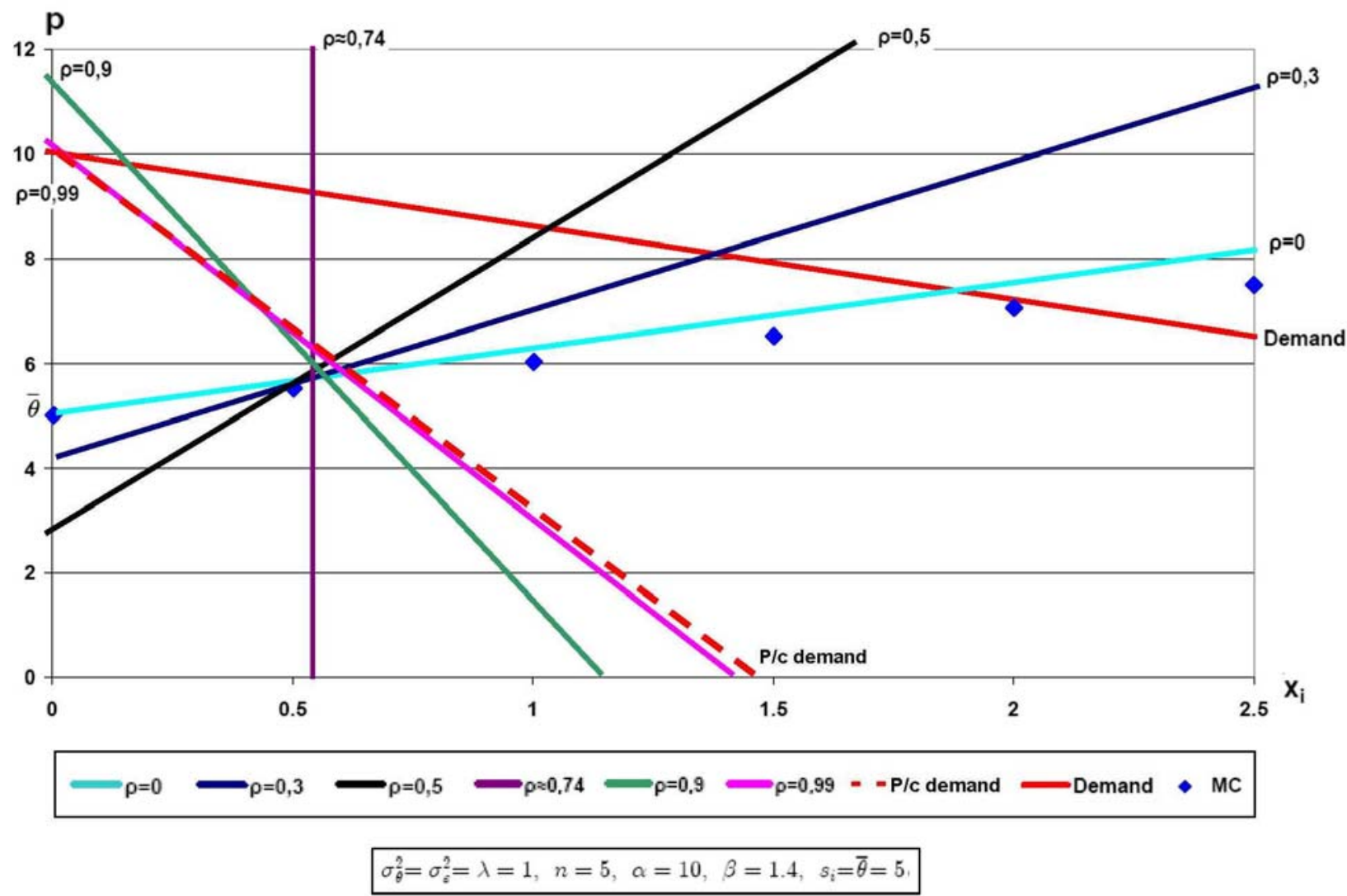

Figure 1 . The $\operatorname{LBSFE} X(\bar{\theta}, \mathrm{p})$ as $\rho$ goes from 0 to 1 .

The results are reminiscent of asymmetric information models where traders submit steeper schedules to protect themselves against adverse selection (Kyle (1989), Biais, Martimort, Rochet (2000))..$^{12}$ The phenomenon is akin to the winner's curse in common

12 Kyle (1989) and Wang and Zender (2002) consider a common value model with noise. Biais et al. (2000) in a common value environment show that adverse selection reduces the aggressiveness of 
value auctions (Milgrom and Weber (1982)): a bidder refrains from bidding aggressively because winning conveys the news that the signal the bidder has received was too optimistic (the highest signal in the pool). Bidders shade their bid more, to protect against the winner's curse, the less precise their signals are. ${ }^{13}$ In our model a seller refrains from competing aggressively with its supply function because a high price conveys the bad new that costs are high and the more so the less precise his signal is. ${ }^{14}$

When increasing $\rho$ the variance of aggregate fundamental volatility $\tilde{\theta}$ also increases. In some situations we would like to know the impact of changing $\rho$ for $\operatorname{var}[\tilde{\theta}]$ constant. This will entail to decrease $\sigma_{\theta}^{2}$ appropriately. If we do so we will find that increasing $\rho$ makes c smaller than when we allow $\operatorname{var}[\tilde{\theta}]$ to change (this is so since $\mathrm{M} \equiv \rho \sigma_{\varepsilon}^{2} /((1-\rho)(\operatorname{var}[\tilde{\theta}]+\operatorname{var}[\tilde{\varepsilon}]))$ increases by more when we keep $\operatorname{var}[\tilde{\theta}]$ constant). In short, in constant aggregate variance environments the impact of changes in correlation on the slope of supply is larger.

\section{Inelastic demand}

The case of inelastic demand where an auctioneer demands $q$ units of the good is easily accommodated letting $\beta \rightarrow \infty$ and $\alpha / \beta \rightarrow q$. Then $y=(\alpha-p) / \beta \rightarrow q$. It can be checked then that there is a unique symmetric LBSFE if only if $n-2-M>0$. In this case we have that $\mathrm{d}=((\mathrm{n}-1) \mathrm{c})^{-1}$ and $\mathrm{c}=\frac{\mathrm{n}-2-\mathrm{M}}{\lambda(\mathrm{n}-1)(1+\mathrm{M})}>0$. A necessary condition for existence of the LBSFE is that $\mathrm{n} \geq 3$. As $M$ increases, $\mathrm{n}-2-\mathrm{M} \rightarrow 0$ and $\mathrm{c} \rightarrow 0$ and the LBSFE collapses. This is because of the combination of adverse selection and market power: the demand schedules become too inelastic to sustain a linear equilibrium as

competition in supply schedules of risk neutral uninformed market makers facing a risk averse informed trader who is subject also to an endowment shock.

13 See also Reece (1978).

14 This is also related to the generalized winner's curse or "champion's plague" pointed out in Ausubel (2004) for multi-unit auctions according to which, and translated in our context, the expected cost of a bidder conditional on being allocated a larger quantity is larger than with a smaller quantity. 
$\mathrm{n}-2-\mathrm{M} \rightarrow 0 .{ }^{15}$ This is similar to the double auction context of Kyle (1989) in which a linear equilibrium exists only if the number of informed traders is larger or equal than 3 (when there are no uninformed traders). This is so since the market breaks down when traders submit vertical schedules. In our general model with strategic agents facing an elastic demand function from passive buyers this does not happen.

Furthermore, with inelastic demand supply functions are always upward sloping (c $>0)$. This is as in the auction models of Kyle (1989) or Wang and Zender (2002) where demand schedules always have the "right" slope: downwards. As before, the supply function is always flatter with full information $\left(\mathrm{c}^{\mathrm{f}}=\frac{\mathrm{n}-2}{\lambda(\mathrm{n}-1)}>\mathrm{c}\right)$.

\section{Common values and information acquisition}

The equilibrium is in contrast with the pure common value model of Kyle (1989) where noise traders or noisy supply are needed in order to prevent the collapse of the market. In our model there is no noise and consequently in the pure common value case $(\rho=1$ and $\left.\sigma_{\varepsilon}^{2}<\infty\right)$ the market collapses. Indeed, when $\rho=1$ and $0<\sigma_{\varepsilon}^{2}<\infty$ a fully revealing REE is not implementable and there is no linear equilibrium. The reason should be well understood: if the price reveals the common value then no seller has an incentive to put any weight on its signal (and the incentives to acquire information disappear as well). But if sellers put no weight on their signals then the price can not contain any information on the costs parameters. As $\rho \rightarrow 1, \mathrm{M} \rightarrow \infty$ and at the linear equilibrium in Proposition 1 we have that $\mathrm{d} \rightarrow \beta \mathrm{n},(\mathrm{a} \rightarrow 0, \mathrm{c} \rightarrow-1 / \beta \mathrm{n}, \mathrm{b} \rightarrow \alpha / \beta \mathrm{n})$ and the equilibrium collapses in the limit. In fact, the supply function of a seller converges to the per capita seller demand function $x=(\alpha-p) / \beta n$. (See Figure 1.) As $\rho \rightarrow 1$ traders are less and less aggressive. This is so because of worsened adverse selection coupled with strategic complementarity in the slopes of the supply functions. Indeed, as other traders make steeper their supply

15 We do not examine the existence of potential nonlinear equilibria. Note, however, than in Battacharya and Spiegel (1991) when the linear equilibrium fails to exist there is no other equilibrium except a degenerate no-trade equilibrium. 
functions the best reply of a trader is to do the same. This will have important implications for competitiveness.

Do sellers have incentives to gather information? If the sellers receive the private signals for free, in the course of their activity for example, then this means that each seller has an incentive to rely on its private signal even though the price provides also information. Indeed, for seller $i$ the signal $s_{i}$ still helps in estimating $\theta_{i}$ even though $p$ reveals $\tilde{s}$ (i.e., the equilibrium is privately revealing).

If the signals are costly to acquire and agents face a convex cost of acquiring precision then, even if there are many sellers in the market, each seller will have an incentive to purchase some precision for any correlation of the costs parameters which is not perfect provided that the marginal cost of acquiring precision is zero for zero precision or the prior diffuse enough. More precisely, consider a market where each seller can purchase a private signal at a cost, increasing and convex in the precision $\tau_{\varepsilon} \equiv 1 / \sigma_{\varepsilon_{\mathrm{i}}}^{2}$ of the signal, according to a smooth function $\mathrm{H}(\cdot)$ that satisfies $\mathrm{H}(0)=0, \mathrm{H}^{\prime}>0$ for $\tau_{\varepsilon}>0$, and $H^{\prime \prime} \geq 0$. There are, thus, nonincreasing returns to information acquisition. We consider the case where each seller does not observe the precision purchased by other sellers and look therefore at a simultaneous move game where each seller chooses its precision and the supply function. Denote by $\psi\left(\tau_{\varepsilon}\right)$ the marginal benefit of acquiring precision evaluated at a symmetric solution and let $\psi(0) \equiv \lim _{\tau_{\varepsilon} \rightarrow 0} \psi\left(\tau_{\varepsilon}\right)>0$. It can be shown (see Proposition A.1 in Appendix II for a formal statement and proof of the result) that there is a symmetric equilibrium in the game with costly information acquisition provided that $\mathrm{H}^{\prime}(0)<\psi(0)$ and $\rho<1$. At equilibrium sellers buy a positive precision of information $\tau_{\varepsilon}^{*}>0$. This is so in particular if $\mathrm{H}^{\prime}(0)=0$ or the prior is diffuse enough $-\tau_{\theta}$ small- (even if the number of sellers is large and/or $\rho$ close to 1). As $\rho \rightarrow 1$ we have that $\psi(0) \rightarrow\left(2(2 \beta n+\lambda) \tau_{\theta}^{2}\right)^{-1}$. This means that for any $\mathrm{n}$ even as $\rho \rightarrow 1$ there are incentives to acquire information when $\mathrm{H}^{\prime}(0)=0$. The intuition is as follows. The 
marginal benefit of acquiring precision is declining with the level $\tau_{\varepsilon}$ acquired and is positive for $\tau_{\varepsilon}=0$ with a finite number of sellers even if parameters are very correlated (a seller by purchasing a signal will improve the information he has on the common value even though he learns the signals of the other sellers through the price). When the number of sellers is large the improvement will be small but if the seller can purchase a little bit of precision at small cost it will do it. ${ }^{16}$ If $\mathrm{H}^{\prime}(0)>0$ then for $\mathrm{n}$ large enough there is no purchase of information. ${ }^{17}$

If $\mathrm{H}^{\prime}(0) \geq \psi(0)$ then there can not be any information acquisition in a symmetric equilibrium and in fact there is no equilibrium (provided that $\mathrm{H}^{\prime}(0)$ is not too high). We have that $\tau_{\varepsilon}^{*}=0$ at a candidate equilibrium but this can not be an overall equilibrium since if other sellers do not purchase information then the price contains no additional information for a seller and it will pay a single seller to get information (provided that $\mathrm{H}^{\prime}(0)$ is not too high). As parameters $\beta, \lambda, \rho$ and $\mathrm{n}$ move in such a way that $\psi(0) \downarrow \mathrm{H}^{\prime}(0)$, then $\tau_{\varepsilon}^{*} \rightarrow 0$ and the linear supply function equilibrium collapses..$^{18}$

\section{Demand uncertainty}

Demand uncertainty can be incorporated easily in the model as long as it follows a Gaussian distribution. It would add noise to the demand function, $\mathrm{P}(\mathrm{y})=\alpha+\mathrm{u}-\beta \mathrm{y}$ with $\mathrm{u} \sim \mathrm{N}\left(0, \sigma_{\mathrm{u}}^{2}\right)$, and to the inference problem of sellers but should not change the qualitative results. We would have a noisy linear equilibrium instead of privately

16 Jackson (1991) shows the possibility of fully revealing prices in a common value environment with costly information acquisition with a finite number of agents and under some specific parametric assumptions.

17 However, there would be positive purchase for any $\mathrm{n}$ if the prior is diffuse enough in the natural case of a large market where the number of buyers and sellers grow together. See Section 6.

18 Note that when $\sigma_{\varepsilon}^{2} / \sigma_{\theta}^{2} \rightarrow \infty$-in which case $M \rightarrow \rho n /(1-\rho)$ - the equilibrium in Proposition 1 collapses also since $\mathrm{a} \rightarrow 0$. However, in the limit $\sigma_{\varepsilon}^{2} / \sigma_{\theta}^{2} \rightarrow \infty$ there is another linear equilibrium (even when $\rho=1$ ) in which $X(p)=c^{f}(p-\bar{\theta})$ (since $\left.E\left[\theta_{i} \mid s_{i}, p\right]=\bar{\theta}\right)$. 
revealing since sellers would have on top of their private signal a noisy estimate of the average signal. A linear equilibrium would exist even in the common value case. Demand noise would lessen the adverse selection problem making the price less informative about the average signal but still for low enough demand noise we would have downward sloping supply functions in similar circumstances as in our model. ${ }^{19}$ As noise in the demand tended to zero the equilibrium would converge to our privately revealing equilibrium. In the other extreme, with infinite noise, the price would contain no information and sellers would rely only on their private signals.

More in general, what makes our model tractable is the combination of a linear-quadratic payoff structure coupled with an affine information structure (that is, a pair of prior and likelihood that yields affine conditional expectations) that allows for the existence of linear equilibria. Here it is crucial that the slopes of demand and costs are not affected by uncertainty. Adding (intercept) demand uncertainty presents no problem as long as the affine information structure is kept.

\section{Competitiveness}

Seller $i$ bids according to the supply function $X\left(s_{i}, p\right)=\left(p-E\left[\theta_{i} \mid s_{i}, p\right]\right) /(d+\lambda)$ where the bid is "shaded" with respect to the expected marginal cost $E_{i}\left[M C_{i}\right] \equiv E\left[\theta_{i} \mid s_{i}, p\right]+\lambda x_{i}$ according to the factor $d=\left(\beta^{-1}+(n-1) c\right)^{-1}$ :

$$
\mathrm{p}-\mathrm{E}_{\mathrm{i}}\left[\mathrm{MC}_{\mathrm{i}}\right]=\mathrm{dx}_{\mathrm{i}}
$$

This has a translation in terms of margins in the usual Lerner index form. Letting $\eta^{r}=p / d x_{i}$ be the elasticity of residual demand for seller i $x^{r}=\beta^{-1}(\alpha-p)-\sum_{j \neq i} X\left(s_{j}, p\right):$

$$
\frac{p-E_{i}\left[M C_{i}\right]}{p}=\frac{1}{\eta^{r}} .
$$

19 See Vives (2009). 
The (absolute value of the) slope of residual demand is $\mathrm{d}^{-1}$. We see therefore that the competitiveness of the LBSFE depends on $d$ and the slope of supply $c$. A consequence of the comparative statics results is that the margin (and amount of bid shading) over expected marginal cost $E\left[\theta_{i} \mid s_{i}, p\right]+\lambda x_{i}$ is increasing in $\sigma_{\varepsilon}^{2}$ and $\rho$.

We know from Proposition 1 that the aggregate slope of supply of rivals of a seller $(\mathrm{n}-1) \mathrm{c}$ increases (i.e. becomes flatter) with $\mathrm{n}$ whenever $\mathrm{c}>0$ for any $\mathrm{n}$ and therefore that $\beta^{-1}+(n-1) c$ is increasing in $n$ (and therefore $d$ decreasing in $n$ ). It follows that when $\mathrm{c}>0$ the margin is decreasing in $\mathrm{n}$. However, this need not hold when $\mathrm{c}<0 .{ }^{20}$

A similar relation holds for the margin over average expected marginal cost

$$
\begin{gathered}
E_{n}\left[M C_{n}\right] \equiv \sum_{i=1}^{n}\left(E\left[\theta_{i} \mid s_{i}, p\right]+\lambda x_{i}\right) / n=n^{-1} \sum_{i=1}^{n} E\left[\theta_{i} \mid s_{i}, p\right]+\lambda \tilde{x}: \\
p-E_{n}\left[M C_{n}\right]=d \tilde{x}
\end{gathered}
$$

or the aggregate Lerner index:

$$
\frac{p-E_{n}\left[M C_{n}\right]}{p}=\frac{1}{(1+\beta(n-1) c) n \eta_{n}}=\frac{d}{\beta n \eta}
$$

where $\eta=p /(\beta n \tilde{x})$ is the elasticity of demand.

Recall that in equilibrium $\mathrm{E}\left[\theta_{\mathrm{i}} \mid \mathrm{s}_{\mathrm{i}}, \mathrm{p}\right]=\mathrm{E}\left[\theta_{\mathrm{i}} \mid \mathrm{s}_{\mathrm{i}}, \tilde{\mathrm{s}}\right]=\mathrm{E}\left[\theta_{\mathrm{i}} \mid \mathrm{s}\right]$ and therefore $\mathrm{n}^{-1} \sum_{\mathrm{i}=1}^{\mathrm{n}} \mathrm{E}\left[\theta_{\mathrm{i}} \mid \mathrm{s}_{\mathrm{i}}, \mathrm{p}\right]=\mathrm{n}^{-1} \sum_{\mathrm{i}=1}^{\mathrm{n}} \mathrm{E}\left[\theta_{\mathrm{i}} \mid \mathrm{s}\right]=\mathrm{E}[\tilde{\theta} \mid \mathrm{s}]=\mathrm{E}[\tilde{\theta} \mid \tilde{\mathrm{s}}]$ (the latter equality holding since $\tilde{\mathbf{s}}$ is a sufficient statistic for $\mathrm{s}$ in relation to $\tilde{\theta}$ ). We have therefore that

20 Simulations show that another possible pattern is for $(n-1) c$ to have a U-shaped form with $n$. Simulations have been performed for the range of parameters $\sigma_{\varepsilon}^{2}$ and $\sigma_{\theta}^{2}$ in $[0.01,10.01]$ with step size 2, $\rho \in[0,0.9]$ with step size 0.1 , and $\beta$ and $\lambda$ in $[1,10]$, with step size 1 , and $\mathrm{n}$ up to 30 . 
$\mathrm{p}=\mathrm{E}[\tilde{\theta} \mid \tilde{\mathrm{s}}]+(\mathrm{d}+\lambda) \tilde{\mathrm{x}}$ and from the demand function we obtain $\tilde{\mathrm{x}}=(\alpha-\mathrm{E}[\tilde{\theta}[\tilde{\mathrm{s}}]) /(\beta \mathrm{n}+\lambda+\mathrm{d})$ and therefore $\mathrm{E}[\tilde{\mathrm{x}}]=(\alpha-\bar{\theta}) /(\beta \mathrm{n}+\lambda+\mathrm{d})$. It follows that the average expected output decreases (and expected price increases) with $\sigma_{\varepsilon}^{2} / \sigma_{\theta}^{2}$ and $\rho$, and with $\mathrm{n}^{-1}$ if $\mathrm{c}>0$ (since in all these cases $\mathrm{d}$ increases). Similarly, expected bid shading $\mathrm{dE}[\tilde{\mathrm{x}}]$ increases with $\sigma_{\varepsilon}^{2} / \sigma_{\theta}^{2}$ and $\rho$, and with $\mathrm{n}^{-1}$ if $\mathrm{c}>0$.

We have also that $\operatorname{var}[\tilde{\mathrm{x}}]=(\beta \mathrm{n}+\lambda+\mathrm{d})^{-2} \operatorname{var}[\mathrm{E}[\tilde{\theta} \mid \tilde{\mathrm{s}}]]$ and $\operatorname{var}[\mathrm{p}]=(\beta \mathrm{n})^{2} \operatorname{var}[\tilde{\mathrm{x}}]$, where $\quad \mathrm{E}[\tilde{\theta} \mid \tilde{\mathbf{s}}]=\xi \tilde{\mathbf{s}}+(1-\xi) \bar{\theta} \quad$ and $\quad \xi \equiv \operatorname{var}[\tilde{\theta}] /\left(\operatorname{var}[\tilde{\theta}]+\sigma_{\varepsilon}^{2} / \mathrm{n}\right)$, $\operatorname{var}[\tilde{\theta}]=(1+(\mathrm{n}-1) \rho) \sigma_{\theta}^{2} / \mathrm{n} \quad$. From this it follows that $\operatorname{var}[\mathrm{E}[\tilde{\theta} \mid \tilde{\mathrm{s}}]]=\xi^{2} \operatorname{var}[\tilde{\mathrm{s}}]=\xi \operatorname{var}[\tilde{\theta}]$ increases in $\rho$ and $\sigma_{\theta}^{2}$, and decreases in $\sigma_{\varepsilon}^{2}$. We conclude that price volatility decreases with $\sigma_{\varepsilon}^{2}$ and increases with $\sigma_{\theta}^{2}$ (since dincreases with $\left.\sigma_{\varepsilon}^{2} / \sigma_{\theta}^{2}\right)$.

The case $\mathrm{c}=0$ corresponds to a Bayesian Cournot equilibrium, where seller i sets a quantity contingent only on its information $\left\{s_{i}\right\}$, and the aggregate margin is $1 / \mathrm{n} \eta$ (the unique Bayesian Cournot equilibrium is derived formally in Proposition A.3 in Appendix III). The supply function and the Cournot equilibrium coincide when $M=n\left(1+\lambda \beta^{-1}\right)^{-1}$, in which case $\mathrm{c}=0$ (indeed, then it can be checked that $\mathrm{a}^{\text {Cournot }}=\mathrm{a}^{\mathrm{SF}}$ and $\mathrm{b}^{\text {Cournot }}=\mathrm{b}^{\mathrm{SF}}$ ).

When $c>0$, we are in the usual case in which the supply function equilibrium has positive slope and is between the Cournot and the competitive outcomes (e.g. Klemperer and Meyer (1989) when uncertainty has unbounded support). However, when $\mathrm{c}<0$ the margin is larger than the Cournot level and, in fact, converges to the collusive level $1 / \eta$ when $\rho \rightarrow 1$ (this is so since as $\rho \rightarrow 1 \quad(1+\beta \mathrm{cn}) \rightarrow 0$ and $\mathrm{c} \rightarrow-1 / \beta \mathrm{n}$; therefore 
$(1+\beta(n-1) c) \rightarrow 1 / n$ or $d \rightarrow n \beta)$. Indeed, if sellers were to share the signals $\mathrm{s}=\left(\mathrm{s}_{1}, \ldots, \mathrm{s}_{\mathrm{n}}\right)$ and maximize joint profits they would solve:

$$
\operatorname{Max}_{\left(\mathrm{x}_{\mathrm{i}}\right)_{i=1}^{n}} \mathrm{E}\left[\sum_{\mathrm{i}=1}^{\mathrm{n}} \pi_{\mathrm{i}} \mid \mathrm{s}\right]
$$

where $\mathrm{E}\left[\sum_{\mathrm{i}=1}^{\mathrm{n}} \pi_{\mathrm{i}} \mid \mathrm{s}\right]=\sum_{\mathrm{i}=1}^{\mathrm{n}} \mathrm{p} \mathrm{x}_{\mathrm{i}}-\sum_{\mathrm{i}=1}^{\mathrm{n}} \mathrm{E}\left[\theta_{\mathrm{i}} \mid \mathrm{s}\right] \mathrm{x}_{\mathrm{i}}-\frac{\lambda}{2} \sum_{\mathrm{i}=1}^{\mathrm{n}} \mathrm{x}_{\mathrm{i}}^{2}$, and (sufficient) F.O.C.

$$
\alpha-2 \beta \sum_{i=1}^{n} x_{i}-E\left[\theta_{i} \mid s\right]-\lambda x_{i}=0, i=1, \ldots, n .
$$

Adding up across sellers we obtain immediately

$$
\frac{p-E_{n}\left[\mathrm{MC}_{\mathrm{n}}\right]}{\mathrm{p}}=\frac{1}{\eta}
$$

where $E_{n}\left[M C_{n}\right]=n^{-1} \sum_{i=1}^{n} E\left[\theta_{i} \mid s\right]+\lambda \tilde{x}$ (as noted at a LBSFE we have that $\left.\mathrm{E}\left[\theta_{\mathrm{i}} \mid \mathrm{s}_{\mathrm{i}}, \mathrm{p}\right]=\mathrm{E}\left[\theta_{\mathrm{i}} \mid \mathrm{s}_{\mathrm{i}}, \tilde{\mathrm{s}}\right]=\mathrm{E}\left[\theta_{\mathrm{i}} \mid \mathrm{s}\right]\right)$. It is also immediate that the (unconditional) expected average collusive output is $(\alpha-\bar{\theta}) /(2 \beta n+\lambda)$ and, indeed, at the LBSFE as $\rho \rightarrow 1: E[\tilde{x}]=(\alpha-\bar{\theta}) /(\beta n+\lambda+d) \rightarrow(\alpha-\bar{\theta}) /(2 \beta n+\lambda)$ since $d \rightarrow n \beta$.

It is remarkable that sellers may approach collusive margins in a one-shot noncooperative equilibrium because of informationally-induced market power. Let us recall that at the full information equilibrium (corresponding to $\rho=0$ ), indicating the pure market power distortion in the market, the aggregate Lerner index would equal $\left(\left(1+\beta(n-1) \mathrm{c}^{\mathrm{f}}\right) \mathrm{n} \eta\right)^{-1}$. As $\rho \rightarrow 1$ the private information distortion becomes more severe and sellers protect themselves by increasing the slope of their supplies in a escalation reinforced by strategic complementarity of slopes. The result is that the margin tends to the collusive level.

The following proposition summarizes results so far on comparative statics and competitiveness. 
Proposition 2. At the LBSFE, with $\rho<1$ and $\sigma_{\varepsilon}^{2} / \sigma_{\theta}^{2}<\infty$ :

(i) The slope of equilibrium supply is steeper (c smaller) with increases in $\rho$ and $\sigma_{\varepsilon}^{2} / \sigma_{\theta}^{2}$, going from $\mathrm{c}>0$ for $\rho=0$ or $\sigma_{\varepsilon}^{2}=0$ to $\mathrm{c}<0$ for large values of $\rho$ or $\sigma_{\varepsilon}^{2} / \sigma_{\theta}^{2}$.

(ii) When $\mathrm{c}>0(\mathrm{c}<0)$ the margin over average expected marginal cost is smaller (larger) than the Cournot level. As $\rho \rightarrow 1$ the margin and expected output tend to the collusive level.

(iii) Expected bid shading and the margin are increasing in $\rho$ or $\sigma_{\varepsilon}^{2} / \sigma_{\theta}^{2}$ (and with $1 / \mathrm{n}$ for $\mathrm{c}>0)$. The opposite happens with the expected price.

(iv) Price volatility decreases with $\sigma_{\varepsilon}^{2}$ and increases with $\sigma_{\theta}^{2}$.

In the case of inelastic demand, in the range of existence $n-2-M>0$, (i) holds (with $\mathrm{c}>0$ always), (iii) holds (and $\mathrm{d}$ is decreasing with $\mathrm{n}$ ) and bid shading also increases with $\mathrm{q}$ (note that $\mathrm{p}-\mathrm{E}_{\mathrm{n}}\left[\mathrm{MC}_{\mathrm{n}}\right]=\mathrm{dq} / \mathrm{n}$ ), and (iv) also holds (and $\operatorname{var}[\mathrm{p}]$ increases also with $\rho$ since in this case $\operatorname{var}[\mathrm{p}]=\operatorname{var}[\mathrm{E}[\tilde{\theta} \mid \tilde{\mathrm{s}}]]$ ). It is worth noting that according to (iii) the expected price and the payment of the buyer are increasing in the precision of public information $1 / \sigma_{\theta}^{2}$. This is a failure of the "linkage principle" of the auction literature where on average, the cost to the buyer decreases by providing the bidders (suppliers) with more information about the value of the good (Milgrom and Weber (1982)). In our case more public information enhances the informational role of the price and makes bidders more cautious instead of more aggressive. It is worth noting that in our model increasing $1 / \sigma_{\theta}^{2}$ decreases both the variance of the common, $\operatorname{var}[\tilde{\theta}]$, and the idiosyncratic component, $\operatorname{var}\left[\eta_{i}\right]$, of $\theta_{i}$ with more weight to the former the higher is $\rho$.

\section{Welfare analysis}

In order to assess the welfare loss at the LBSFE we provide an alternative outcome-based characterization of the equilibrium and compare it with the full information and with the fully efficient outcomes. At the full information equilibrium sellers have market power 
and there is no private information. There is a welfare loss due to market power with respect to the efficient outcome. At the LBSFE there is on top a welfare loss due to private-information-induced extra market power. I show also that the efficient outcome can be implemented with a price-taking SFE. The section studies whether optimal subsidies can implement the efficient allocation and ends with a characterization of the deadweight losses at the LBSFE.

\subsection{An alternative characterization of the LBSFE outcome and welfare}

The strategies at a LBSFE induce the outcomes $\left(\mathrm{x}_{\mathrm{i}}(\mathrm{s})\right)_{\mathrm{i}=1}^{\mathrm{n}}$ and $\mathrm{p}(\mathrm{s})$ as a function of the realized vector of signals s. At the LBSFE we know that the price reveals $\tilde{\mathrm{s}}$ and that $E\left[\theta_{i} \mid s_{i}, p\right]=E\left[\theta_{i} \mid s_{i}, \tilde{s}\right]=E\left[\theta_{i} \mid s\right]$. It is easy to see then than the outcome at the LBSFE maximizes a distorted surplus function with common information s:

$$
\max _{\left(\mathrm{x}_{\mathrm{i}}\right)_{\mathrm{i}=1}^{\mathrm{n}}}\left\{\mathrm{E}[\mathrm{TS} \mid \mathrm{s}]-\frac{\mathrm{d}}{2} \sum_{\mathrm{i}=1}^{\mathrm{n}} \mathrm{x}_{\mathrm{i}}^{2}\right\}
$$

where $\quad \mathrm{TS}=\mathrm{U}\left(\sum_{\mathrm{i}} \mathrm{x}_{\mathrm{i}}\right)-\sum_{\mathrm{i}} \mathrm{C}\left(\mathrm{x}_{\mathrm{i}}, \theta_{\mathrm{i}}\right)$ and $\mathrm{d}=\left(\beta^{-1}+(\mathrm{n}-1) \mathrm{c}\right)^{-1} \quad$ (where $\mathrm{c}$ is the equilibrium LBSFE parameter). That is, the market solves the surplus maximizing program with a distorted cost function which represents both higher costs and marginal costs:

$$
\hat{\mathrm{C}}\left(\mathrm{x}_{\mathrm{i}}, \theta_{\mathrm{i}}\right) \equiv \mathrm{C}\left(\mathrm{x}_{\mathrm{i}}, \theta_{\mathrm{i}}\right)+\frac{\mathrm{d}}{2} \mathrm{x}_{\mathrm{i}}^{2} .
$$

The result follows since the F.O.C. of the distorted planning problem are:

$$
p-E\left[\theta_{i} \mid s\right]-(d+\lambda) x_{i}=0, i=1, \ldots, n,
$$

which are identical to those of the LBSFE since at the LBSFE: $E\left[\theta_{i} \mid s_{i}, p\right]=E\left[\theta_{i} \mid s\right]$.

It is worth to remark that, indeed, at the LBSFE bids are always shaded according to the distortion $\mathrm{d}, \mathrm{p}=\mathrm{E}\left[\theta_{\mathrm{i}} \mid \mathrm{s}\right]+(\mathrm{d}+\lambda) \mathrm{x}_{\mathrm{i}}$. The LBSFE allocation would be obtained by pricetaking sellers with distorted costs functions $\hat{\mathrm{C}}\left(\mathrm{x}_{\mathrm{i}}, \theta_{\mathrm{i}}\right)$ and full information s. However in 
this case, supply functions would always be upward sloping, $x_{i}=\left(p-E\left[\theta_{i} \mid s\right]\right) /(d+\lambda)$, since there is no informative role for the price to play.

Similarly, the full information supply function equilibrium can be obtained as the solution to a distorted planning program replacing $\mathrm{d}$ by $\mathrm{d}^{\mathrm{f}}$.

It is clear that the full (shared-) information efficient allocation obtains setting $d=0$. This is a Pareto optimal allocation and is characterized by the equality of price and expected marginal cost (with full information):

$$
\mathrm{p}=\mathrm{E}\left[\theta_{\mathrm{i}} \mid \mathrm{s}_{\mathrm{i}}, \tilde{\mathrm{s}}\right]+\lambda \mathrm{x}_{\mathrm{i}}, \mathrm{i}=1, . ., \mathrm{n} .
$$

The implied allocation is symmetric (since the total surplus optimization problem is strictly concave and sellers and information structure are symmetric).

In order to understand the properties of the deadweight losses it is useful to look at outcomes for given predicted values for $\theta$ with full information: $t=\left(t_{1}, \ldots, t_{n}\right)$, $\mathrm{t}_{\mathrm{i}} \equiv \mathrm{E}\left[\theta_{\mathrm{i}} \mid \mathrm{s}\right], \mathrm{i}=1, \ldots, \mathrm{n}$. Note that $\mathrm{E}[\tilde{\theta} \mid \mathrm{s}]=\mathrm{n}^{-1} \sum_{\mathrm{i}=1}^{\mathrm{n}} \mathrm{E}\left[\theta_{\mathrm{i}} \mid \mathrm{s}\right]=\mathrm{n}^{-1} \sum_{\mathrm{i}=1}^{\mathrm{n}} \mathrm{t}_{\mathrm{i}} \equiv \tilde{\mathrm{t}}$. To condition on $t$ is equivalent to condition on $\mathrm{s}$.

The wedge $\mathrm{d}>0$ induces both distributive/productive and aggregate/allocative inefficiency. Distributive inefficiency refers to an inefficient distribution of sales/production of a given aggregate (average) quantity $\tilde{\mathrm{x}}$. Sellers minimize distorted costs $\hat{C}\left(x_{i}, \theta_{i}\right)$ with $d>0$, equivalent to a fictitious more convex technology, and the choices of individual quantities are biased towards too similar sales. Indeed, the market solves the program

$$
\min _{\left(\mathrm{x}_{\mathrm{i}} \mathrm{i}_{\mathrm{i}=1}^{\mathrm{n}}\right.}\left\{\mathrm{E}\left[\sum_{\mathrm{i}=1}^{\mathrm{n}} \hat{\mathrm{C}}\left(\mathrm{x}_{\mathrm{i}}, \theta_{\mathrm{i}}\right) \mid \mathrm{t}\right] \text { s.t. } \mathrm{n}^{-1} \sum_{\mathrm{i}=1}^{\mathrm{n}} \mathrm{x}_{\mathrm{i}}=\tilde{\mathrm{x}}\right\}
$$

yielding $\hat{\mathrm{x}}_{\mathrm{i}}=\tilde{\mathrm{x}}+\left(\tilde{\mathrm{t}}-\mathrm{t}_{\mathrm{i}}\right) /(\mathrm{d}+\lambda), \mathrm{i}=1, \ldots, \mathrm{n}$, while the true cost minimization allocation would obtain setting $d=0$. It follows that the total average minimized cost 


$$
\Omega(\tilde{\mathrm{x}} ; \mathrm{t}, \mathrm{d}) \equiv \mathrm{E}\left[\sum_{\mathrm{i}=1}^{\mathrm{n}} \mathrm{C}\left(\hat{\mathrm{x}}_{\mathrm{i}}, \theta_{\mathrm{i}}\right) \mid \mathrm{t}\right] / \mathrm{n}
$$

is increasing in $\mathrm{d}$. Indeed, it can be checked that

$$
\frac{\partial \Omega}{\partial \mathrm{d}}=\frac{\mathrm{d}}{(\lambda+\mathrm{d})^{2}}\left(\frac{1}{\mathrm{n}} \sum_{\mathrm{i}} \mathrm{t}_{\mathrm{i}}^{2}-\tilde{\mathrm{t}}^{2}\right)>0 .
$$

Aggregate inefficiency refers to a distorted level of average quantity. With $d>0$ average quantity for given $t, E[\tilde{x} \mid t]=(\alpha-\tilde{t}) /(\beta n+\lambda+d)$, is too low with respect to the optimal one -which corresponds to $d=0$. The latter would be the solution to

$$
\max _{\tilde{x}}\{U(n \tilde{x})-\Omega(\tilde{x} ; \mathrm{t}, \mathrm{d}=0)\} .
$$

Average quantity is decreasing in $\mathrm{d}$ and, since total surplus is concave in $\tilde{\mathrm{x}}$, aggregate inefficiency increases with $d$. Since $d>d^{f}>0$ the following ranking of expected average quantity at the LBSFE, full information equilibrium, and efficient allocation follows: $\mathrm{E}[\tilde{\mathrm{x}}]<\mathrm{E}\left[\tilde{\mathrm{X}}^{\mathrm{f}}\right]<\overline{\mathrm{x}} \equiv(\alpha-\bar{\theta}) /(\beta \mathrm{n}+\lambda)$, and correspondingly expected prices follow the reverse ranking.

The distortion $\mathrm{d}^{\mathrm{f}}$ can be assigned to standard market power (since sellers act with full information) while the additional distortion $\mathrm{d}-\mathrm{d}^{\mathrm{f}}>0$ can be assigned to increased market power induced by the private information. Increasing $\sigma_{\varepsilon}^{2}$ or $\rho$ increases $d-d^{f}$ (by increasing d) and therefore raise both aggregate and distributive inefficiency due to a worsened adverse selection problem. The distortion $\mathrm{d}^{\mathrm{f}}$ decreases with $\mathrm{n}$ and the inefficiency is reduced ( $d$ decreases with $n$ when $c>0$ when may increase with $n$ otherwise). The following proposition is then immediate.

Proposition 3. Consider an allocation parameterized by $\mathrm{d}$ for a given realization of predicted values t. Then both aggregate and distributive inefficiency are increasing in $\mathrm{d}$. Furthermore, for given $\mathrm{t}$,

(i) Increases in $\rho$ or $\sigma_{\varepsilon}^{2}$ increase both types of inefficiency at the LBSFE both with respect to the efficient allocation and with respect the full information supply function equilibrium. 
(ii) As $\rho$ or $\sigma_{\varepsilon}^{2}$ increase the inefficiency due to standard market power $\left(\mathrm{d}^{\mathrm{f}}\right)$ stays constant while the one due to information-induced market power $\left(d-d^{f}\right)$ increases.

(iii) Increases in $n$ reduce the inefficiency due to standard market power $\left(\mathrm{d}^{\mathrm{f}}\right)$ but need not reduce the overall one.

The intuition for the result should be clear since increases in $d$, for a given realization of predicted values, reduce average output and bias individual outputs towards excessive similarity. We will see in section 3.3 how these results extend when averaging over the $\mathrm{t}_{\mathrm{i}}{ }^{\prime} \mathrm{s}$, that is, when taking unconditional expectations.

When demand is inelastic Proposition 3 holds with respect to distributive inefficiency (there is no inefficiency in the aggregate quantity) with the exception that now increases in $n$ reduce the overall inefficiency also since they reduce $n$.

\subsection{Price-taking LBSFE and the efficient allocation}

Provided that $\rho<1, \sigma_{\theta}^{2}>0$ and $\sigma_{\varepsilon}^{2}<\infty$, the efficient full information allocation is implemented by a symmetric price-taking LBSFE (denoted by a superscript "c" -for competitive- on the coefficients). The equilibrium strategy of seller $i$ will be of the form $X^{c}\left(s_{i}, p\right)=b^{c}-a^{c} s_{i}+c^{c} p$ and it will arise out of the maximization of expected profits taking prices as given but using the information contained in the price:

$$
\operatorname{Max}_{x_{i}}\left\{\left(p-E\left[\theta_{i} \mid s_{i}, p\right]\right) x_{i}-\frac{\lambda}{2} x_{i}^{2}\right\} .
$$

This will yield the following system of F.O.C.

$$
\mathrm{p}=\mathrm{E}\left[\theta_{\mathrm{i}} \mid \mathrm{s}_{\mathrm{i}}, \mathrm{p}\right]+\lambda \mathrm{x}_{\mathrm{i}} \text { for } \mathrm{i}=1, \ldots, \mathrm{n},
$$

where $p=\left(1+\beta n c^{c}\right)^{-1}\left(\alpha-\beta n b^{c}+\beta n a^{c} \tilde{s}\right)$ provided that $1+\beta n c^{c} \neq 0$. In the linear equilibrium $1+\beta n c^{c}>0$ and $\mathrm{a}^{\mathrm{c}}>0$. Therefore, $\mathrm{p}$ reveals $\tilde{\mathrm{s}}, \mathrm{E}\left[\theta_{\mathrm{i}} \mid \mathrm{s}_{\mathrm{i}}, \mathrm{p}\right]=\mathrm{E}\left[\theta_{\mathrm{i}} \mid \mathrm{s}_{\mathrm{i}}, \tilde{\mathrm{s}}\right]$, and the price-taking LBSFE implements the efficient solution. 
The following proposition can be derived similarly as Proposition 1 (see Appendix I).

Proposition 4. Let $\rho<1$ and $\sigma_{\varepsilon}^{2} / \sigma_{\theta}^{2}<\infty$, then there is a unique symmetric price-taking LBSFE. This equilibrium implements the efficient allocation. It is given by the supply function $X^{c}\left(s_{i}, p\right)=\left(p-E\left[\theta_{i} \mid s_{i}, p\right]\right) / \lambda$. The slope of supply is given by

$$
c^{c}=\frac{\lambda^{-1}-(\beta n)^{-1} M}{M+1} \text { where } M \equiv \frac{\rho \sigma_{\varepsilon}^{2} n}{(1-\rho)\left(\sigma_{\varepsilon}^{2}+(1+(n-1) \rho) \sigma_{\theta}^{2}\right)} .
$$

We have that $1 / \lambda>c^{c}>-M /(1+M) \beta n \quad c^{c}$ decreases with $M$ and $\lambda$, and $c^{c}>0$ for $M=0$. The sensitivity to private information is

$$
\mathrm{a}^{\mathrm{c}}=\frac{(1-\rho) \sigma_{\theta}^{2}}{\left(\sigma_{\varepsilon}^{2}+(1-\rho) \sigma_{\theta}^{2}\right)} \lambda^{-1}>0
$$

Note that we may have also $\mathrm{c}^{\mathrm{c}}<0$. As before the equilibrium supply function can be upward or downward sloping. It will be downward sloping when the reaction to private information is small (i.e. when we are close to the common value case, when prior uncertainty is low or noise in the signals is high). It is worth to remark that the pricetaking supply function will coincide with the marginal cost schedule only when there is no learning from prices (that is, when $\rho \sigma_{\varepsilon}^{2}=0$ ). In this case both boil down to $\mathrm{p}=\mathrm{E}\left[\theta_{\mathrm{i}} \mid \mathrm{s}_{\mathrm{i}}\right]+\lambda \mathrm{x}_{\mathrm{i}}$. The supply functions always go through the point $(\overline{\mathrm{x}}, \overline{\mathrm{p}})$ where $\overline{\mathrm{x}} \equiv(\alpha-\bar{\theta}) /(\beta n+\lambda)$ and $\overline{\mathrm{p}} \equiv(\lambda \alpha+\beta \mathrm{n} \bar{\theta}) /(\beta \mathrm{n}+\lambda)$. This follows easily from the fact that $X^{c}(\bar{\theta}, p)=\bar{X}+c^{c}(p-\bar{p})$. As in the strategic case the supply function of a seller converges to the per capita seller demand function $x=(\alpha-p) / \beta n$ as $\rho \rightarrow 1$. When $\rho=$ 0 we have that $x_{i}=\lambda^{-1}\left(p-E\left[\theta_{i} \mid s_{i}\right]\right)\left(M=0, c^{c}=1 / \lambda\right.$, and $\left.b^{c}=-a^{c} \bar{\theta}\right)$.

For $\rho<1$, and $\sigma_{\varepsilon}^{2} / \sigma_{\theta}^{2}<\infty$, the supply function of a seller in the price-taking equilibrium is always flatter than the supply function of the seller in the strategic equilibrium: 


$$
\mathrm{c}^{\mathrm{c}}-\mathrm{c}=\left(\lambda^{-1}-(\mathrm{d}+\lambda)^{-1}\right) /(\mathrm{M}+1)>0
$$

since in equilibrium $\mathrm{d}>0$. It is immediate also that sellers are more cautious responding to their private signals when they are strategic:

$$
a^{c}-a=\frac{(1-\rho) \sigma_{\theta}^{2}}{\left(\sigma_{\varepsilon}^{2}+(1-\rho) \sigma_{\theta}^{2}\right)}\left(\lambda^{-1}-(d+\lambda)^{-1}\right)>0 .
$$

By the same token, given that $d>d^{f}>0$ we have that $c^{c}>c^{f}>c$ and $a^{c}>a^{f}>a$.

This is because of the usual effect of market power: A seller takes into account the price impact coming from the amount sold. Note that in principle a seller with market power would also be cautious because of the informational leakage from his action, but here the equilibrium is revealing. It should be recalled also that here market power above the full information level $\mathrm{d}^{\mathrm{f}}$ is induced by the adverse selection problem.

Given that the outcome at the LBSFE is like in a price-taking equilibrium with steeper marginal costs (by the amount $\mathrm{d}$ ) the movements in the intercept of marginal costs will have damped effects on prices and quantities in relation to the "true" price-taking equilibrium. Indeed, we confirm in the simulations that price and average output volatility is always larger in the competitive case. Indeed, sellers react more to information in this case.

\subsection{Optimal subsidies}

From the results in Proposition 3 it may be conjectured that first best efficiency may be restored by a quadratic subsidy $\mathrm{kx}_{\mathrm{i}}^{2} / 2$ that "compensates" for the distortion $\mathrm{dx}_{\mathrm{i}}^{2} / 2$ and induces sellers to act competitively. We will see that the conjecture is partially true, a quadratic subsidy can always reduce the distortion but can not eliminate it in some circumstances. $^{21}$

21 See Angeletos and Pavan (2009) for a thorough analysis of tax-subsidy schemes in quadratic continuum economies with private information and with agents using non-contingent strategies (e.g. Cournot type). 
The question is whether we can find a $\kappa$ (with $\kappa>0$ for a subsidy) such that $\lambda-\kappa+d(\kappa)=\lambda$ or $d(\kappa)=\kappa$, where $d(\kappa) \equiv\left(\beta^{-1}+(n-1) c(\lambda-\kappa)\right)^{-1}$ is the (endogenous) distortion when the slope of marginal cost is $\lambda-\kappa$. In this case a seller would act effectively as if he was competitive and facing a marginal cost with slope $\lambda$ and the FOC would be $p-E\left[\theta_{i} \mid s\right]-(d(\kappa)+\lambda-\kappa) x_{i}=p-E\left[\theta_{i} \mid s\right]-\lambda x_{i}=0$. For a given $\kappa<\lambda$ and induced slope of marginal cost $\lambda-\kappa>0$, we know that $\partial \mathrm{c} / \partial \kappa>0$ since $\mathrm{c}$ is strictly decreasing in $\lambda$ (Proposition 1). It follows that $d(\kappa)$ is decreasing in $\kappa$ up to $\kappa=\lambda$.

Equivalently, and given Proposition 4, we have to find a $\kappa$ such that $c(\lambda-\kappa)=c^{c}(\lambda)$ (and this will yield $\left.\mathrm{d}(\kappa) \equiv\left(\beta^{-1}+(\mathrm{n}-1) \mathrm{c}^{\mathrm{c}}(\lambda)\right)^{-1} \quad\right) . \quad$ We have that $c^{c}(\lambda)=\left(\lambda^{-1}-(\beta n)^{-1} M\right) /(M+1)$ goes from $+\infty$ to $-M /(1+M) \beta n$ as $\lambda$ moves in the range $(0,+\infty)$. Therefore given that $c^{c}(\lambda)>c(\lambda)$ and that both are strictly decreasing in $\lambda$, for any $\lambda>0$ there is always a $\kappa>0$ such that $c(\lambda-\kappa)=\mathrm{c}^{\mathrm{c}}(\lambda)$ provided that the range of $\mathrm{c}(\lambda)$ is also from $+\infty$ to $-\mathrm{M} /(1+\mathrm{M}) \beta \mathrm{n}$ as $\lambda$ moves in the range $(0,+\infty)$. This is so if and only if $n-M-2 \geq 0$. In this case as $\lambda \rightarrow 0, \mathrm{c}(\lambda) \rightarrow \infty$. If $\mathrm{n}-\mathrm{M}-2<0$ then as $\lambda \rightarrow 0, \mathrm{c}(\lambda) \rightarrow-(\mathrm{n}-\mathrm{M}) /(\mathrm{n}-\mathrm{M}-2) \beta \mathrm{n}$ (see the Lemma after the proof of Proposition 1 in Appendix I). Then only if $\lambda$ is such that $c^{c}(\lambda) \leq-(n-M) /(n-M-2) \beta n$ we can find the desired $\kappa>0$. If $c^{c}(\lambda)>-(n-M) /(n-M-2) \beta n$ then there is no $\kappa>0$ such that $c(\lambda-\kappa)=c^{c}(\lambda)$. (It would not help either to give a $\kappa$ so that $\lambda-\kappa<0$ since it can be checked that $\partial \mathrm{c} / \partial \lambda>0$ for $\lambda<0)$. When $\mathrm{n}<\mathrm{M}-2$ and $\mathrm{c}^{\mathrm{c}}(\lambda)>-(\mathrm{n}-\mathrm{M}) /(\mathrm{n}-\mathrm{M}-2) \beta \mathrm{n}$ then a quadratic subsidy can reduce the distortion $d$ up to $d(\lambda)$ (since $d$ is decreasing in $\kappa$ ) but the first best is not attained.

In summary: An appropriate quadratic subsidy reduces always the distortion $d$ but can eliminate it completely only when $n-2 \geq M$ or when $n-2<M$ and 
$c^{c}(\lambda) \leq-(n-M) /(n-M-2) \beta n$. The optimal subsidy is given by $\kappa^{*}=\left(\beta^{-1}+(n-1) c^{c}(\lambda)\right)^{-1}$ if feasible to attain the first best or by $\kappa^{*}=\lambda$ otherwise. In the first case the subsidy is increasing in $M$ and $\lambda$ (since $c^{c}$ decreases with $M$ and $\lambda$ ). Indeed, the subsidy parameter $\kappa^{*}$ depends in general on all the deep parameters of the model. This means that $\kappa^{*}$ increases with $\rho$ and $\sigma_{\varepsilon}^{2}$.

Note that the first best can always be attained when there is no adverse selection problem $(\mathrm{M}=0)$ and only standard market power.

If demand is inelastic then $c^{c}=(\lambda(M+1))^{-1}$ and $c=(n-2-M) /(\lambda(n-1)(1+M))>0$ and in both cases $\mathrm{c} \rightarrow \infty$ as $\lambda \rightarrow 0$. Therefore for any $\lambda>0$ there is always a $\kappa \in(0, \lambda)$ such that $c(\lambda-\kappa)=c^{c}(\lambda)$. This is precisely $\kappa^{*}=\left((n-1) c^{c}(\lambda)\right)^{-1}=\lambda(1+M) /(n-1)$. The subsidy $\kappa^{*}$ increases with $\rho, \sigma_{\varepsilon}^{2} / \sigma_{\theta}^{2}$ and $\lambda$, and decreases with $n$.

\subsection{Characterization of the deadweight losses}

The (expected) deadweight loss (DWL) at the LBSFE is the difference between expected total surplus at the LBSFE (ETS) and at the price-taking LBSFE $\left(\right.$ ETS $\left.^{\mathrm{c}}\right),\left(\mathrm{ETS}^{\mathrm{c}}-\mathrm{ETS}\right)$. It can be shown that

$$
\mathrm{DWL} \equiv \mathrm{ETS}^{\mathrm{c}}-\mathrm{ETS}=\mathrm{n}\left(\beta \mathrm{nE}\left[\left(\tilde{\mathrm{x}}-\tilde{\mathrm{x}}^{\mathrm{c}}\right)^{2}\right]+\lambda \mathrm{E}\left[\left(\mathrm{x}_{\mathrm{i}}-\mathrm{x}_{\mathrm{i}}^{\mathrm{c}}\right)^{2}\right]\right) / 2 .
$$

The result follows considering a Taylor series expansion of TS (stopping at the second term due to the quadratic nature of the payoff) around price-taking equilibria. ${ }^{22}$ The key to simplify the computations is to notice that at price-taking equilibria total surplus is maximized. Letting $\mathrm{u}_{\mathrm{i}} \equiv \mathrm{x}_{\mathrm{i}}-\tilde{\mathrm{x}}$ and $\mathrm{u}_{\mathrm{i}}^{\mathrm{c}} \equiv \mathrm{x}_{\mathrm{i}}^{\mathrm{c}}-\tilde{\mathrm{x}}^{\mathrm{c}}$, as in section 3.1, we can further decompose the total inefficiency in terms of aggregate and distributive inefficiency:

22 The result holds true, in fact, comparing a price-taking regime with any another regime which is based on weakly coarser information. 


$$
\operatorname{ETS}^{c}-\operatorname{ETS}=n\left((\beta n+\lambda) E\left[\left(\tilde{x}-\tilde{x}^{c}\right)^{2}\right]+\lambda E\left[\left(u_{i}-u_{i}^{c}\right)^{2}\right]\right) / 2
$$

where $n(\beta n+\lambda) E\left[\left(\tilde{x}-\tilde{x}^{c}\right)^{2}\right] / 2$ corresponds to aggregate inefficiency (loss in surplus when supplying, in a cost-minimizing way, an average output $\tilde{\mathrm{x}}$ different from the benchmark $\tilde{x}^{c}$ ), and $n \lambda E\left[\left(u_{i}-u_{i}^{c}\right)^{2}\right] / 2$ to distributive inefficiency (supply of an average quantity in a non cost-minimizing way). The decomposition follows noting that if average quantities $\tilde{\mathrm{x}}$ and $\tilde{\mathrm{x}}^{\mathrm{c}}$ are supplied in a cost minimizing way then for all $\mathrm{i}$, $\mathrm{u}_{\mathrm{i}}=\mathrm{u}_{\mathrm{i}}^{\mathrm{c}}$.

From the analysis in section 3.1 we have that for aggregate inefficiency,

$$
\tilde{\mathrm{x}}-\tilde{\mathrm{x}}^{\mathrm{c}}=\left((\beta \mathrm{n}+\lambda)^{-1}-(\beta \mathrm{n}+\lambda+\mathrm{d})^{-1}\right)(\alpha-\tilde{\mathrm{t}})
$$

and therefore

$$
E\left[\left(\tilde{x}-\tilde{x}^{c}\right)^{2}\right]=\left((\beta n+\lambda)^{-1}-(\beta n+\lambda+d)^{-1}\right)^{2} E\left[(\alpha-\tilde{t})^{2}\right]
$$

We know that increases in $\rho$ or $1 / \sigma_{\varepsilon}^{2}$ increase the variance of the prediction $\tilde{\mathrm{t}}=\mathrm{E}[\tilde{\theta} \mid \tilde{\mathrm{s}}]$. From this it follows that $E\left[\tilde{\mathrm{t}}^{2}\right]$ and therefore $E\left[(\alpha-\tilde{\mathrm{t}})^{2}\right]$ increase in $\rho$ and decrease in $\sigma_{\varepsilon}^{2}$. This is bad for aggregate efficiency. Since $d$ increases in $\rho\left(\right.$ for $\sigma_{\varepsilon}^{2}>0$ ) we can conclude that aggregate inefficiency increases with $\rho$. We have also that $d$ increases in $\sigma_{\varepsilon}^{2}$ and it can be checked that aggregate inefficiency may be non-monotonic with respect to $\sigma_{\varepsilon}^{2}$ (although it tends to be increasing in $\sigma_{\varepsilon}^{2}$ for $\rho$ not too small).

We have that for distributive inefficiency, $u_{i} \equiv x_{i}-\tilde{x}=\left(\tilde{t}-t_{i}\right) /(\lambda+d)$ and $u_{i}^{c} \equiv x_{i}^{c}-\tilde{x}^{c}=\left(\tilde{t}-t_{i}\right) / \lambda$. Therefore:

$$
E\left[\left(u_{i}-u_{i}^{c}\right)^{2}\right]=\left(\lambda^{-1}-(\lambda+d)^{-1}\right)^{2} E\left[\left(t_{i}-\tilde{t}\right)^{2}\right]
$$


where $\mathrm{t}_{\mathrm{i}} \equiv \mathrm{E}\left[\theta_{\mathrm{i}} \mid \mathrm{s}\right]$.

The deadweight loss due to distributive inefficiency increases with $E\left[\left(t_{i}-\tilde{t}\right)^{2}\right]=\operatorname{var}\left[t_{i}-\tilde{t}\right]=\operatorname{var}\left[\theta_{i}-\tilde{\theta}\right]-\operatorname{var}\left[\left(\theta_{i}-\tilde{\theta}\right) \mid s\right]$. Indeed with $t_{i}=\tilde{t}, i=1, \ldots, n$, there would be no distributive inefficiency. This would happen with $\rho=1$ or $\sigma_{\varepsilon}^{2}=\infty$. Increasing $\rho \quad$ aligns probabilistically $\theta_{\mathrm{i}}$ with $\tilde{\theta}$ and increasing $\sigma_{\varepsilon}^{2}$ increases $\operatorname{var}\left[\left(\theta_{\mathrm{i}}-\tilde{\theta}\right) \mid \mathrm{s}\right]$, both reduce $\operatorname{var}\left[\mathrm{t}_{\mathrm{i}}-\tilde{\mathrm{t}}\right]$. It can be checked with simulations (see Section 5 for details of simulations) that $\mathrm{E}\left[\left(\mathrm{t}_{\mathrm{i}}-\tilde{\mathrm{t}}\right)^{2}\right]$ is decreasing in $\rho$ and $\sigma_{\varepsilon}^{2}$. The effect of $\rho$ $\left(\sigma_{\varepsilon}^{2}\right)$ on $E\left[\left(t_{i}-\tilde{t}\right)^{2}\right]$ is particularly strong when $\sigma_{\varepsilon}^{2}(\rho)$ is small.

If $\rho=0$ then $\mathrm{d}$ is independent of $\sigma_{\varepsilon}^{2}$ and aggregate and distributive inefficiency decrease in $\sigma_{\varepsilon}^{2}$. In consequence, DWL is decreasing in $\sigma_{\varepsilon}^{2}$

If $\sigma_{\varepsilon}^{2}=0$ then $\mathrm{d}$ is independent of $\rho$ and aggregate inefficiency increases in $\rho$ and distributive inefficiency decreases in $\rho$. The second effect dominates always in our simulations and the DWL is decreasing in $\rho$

The welfare loss induced by standard market power, that is, with respect to the full information allocation, is given by

$$
\operatorname{ETS}^{c}-\operatorname{ETS}^{\mathrm{f}}=n\left((\beta n+\lambda) E\left[\left(x^{\mathrm{f}}-\mathrm{x}^{\mathrm{c}}\right)^{2}\right]+\lambda \mathrm{E}\left[\left(\mathrm{u}_{\mathrm{i}}^{\mathrm{f}}-\mathrm{u}_{\mathrm{i}}^{\mathrm{c}}\right)^{2}\right]\right) / 2
$$

and since neither $\rho$ nor $\sigma_{\varepsilon}^{2}$ affect $\mathrm{d}^{\mathrm{f}}$ it follows that both aggregate and distributive inefficiency decrease in $\sigma_{\varepsilon}^{2}$ and therefore the deadweight loss is decreasing in $\sigma_{\varepsilon}^{2}$, and aggregate (distributive) inefficiency increases (decreases) in $\rho$. 
The following proposition summarizes the formal results thus far. We know that for given predicted values $t$ both types of inefficiency increase with $\rho$ and $\sigma_{\varepsilon}^{2}$ but changes in those parameters change the probability distribution over $\mathrm{t}$.

\section{Proposition 5.}

(i) The deadweight loss due to aggregate inefficiency increases always in $\rho$ while distributive inefficiency may increase or decrease in $\rho$. If $\sigma_{\varepsilon}^{2}=0$ then distributive inefficiency decreases in $\rho$.

(ii) Both the deadweight loss due to aggregate and distributive inefficiency may increase or decrease in $\sigma_{\varepsilon}^{2}$. If $\rho=0$ then they both decrease in $\sigma_{\varepsilon}^{2}$.

(iii) With respect to the welfare loss induced by standard market power: both aggregate and distributive inefficiency decrease in $\sigma_{\varepsilon}^{2}$, and aggregate (distributive) inefficiency increases (decreases) in $\rho$.

In the case of inelastic demand the results for distributive inefficiency apply.

Simulations show that the central scenario for the comparative statics of the DWL with respect to $\rho$ and $\sigma_{\varepsilon}^{2}$ confirm the results of Proposition 4 derived for given predicted values of cost parameters provided that $\rho$ and $\sigma_{\varepsilon}^{2}$ are not too small. In this case, increases in $\rho$ or $\sigma_{\varepsilon}^{2}$ increase both aggregate and distributive inefficiency at the LBSFE both with respect to the efficient allocation and with respect the full information supply function allocation. However, increasing $\rho\left(\sigma_{\varepsilon}^{2}\right)$ may decrease the DWL when $\sigma_{\varepsilon}^{2}(\rho)$ is small. ${ }^{23}$

The intuition for the result is that for given $t$ increases in $\rho$ or $\sigma_{\varepsilon}^{2}$ increase both aggregate and distributive inefficiency. When averaging over predicted values distributive

23 See Section 5 for details of the simulations. 
inefficiency decreases with increases in $\rho$ or $\sigma_{\varepsilon}^{2}$ and the effect overwhelms the impact given $\mathrm{t}$ when $\sigma_{\varepsilon}^{2}(\operatorname{or} \rho)$ are small enough.

In the central scenario of the simulations increases in $\rho$ or $\sigma_{\varepsilon}^{2}$ increase the DWL due to private-information-induced market power (the total DWL minus the DWL in the full information equilibrium). This so since the DWL tends to increase with increases in $\rho$ or $\sigma_{\varepsilon}^{2}$ while the DWL in the full information equilibrium diminishes with $\sigma_{\varepsilon}^{2}$ always and distributive inefficiency also diminishes with $\rho$.

\section{Convergence to price-taking behavior in large markets}

In order to study how fast the inefficiency of supply function equilibria disappears in large markets we consider replica markets where the numbers of sellers and buyers grow at the same rate $\mathrm{n}$. More precisely, suppose that there are $\mathrm{n}$ buyers, each with quasilinear preferences and benefit function $\mathrm{u}(\mathrm{x})=\alpha \mathrm{x}-\beta \mathrm{x}^{2} / 2$ where $\mathrm{x}$ is the consumption level. This gives rise to the inverse demand $P_{n}(y)=\alpha-\beta y / n$ where $y$ is total consumption. There are $\mathrm{n}$ sellers as before. Total surplus is therefore given by $\mathrm{TS}=\mathrm{nu}(\mathrm{y} / \mathrm{n})-\sum_{\mathrm{i}} \mathrm{C}\left(\mathrm{x}_{\mathrm{i}}, \theta_{\mathrm{i}}\right)$ and per capita surplus by $\mathrm{TS} / \mathrm{n}=\mathrm{u}(\mathrm{y} / \mathrm{n})-\left(\sum_{\mathrm{i}} \mathrm{C}\left(\mathrm{x}_{\mathrm{i}}, \theta_{\mathrm{i}}\right)\right) / \mathrm{n}$.

We will denote with subscript $\mathrm{n}$ the magnitudes in the $\mathrm{n}$-replica market. The results we have obtained so far, except possibly comparative statics with respect to $\mathrm{n}$, hold replacing $\beta$ beta by $\beta / \mathrm{n}$. In the n-replica market the distortion at the LBFSE is

$d_{n}=\left(n \beta^{-1}+(n-1) c_{n}\right)^{-1}$. It is also true that $c_{n}^{f}$ increases in $n$. Using simulations it can be checked that the aggregate slope of supply of rivals of a seller $(n-1) c_{n}$ increases (i.e. 
becomes flatter) with $\mathrm{n}$ whenever $\mathrm{c}_{\mathrm{n}}>0$ for any $\mathrm{n}^{24}$ and that $\mathrm{n} \beta^{-1}+(\mathrm{n}-1) \mathrm{c}_{\mathrm{n}}$ is increasing in $n$ always (and therefore $d_{n}$ decreasing in $n$ ). It follows that the margin is decreasing in $n$. The same is true of the optimal subsidy $\kappa_{\mathrm{n}}^{*}=\left(\beta^{-1} \mathrm{n}+(\mathrm{n}-1) \mathrm{c}_{\mathrm{n}}^{\mathrm{c}}(\lambda)\right)^{-1}$ when the distortion can be eliminated since it can be checked that it is strictly decreasing in $\mathrm{n}$.

It is worth noting also that if we want to keep $\operatorname{var}\left[\tilde{\theta}_{\mathrm{n}}\right]$ constant when increasing $\mathrm{n}$ (which will mean to decrease $\sigma_{\theta}^{2}$ appropriately since $\operatorname{var}\left[\tilde{\theta}_{n}\right]$ is decreasing in $n$ ), then $c_{n}$ will be smaller than when we allow $\operatorname{var}\left[\tilde{\theta}_{n}\right]$ to vary (this is so since $M_{n}$ increases by more when we keep $\operatorname{var}\left[\tilde{\theta}_{n}\right]$ constant). This will mean that the distortion $d_{n}$ will be larger.

We can examine the incentives to acquire information in the replica market (see Appendix II). The same characterization as in Section 2 holds but now as $\rho \rightarrow 1$ we have that $\psi_{\mathrm{n}}(0) \rightarrow\left(2(2 \beta+\lambda) \tau_{\theta}^{2}\right)^{-1}$. This means that $\rho$ close to 1 for any number of sellers we will need the same degree of diffusion of the prior in order to have positive precision acquisition.

What happens in a large market (that is, a market where the limit $n \rightarrow \infty$ is taken first)? Then $\psi_{\infty}\left(\tau_{\varepsilon}\right) \equiv \lim _{\mathrm{n} \rightarrow \infty} \psi_{\mathrm{n}}\left(\tau_{\varepsilon}\right)=\frac{1}{2 \lambda\left(\tau_{\varepsilon}+\tau_{\theta}(1-\rho)^{-1}\right)^{2}}$. If $\mathrm{H}^{\prime}(0)>0$ let $\bar{\rho}$ be such that

$$
\psi_{\infty}(0)=\frac{(1-\bar{\rho})^{2}}{2 \lambda \tau_{\theta}^{2}}=H^{\prime}(0) \text {. }
$$

24 Another possible pattern is for $(\mathrm{n}-1) \mathrm{c}_{\mathrm{n}}$ to have a hump-shaped form with $\mathrm{n}$ being positive and increasing first to become decreasing and eventually negative ( $c_{n}$ may increase or decrease with $n$ ). See Section 5 for the details of the simulations. 
This yields $\bar{\rho}=1-\tau_{\theta} \sqrt{2 \lambda H^{\prime}(0)}$. There is a unique symmetric equilibrium in the game with costly information acquisition provided that $\rho<\bar{\rho}$. Indeed, then we have $\phi_{\infty}(0)>0$, $\phi_{\infty}(\infty)<0$ and $\phi_{\infty}^{\prime}<0$ where $\phi_{\infty}\left(\tau_{\varepsilon}\right) \equiv \psi_{\infty}\left(\tau_{\varepsilon}\right)-H^{\prime}\left(\tau_{\varepsilon}\right)$

In summary, in a large market, there is a unique symmetric equilibrium in the game with costly information acquisition provided that $\rho<\bar{\rho} \equiv 1-\tau_{\theta} \sqrt{2 \lambda \mathrm{H}^{\prime}(0)}$. With $\rho<1$ this is so in particular if $H^{\prime}(0)=0$ or the prior is diffuse ( $\tau_{\theta}$ small). At equilibrium sellers buy a positive precision of information $\tau_{\varepsilon}^{*}>0$. As $\rho \rightarrow \bar{\rho}$ we have that $\tau_{\varepsilon}^{*} \rightarrow 0$ and the linear supply function equilibrium collapses.

Remark: We could also consider the case where information acquisition is observable in a first stage of the game and then at a second stage sellers compete in supply functions for given precisions. In this case we add a strategic effect of information acquisition and the characterization is much more involved. However, it is possible at least to check that the results are very similar for $\rho$ close to 1 . (For example, we also have that $\psi_{\mathrm{n}}(0) \rightarrow \frac{1}{2(2 \beta+\lambda) \tau_{\theta}^{2}}$ as $\rho \rightarrow 1$.)

We show next how equilibria in finite economies become price-taking. We characterize the rates of convergence and the order of magnitude of the deadweight loss at the LBSFE.

Before stating the convergence results we will recall some measures of speed of convergence. We say that the sequence (of real numbers) $b_{n}$ is of the order $n^{v}$, with $v$ a real number, whenever $\mathrm{n}^{-\mathrm{v}} \mathrm{b}_{\mathrm{n}} \longrightarrow \mathrm{n}$ k for some nonzero constant $\mathrm{k}$. We say that the sequence of random variables $\left\{\mathrm{y}_{\mathrm{n}}\right\}$ converges in mean square to zero at the rate $1 / \sqrt{\mathrm{n}^{\mathrm{r}}}$ (or that $\mathrm{y}_{\mathrm{n}}$ is of the order $1 / \sqrt{\mathrm{n}^{\mathrm{r}}}$ ) if $\mathrm{E}\left[\left(\mathrm{y}_{\mathrm{n}}\right)^{2}\right]$ converges to zero at the rate $1 / \mathrm{n}^{\mathrm{r}}$ (i.e. $E\left[\left(y_{n}\right)^{2}\right]$ is of the order $\left.1 / n^{r}\right)$. Given that $E\left[\left(y_{n}\right)^{2}\right]=\left(E\left[y_{n}\right]\right)^{2}+\operatorname{var}\left[y_{n}\right]$, a 
sequence $\left\{\mathrm{y}_{\mathrm{n}}\right\}$ such that $\mathrm{E}\left[\mathrm{y}_{\mathrm{n}}\right]=0$ and $\operatorname{var}\left[\mathrm{y}_{\mathrm{n}}\right]$ is of the order of $1 / \mathrm{n}$, converges to zero at the rate $1 / \sqrt{\mathrm{n}}$.

In our case $\tilde{\theta}_{\mathrm{n}} \equiv\left(\sum_{\mathrm{i}=1}^{\mathrm{n}} \theta_{\mathrm{i}}\right) / \mathrm{n}$ is normally distributed with mean $\bar{\theta}$ and $\operatorname{var}\left[\tilde{\theta}_{\mathrm{n}}\right]=(1+(\mathrm{n}-1) \rho) \sigma_{\theta}^{2} / \mathrm{n}$. We have therefore that $\tilde{\theta}_{\mathrm{n}} \rightarrow \tilde{\theta}$ in mean square at the rate $1 / \sqrt{\mathrm{n}}$ where $\tilde{\theta}$ is normally distributed with mean $\bar{\theta}$ and variance $\rho \sigma_{\theta}^{2}$.

The following proposition characterizes the convergence of the LBSFE to a price-taking equilibrium as the market grows. As we have seen before the price-taking equilibrium is first best efficient since it aggregates information.

Proposition 6. As the market grows large the market price $\mathrm{p}_{\mathrm{n}}$ (at the LBSFE) converges in mean square to the price-taking Bayesian price $p_{n}^{c}$ at the rate of $1 / n$. (That is, $E\left[\left(p_{n}-p_{n}^{c}\right)^{2}\right]$ tends to 0 at the rate of $1 / n^{2}$.) The deadweight loss at the LBSFE $\left(\mathrm{ETS}_{\mathrm{n}}^{\mathrm{c}}-\mathrm{ETS}_{\mathrm{n}}\right) / \mathrm{n}$ is of the order of $1 / \mathrm{n}^{2}$.

The rate of convergence to price-taking behavior is $1 / \mathrm{n}$, which is the same as the usual rate under complete information. This is a statement that bid shading is of the order of $1 / n$. It follows from the fact that the distortion $d_{n}$ is of order $1 / n$ (alternatively because the difference in equilibrium parameters $a_{n}^{c}-a_{n}$ and $c_{n}^{c}-c_{n}$ is of the order of $1 / n$ ) and both equilibria aggregate information $-p_{n}$ and $p_{n}^{c}$ depend on the average signal $\tilde{s}_{n}$. The departure from price taking (marginal cost) is of the order of $1 / \mathrm{n}$ and the deadweight loss is of the order of the square of it. (See proof in Appendix I.) This result should not be surprising since the LBSFE aggregates information. Cripps and Swinkels (2006) obtain a parallel result in a double auction environment. The authors consider a generalized private value setting where bidders can be asymmetric and can demand or supply multiple units. Under some regularity conditions (and a weak requirement of "a little 
independence" where each player's valuation has a small idiosyncratic component), they find that as the number of players grows (say that there are $n$ buyers and $n$ sellers) all nontrivial equilibria of the double auction converge to the competitive outcome and inefficiency vanishes at the rate of $1 / \mathrm{n}^{2-\alpha}$ for any $\alpha>0$.

As in Kyle (1989) we could ask what happens when the total amount of precision available to agents is fixed as the market grows large. Then as $\mathrm{n}$ tends to infinity $\tau_{\varepsilon} \rightarrow 0$. In this case it is easy to see that the market collapses and the supply function of a seller converges to the per capita demand. ${ }^{25}$ Therefore the non-competitive limit of Kyle does not arise in our private value environment.

At the Bayesian Cournot equilibrium Proposition 6 holds (with the important proviso that now $\left(\mathrm{ETS}_{\mathrm{n}}^{\mathrm{c}}-\mathrm{ETS}_{\mathrm{n}}\right) / \mathrm{n}$ is the deadweight loss with respect to the price-taking equilibrium but not with respect to the full information first best, see Appendix III). The price-taking Bayesian Cournot equilibrium coincides with the full information first best in a large economy only in the independent values case, where there is no aggregate uncertainty (see Vives (2002)). Otherwise, as the market grows large there is no convergence to a full information equilibrium.

In summary, convergence to price-taking is, in both cases, at the rate of $1 / \mathrm{n}$ for prices and $1 / \mathrm{n}^{2}$ for the welfare loss with respect to price-taking behavior.

\section{Simulations and comparison with Cournot}

In this section we simulate the n-replica market and compare the efficiency properties of the supply function mechanism with the Cournot mechanism.

25 This is so since in this case as $\mathrm{n} \rightarrow \infty \mathrm{M}_{\mathrm{n}} \rightarrow \infty$. 


\subsection{Simulating the deadweight losses}

In the central scenario of the simulations ${ }^{26}$ increases in $\rho$ or $\sigma_{\varepsilon}^{2}$ increase the (per capita) deadweight loss at the LBSFE both with respect to the efficient allocation $\left(\mathrm{DWL} / \mathrm{n} \equiv\left(\mathrm{ETS}_{\mathrm{n}}^{\mathrm{c}}-\mathrm{ETS}_{\mathrm{n}}\right) / \mathrm{n}\right)$ and with respect the full information supply function allocation $\left(\left(\operatorname{ETS}_{n}^{\mathrm{f}}-\operatorname{ETS}_{\mathrm{n}}\right) / \mathrm{n}\right)$. (See Figure 2a, b). However, increasing $\rho\left(\right.$ resp. $\left.\sigma_{\varepsilon}^{2}\right)$ may decrease DWL/n when $\sigma_{\varepsilon}^{2}$ (resp. $\rho$ ) is small (see for example in Figure 2.b that the effect of increases in $\sigma_{\varepsilon}^{2}$ are small when $\rho$ is small). The deadweight loss decreases with $\rho\left(\right.$ resp. $\left.\sigma_{\varepsilon}^{2}\right)$ whenever $\sigma_{\varepsilon}^{2}($ resp. $\rho)$ is small. ${ }^{27}$

26 Simulations have been performed for $\beta$ and $\lambda$ in $\{1,5\}, \rho \in[0.01,0.99]$ with step size $0.01, \sigma_{\varepsilon}^{2}$ and $\sigma_{\theta}^{2}$ in $[0.01,10.01]$ with step size 2 , and $n \in[2,82]$ with step size 20. (When needed we extend the simulations to $\rho$ in $[0.001,0.999]$ with step size 0.001 and $\sigma_{\varepsilon}^{2}$ in $[0,10]$ with step size 0.01 .) In this range of simulations and with $\bar{\theta}=30, \alpha=50$ the probability of a negative output is at most $15 \%$ in either the SFE (strategic or competitive versions) or the Cournot equilibrium and the upper bounds are attained only when $\beta=5$ and $\lambda=1$. Otherwise the probabilities of negative output tend to be very low.

27 In our range of simulations we confirm that the total DWL decreases in $\rho\left(\sigma_{\varepsilon}^{2}\right)$ when $\sigma_{\varepsilon}^{2}(\rho)$ is small (in our case below $\sigma_{\varepsilon}^{2}=0.07$ (or below $\rho=0.01$ ). 


\section{[ETS(SFEcomp)-ETS(SFE)]/n}

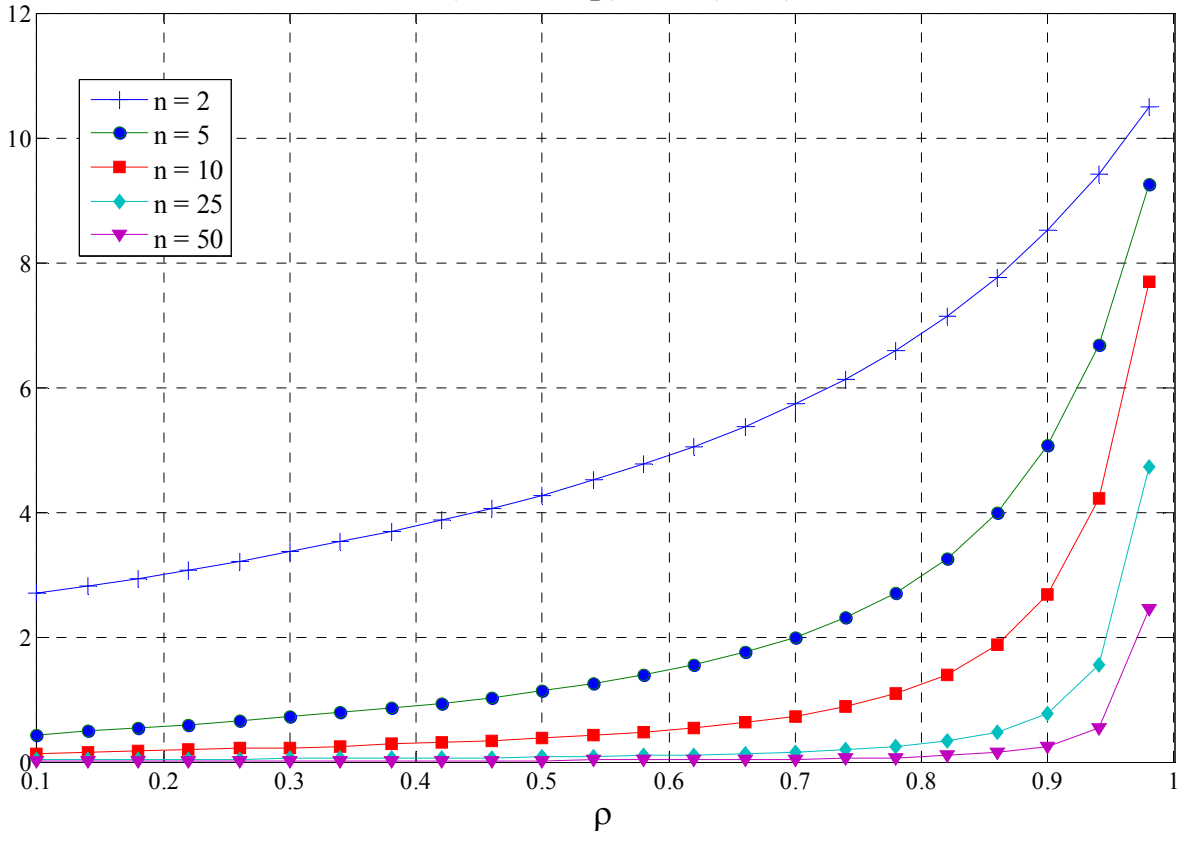

Figure 2a. DWL $/ \mathrm{n} \equiv\left(\operatorname{ETS}_{\mathrm{n}}^{\mathrm{c}}-\mathrm{ETS}_{\mathrm{n}}\right) / \mathrm{n}$ as a function of $\rho$ (with parameters $\beta=\lambda=1$, $\left.\bar{\theta}=30, \alpha=50, \sigma_{\theta}^{2}=\sigma_{\varepsilon}^{2}=1\right)$

[ETS(SFEcomp)-ETS(SFE)]/n

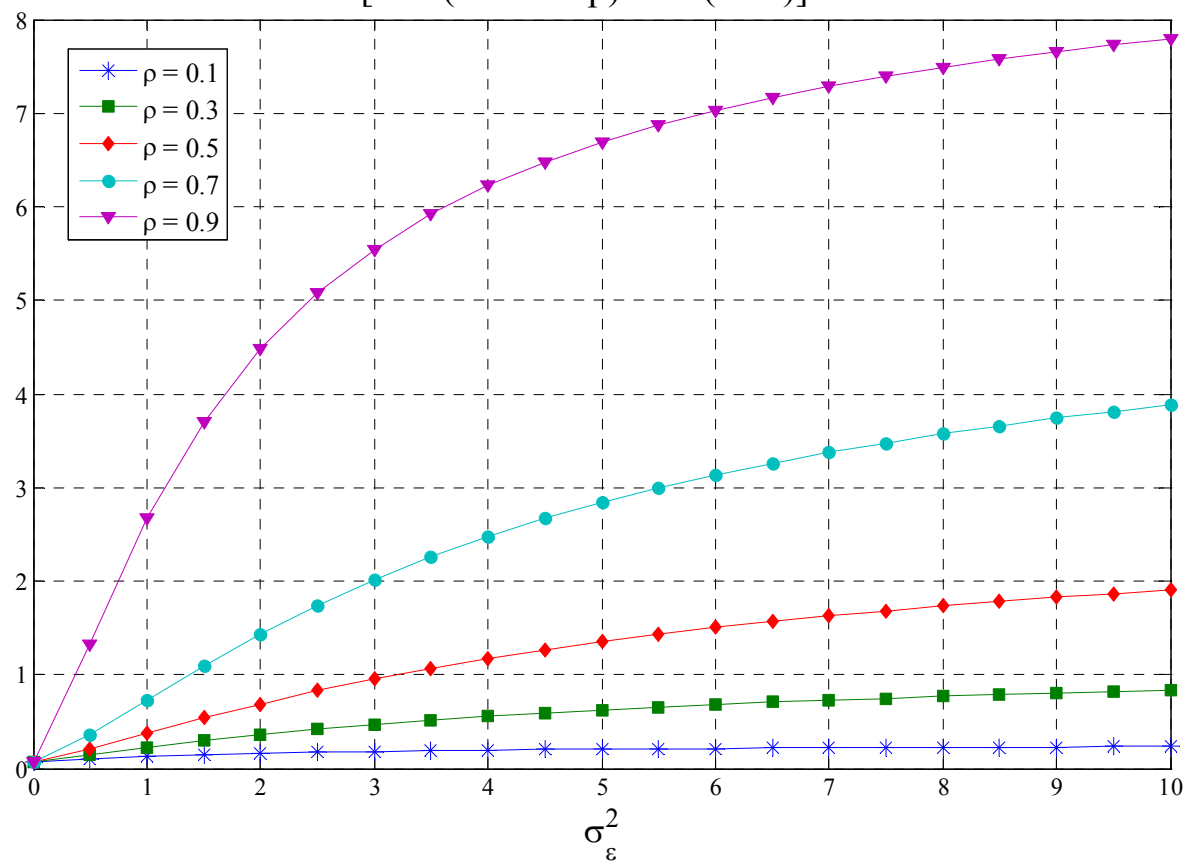

Figure $2 \mathrm{~b} . \mathrm{DWL} / \mathrm{n} \equiv\left(\mathrm{ETS}_{\mathrm{n}}^{\mathrm{c}}-\mathrm{ETS}_{\mathrm{n}}\right) / \mathrm{n}$ as a function of $\sigma_{\varepsilon}^{2}$ (with parameters $\beta=\lambda=1$, $\bar{\theta}=30, \alpha=50, \sigma_{\theta}^{2}=1$, and $\mathrm{n}=10$ ) 
It is also found that $\mathrm{DWL} / \mathrm{n}$ decreases as the market gets large (i.e. with $\mathrm{n}$, see Figure 2.a) and that the rate of decrease is slow for low $\sigma_{\theta}^{2}$. This is driven by the decrease in $d_{n}$ with $\mathrm{n}$ (which overwhelms the fact that when averaging over predictions both $E\left[\left(\alpha-\tilde{t}_{n}\right)^{2}\right]$ and $E\left[\left(t_{i}-\tilde{t}_{n}\right)^{2}\right]$ tend to increase with $\left.n\right)$. Typically, the speed of convergence of the deadweight loss to zero (in terms of the constant of convergence) is slower when $\rho$ is larger. That is, the limit as $n$ tends to infinity of $n\left(\operatorname{ETS}_{n}^{c}-\operatorname{ETS}_{n}\right)$ is increasing with $\rho$. (This is so since $\left(\operatorname{ETS}_{n}^{c}-\operatorname{ETS}_{n}\right)$ is typically increasing in $\rho$ for any $n$ and the limit of $n\left(\operatorname{ETS}_{\mathrm{n}}^{\mathrm{c}}-\mathrm{ETS}_{\mathrm{n}}\right)$ as $\mathrm{n}$ tends to infinity is well defined.)

It is worth noting also that the (per capita) deadweight loss at the full information equilibrium $\left(\left(\operatorname{ETS}_{\mathrm{n}}^{\mathrm{c}}-\mathrm{ETS}_{\mathrm{n}}^{\mathrm{f}}\right) / \mathrm{n}\right.$ or deadweight loss due to standard market power) also decreases with $\mathrm{n}$ but that the (per capita) deadweight loss due to the private-informationinduced market power (that is, $\left(\mathrm{ETS}_{\mathrm{n}}^{\mathrm{f}}-\mathrm{ETS}_{\mathrm{n}}\right) / \mathrm{n}$ may increase with $\mathrm{n}$ for $\mathrm{n}$ low). This is due to the fact that the deadweight loss due to standard market power falls more sharply at the beginning that the one due to the private information induced market power. ${ }^{28}$

\subsection{Comparison with Cournot}

The welfare evaluation of the LBSFE is in marked contrast with the Bayesian Cournot equilibrium. At the LBSFE sellers act with full information and the deadweight loss is due to market power (which is increased in equilibrium due to adverse selection). There would be no welfare loss if sellers would act as price takers. At the price-taking Bayesian Cournot equilibrium there is always a welfare loss because the Cournot market mechanism does not aggregate information. ${ }^{29}$

For example, this happens from $\mathrm{n}=2$ to $\mathrm{n}=4$ when $\beta=\lambda=1, \bar{\theta}=30, \alpha=50, \sigma_{\theta}^{2}=1, \sigma_{\varepsilon}^{2}=10$ and $\rho=0.9$.

29 Except possibly with constant marginal costs (see Palfrey (1985) and Vives (1988). However, a pricetaking Bayesian Cournot equilibrium is team optimal (i.e. maximizes total expected surplus subject to the constraint that sellers use decentralized -quantity- strategies in information, see Vives (1988)). 
It is worth to compare the relative efficiency of the Cournot market $\left(\operatorname{ETS}_{n}^{\text {Cournot }}\right)$ in relation to the supply function market $\left(\mathrm{ETS}_{\mathrm{n}}^{\mathrm{SF}}\right)$ in per capita terms. A typical pattern for moderate $\mathrm{n}$ is for $\left(\mathrm{ETS}_{\mathrm{n}}^{\mathrm{SF}}-\mathrm{ETS}_{\mathrm{n}}^{\text {Cournot }}\right) / \mathrm{n}$ to be positive for $\rho$ close to zero and negative for $\rho$ close to 1 , being zero at the point for which the supply function equilibrium calls for a vertical supply. For large $\mathrm{n}$ we may have $\left(\operatorname{ETS}_{\mathrm{n}}^{\mathrm{SF}}-\mathrm{ETS}_{\mathrm{n}}^{\text {Cournot }}\right) / \mathrm{n}>0$ all along (except for $\rho$ very close to 1). (See Figure 3a.) In fact, for a given $\rho$ and for large $n$ we have always that $\left(\mathrm{ETS}_{\mathrm{n}}^{\mathrm{SF}}-\mathrm{ETS}_{\mathrm{n}}^{\text {Cournot }}\right) / \mathrm{n}>0$. (See Figure 4.) Furthermore, when signals are perfect $\left(\sigma_{\varepsilon}^{2}=0\right)$ we have also that $\left(\operatorname{ETS}_{\mathrm{n}}^{\mathrm{SF}}-\mathrm{ETS}_{\mathrm{n}}^{\text {Cournot }}\right) / \mathrm{n}>0$ always. When signals are close to perfect we have that $\left(\mathrm{ETS}_{\mathrm{n}}^{\mathrm{SF}}-\mathrm{ETS}_{\mathrm{n}}^{\text {Cournot }}\right) / \mathrm{n}>0$ except for $\rho$ very close to 1 . The typical pattern of $\left(\operatorname{ETS}_{\mathrm{n}}^{\mathrm{SF}}-\mathrm{ETS}_{\mathrm{n}}^{\text {Cournot }}\right) / \mathrm{n}$ as a function of $\sigma_{\varepsilon}^{2}$ is similar to $\rho$, being positive for $\sigma_{\varepsilon}^{2}$ small and negative for $\sigma_{\varepsilon}^{2}$ large, and zero at the point for which the supply function equilibrium calls for a vertical supply. (See Figure 3b.)

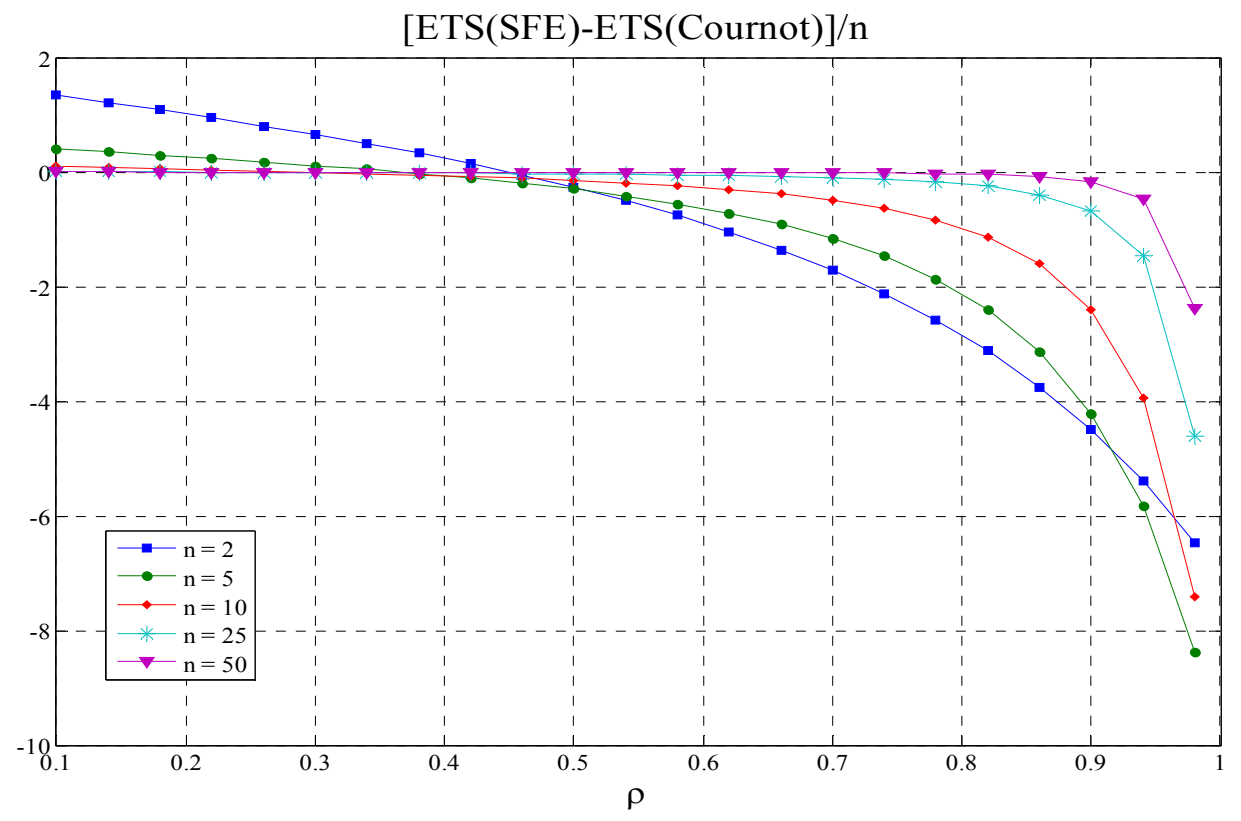

Figure 3a. Efficiency differential between supply function and Cournot equilibria as a function of $\rho$ (with parameters $\beta=\lambda=1, \bar{\theta}=30, \alpha=50$, and $\sigma_{\varepsilon}^{2}=\sigma_{\theta}^{2}=1$ ) 


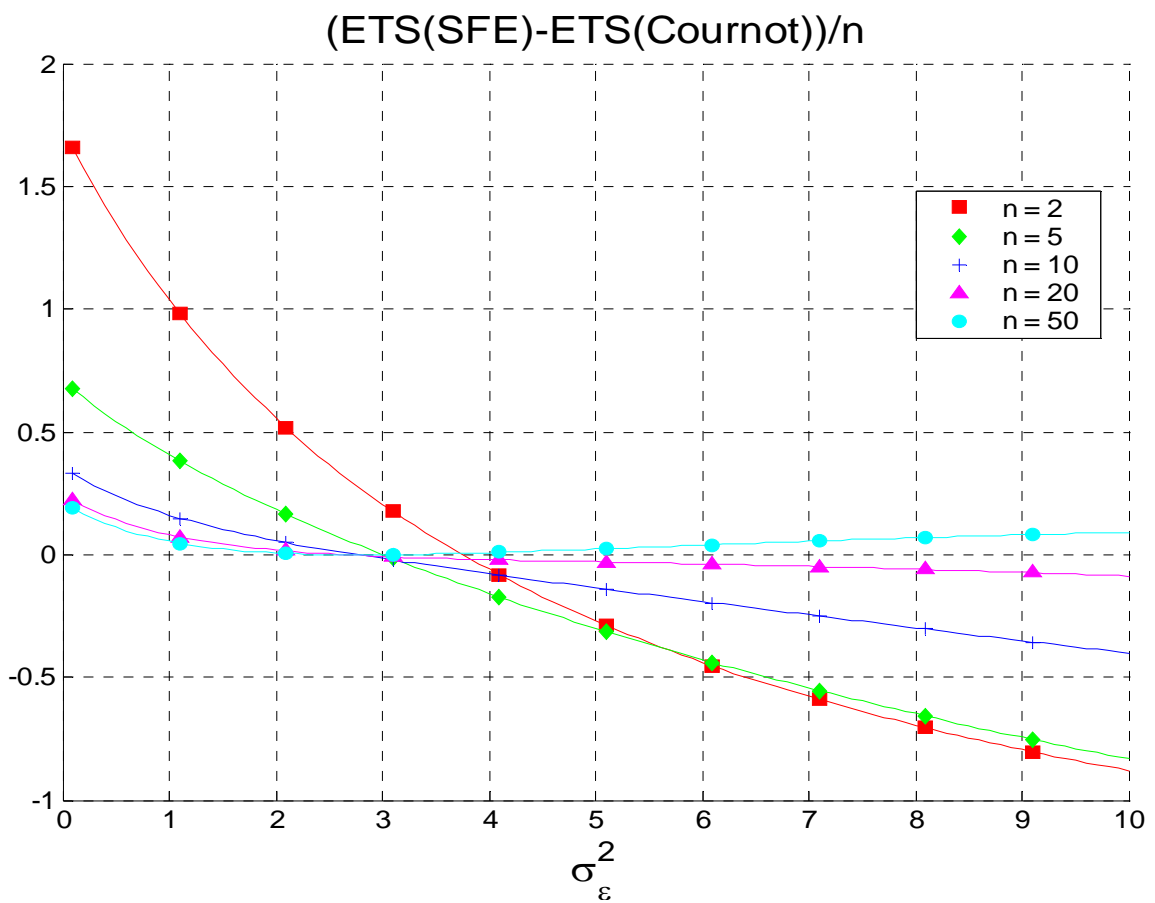

Figure $3 \mathrm{~b}$. Efficiency differential between supply function and Cournot equilibria as a function of $\sigma_{\varepsilon}^{2}$ (with parameters $\beta=\lambda=1, \bar{\theta}=30, \alpha=50, \sigma_{\theta}^{2}=5$, and $\rho=0.5$ ).

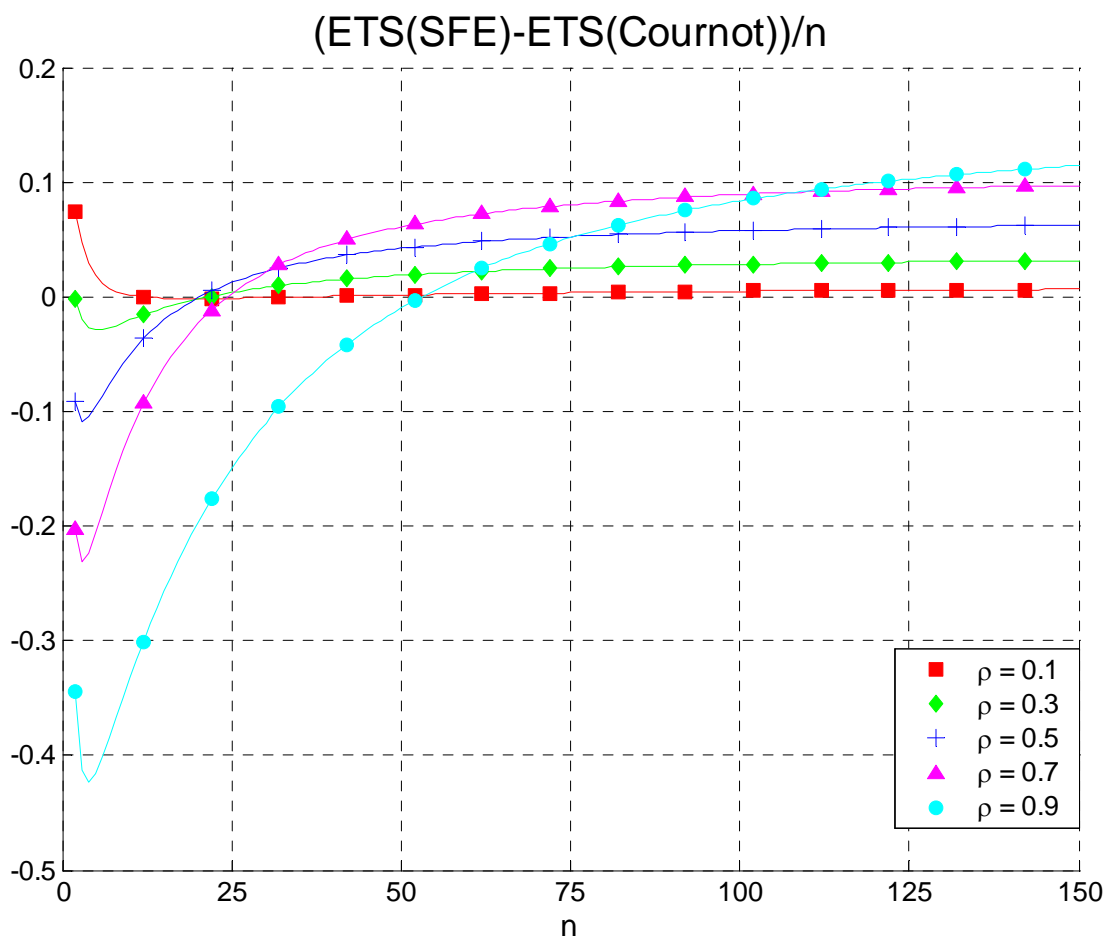

Figure 4. Efficiency differential between supply function and Cournot equilibria as a function of $\mathrm{n}$ (with parameters $\beta=\lambda=1, \bar{\theta}=15, \alpha=20, \sigma_{\theta}^{2}=1$, and $\sigma_{\varepsilon}^{2}=5$ ). 
The intuition for the results should be clear. The supply function market always dominates in efficiency in terms of information because sellers have full information (although they do not behave as in a full information equilibrium) while in the Cournot market they do not. For $\sigma_{\varepsilon}^{2}$ or $\rho$ small the supply function market dominates overall because on top sellers have less market power (since supply functions slope upwards). The result is that $\mathrm{ETS}_{\mathrm{n}}^{\mathrm{SF}}-\mathrm{ETS}_{\mathrm{n}}^{\text {Cournot }}>0$ for $\sigma_{\varepsilon}^{2}$ or $\rho$ small. For larger $\rho$ and $\sigma_{\varepsilon}^{2}>0$ (or for larger $\sigma_{\varepsilon}^{2}$ and $\rho>0$ ) when supply functions slope downwards, sellers in the supply function market have more market power and this may dominate the information effect for $\mathrm{n}$ low, with the result that $\operatorname{ETS}_{\mathrm{n}}^{\mathrm{SF}}-\mathrm{ETS}_{\mathrm{n}}^{\text {Cournot }}<0$. At the critical value of $\rho\left(\right.$ or $\sigma_{\varepsilon}^{2}$ ) for which the supply function equilibrium calls for a vertical supply we have $\operatorname{ETS}_{\mathrm{n}}^{\mathrm{SF}}-\mathrm{ETS}_{\mathrm{n}}^{\text {Cournot }}=0$ since then both equilibria coincide. For $\mathrm{n}$ large the market power effect is not very important and we may have that $\left(\mathrm{ETS}_{\mathrm{n}}^{\mathrm{SF}}-\mathrm{ETS}_{\mathrm{n}}^{\text {Cournot }}\right) / \mathrm{n}>0$.

Indeed, for $\mathrm{n}$ large, for a fixed $\rho$, we must have $\left(\operatorname{ETS}_{\mathrm{n}}^{\mathrm{SF}}-\mathrm{ETS}_{\mathrm{n}}^{\text {Cournot }}\right) / \mathrm{n}>0$ since, as we have seen, as $\mathrm{n}$ grows the supply function equilibrium converges to the (full information) first best but not the Cournot equilibrium. At the LBSFE there is only a deadweight loss due to market power (which is aggravated by the adverse selection problem), which dissipates in a large market; at the Bayesian Cournot equilibrium the deadweight loss due to private information remains in a large market. It is worth noting that the welfare loss at the Bayesian Cournot equilibrium increases with $\rho$.

The comparison between the Cournot and supply function outcomes has practical implications.

First when a supply function market is modeled, for convenience, à la Cournot we want to know what biases are introduced. The result is that in a market characterized by supply function competition using the Cournot model overestimates the welfare loss with respect to the actual supply function mechanism on two counts when supply function slope 
upwards: excessive market power and lack of information aggregation. When the equilibrium supply function slopes downwards the Cournot market underestimates market power and then the comparison is ambiguous: the Cournot market may under- or overestimate the deadweight loss in relation to supply function competition. In a large market the Cournot model always overestimates the welfare loss since at the LBSFE there is (almost) no efficiency loss while there is a significant one with Cournot competition due to private information.

Second, when sellers are restricted to use upward sloping schedules they may end up using vertical ones when in the supply function equilibrium they would be called to use downward sloping ones. The restriction to upward sloping schedules caps the market power of sellers in the supply function market. Forcing sellers to use increasing schedules when they would like to use decreasing ones may or not may be a good idea depending basically on the number of sellers. It will be good when the number of sellers (and size of the market) is moderate.

\section{Applications}

In this section we provide several applications of the model: electricity markets, agency and strategic trade policy, pollution damages, revenue management, and financial markets. We consider first supply schedule competition examples first and then we move on to demand schedule competition.

\subsection{Supply schedule competition}

\section{Wholesale electricity markets}

A potential application of the model is to competition in wholesale electricity markets: the day-ahead or spot market, with separate auctions for each delivery period (half-hourly or hourly), and the balancing market, that secures that demand and supply match at each point in time. Those markets are typically organized as uniform price multiunit auctions. In the British Pool, the first liberalized wholesale market, generators had to submit a 
single supply schedule for the entire day. ${ }^{30}$ Over this period residual demand facing a firm may vary considerably due to demand uncertainty and plant outings. The rules typically require producers to submit nondecreasing (step) function offers (although in some markets, like the Amsterdam Power Exchange, retailers may submit nonincreasing demands).

In our modeling the supply functions are smooth (the old English pool was modeled like this by Green and Newbery $(1992)$ and Green $(1996,1999))$ while typically supplies are discrete. The modeling of the auction with discrete supplies leads to existence problems of equilibrium in pure strategies (see von der Fehr and Harbord (1993)). However, Holmberg at al. (2008) show that if prices are selected from a discrete grid, where (realistically) the number of price levels is small in comparison to the number of quantity levels, then the step functions converge to continuous supply functions as the number of steps increase. This justifies the approximation of step-functions with smooth supply functions. The linear supply function model has been widely used in electricity markets and new developments include cost asymmetries, capacity constraints, piecewise affine supply functions and non-negativity generation constraints (see Baldick, Grant, and Kahn (2004) and Rudkevich (2005)). Furthermore, empirical studies of the Texas balancing market suggest that the continuous supply approach approximates well the behavior of the largest producers in the Texas balancing market (ERCOT). ${ }^{32}$ Baldick and Hogan (2006) justify to concentrate attention on linear (affine) supply function equilibria in a

30 The British Pool was replaced by NETA in 2001, in this system the balancing mechanism auction is not uniform.

31 In the day-ahead market in the Spanish pool generators submit supply functions which have to be nondecreasing and can include up to 25 price-quantity pairs for each production unit, as well as some other ancillary conditions. The demand side can bid in a similar way and the market operator constructs a merit order dispatch by ordering in the natural way supply and demand bids. The intersection of the demand and supply schedules determines the (uniform) price. Once the market closes the system operator solves congestion problems and market participants may adjust their positions in a sequence of intra-day markets, which have similar clearing procedures as in the dayahead market. (See Crampes and Fabra (2005).)

32 See Niu et al. (2005), Hortaçsu and Puller (2008), and Sioshansi and Oren (2007). 
linear-quadratic model because other equilibria (in the range between the least competitive Cournot one and the most competitive) are unstable. ${ }^{33}$

Both strategic behavior and private information are relevant in electricity markets. There is ample evidence by now that firms bid over marginal costs (see, e.g. Borenstein and Bushnell (1999), Borenstein et al. (2002), Green and Newbery (1992), and Wolfram (1998)). Hortaçsu and Puller (2008) introduce private information on the contract positions of firms in the Texas balancing market (the day-ahead market is resolved with bilateral contracts). ${ }^{34}$ Information on costs is available because the balancing market takes place very close to the generation moment and also from information sellers. Kühn and Machado (2004) introduce private information on retail sales in their study of vertically integrated firms in the Spanish pool. Private cost information related to plant availability will be relevant when there is a day-ahead market organized as a pool where firms submit hourly or daily supply schedules..$^{35}$ This means that the residual demand faced by a firm will be random since the supply of other firms depends on plant availability, which is random. The firm may have privileged information because of technical issues or transport problems. Furthermore, hydro availability in the reservoirs of each firm as well as the terms of supply contracts for energy inputs or imports are also private information. The latter include constraints in take-or-pay contracts for gas where the marginal cost of gas is zero until the constraint-typically private information to the firm- binds, or price of transmission rights in electricity imports depending on the private arrangements for the use of a congested interconnector. (It is worth noting that even if the opportunity costs of the inputs are the prices of those inputs in international markets in many instances there is not a single reference market.) Furthermore, in an emission rights system, future rights allocations may depend on current emissions and firms may have

33 Unstable in the sense that a small perturbation from the equilibrium supply functions induce sellers to deviate still more from the equilibrium.

34 The authors also argue that to take a linear approximation to marginal costs in the Texas electricity market is reasonable.

35 Note that even if there was a market for information on costs the solution of the model with private information would yield the value of information. 
different private estimates of such allocation. This will affect the opportunity cost of using current emission rights.

In our model demand is not random and the random residual demand a firms faces is due to cost uncertainty. In a wholesale electricity market the demand intercept $\alpha$ is a continuous function of time (load-duration characteristic) that yields the variation of demand over the time horizon considered. At any time there is a fixed $\alpha$ and the market clears. Mansur and White (2009) show how a centralized auction market in the Eastern US yields very important information aggregation benefits over bilateral trading in order to achieve an efficient allocation in a situation where differences in marginal costs and production are private information among firms. In our model prices are revealing of average cost conditions but strategic behavior on the basis of private information prevents the achievement of an efficient allocation. We have seen also how increasing the noise in the private signal $\sigma_{\varepsilon}^{2}$ makes the slope of supply steeper. This result may help explain the fact that in the Texas balancing market small firms use steeper supply functions than those predicted by theory and that those departures explain the major portion of losses in productive efficiency (Hortaçsu and Puller (2008)). ${ }^{36}$ Indeed, smaller firms may have signals of worse quality because of economies of scale in information gathering while residual non-contract private cost information has not been taken into account in the estimation. Consistently with our analysis the losses due to the "excess steepness" of supply functions over and above standard market power may be more important than the losses due to the latter.

The Cournot framework has been used in a variety of studies. ${ }^{37}$ The advantage of the Cournot model is that it is a robust model in which capacity constraints and fringe suppliers are easily incorporated. A drawback is that the Cournot model tends to predict

36 The authors explain the finding by the complexity faced by small firms in set up the bidding.

37 See, for example, Borenstein and Bushnell (1999) for the US; Alba et al. (1999) and Ramos et. al. (1998) for Spain; and Andersson and Bergman (1995) for Scandinavia. 
prices that are too high given realistic estimates of the demand elasticity. ${ }^{38}$ The supply function approach is more realistic. Our model helps understand the biases introduced when taking the Cournot modeling short-cut when firms compete in supply functions.

\section{Pollution control}

The cost shock could be also related to some ex post pollution or emission damage which is assessed on the firm and for which the producer has some private information. The unit tax would be given by $\tilde{\theta}$ and the effective cost to the firm would include also an idiosyncratic component $\theta_{\mathrm{i}}=\tilde{\theta}+\eta_{\mathrm{i}}$, where $\operatorname{cov}\left[\eta_{\mathrm{i}}, \tilde{\theta}\right]=0$. In the pollution damage interpretation of the shock, and when the equilibrium calls for a downward sloping supply, we would have that when firms see the price going up they reduce supply because they figure out that the assessed pollution damage will be higher.

\section{Revenue management}

The cost shock can also be interpreted as a random opportunity cost of serving the market which is related to dynamic considerations (e.g. revenue management on the face of products with expiration date and costly capacity changes). Revenue management deals with situations where the product, be it a hotel room, airline flight, generated electricity or tickets for a concert, has an expiration date and capacity is fixed well in advance and can be added only at high marginal cost. ${ }^{39}$ The problem arises then of predicting the opportunity cost of sale (the value of a unit in a shortage situation). A high opportunity cost is an indication of high value of sales in the future. In this case a firm would have a private assessment of the opportunity cost with which it would form its supply schedule.

Patterns of pricing for airline flights have proved difficult to explain with extant theoretical models (see e.g. McAfee and te Velde (2006)). If we believe that supply function competition provides a suitable reduced form for pricing in such markets then

38 However, including vertical relations and contracts in a Cournot setting provides better estimates (see Bushnell, Mansur, and Saravia (2008)).

39 Talluri and Van Ryzin (2004) for the basics of revenue management. 
taking into account the information aggregation role of price may help explaining some pricing patterns. ${ }^{40} \mathrm{We}$ have seen that when the information role of the price dominates is index of scarcity role then supply is downward sloping. If this is the case the interpretation would be that when airlines see prices going up they may infer, correctly, that the opportunity cost is high (i.e. that expected next period demand is high) and they reduce supply in the present period to be able to supply next period at a higher profit. And, indeed, an airline when thinking about selling a seat in a flight today has to think about whether the same seat could be sold tomorrow at a higher price. In any case, when the variance of the (opportunity) cost shock increases the equilibrium reaction of firms is to set a flatter supply schedule inducing lower margins. Higher volatility of demand would translate then in lower margins.

\section{Strategic agency and trade policy}

Strategic agency models where an owner provides incentives to the manager to compete in the market place have typically a reduced form which is a supply function..$^{41}$ This is similar to the presence of adjustment costs in certain industries committing the firms to supply functions (internal incentives in management consulting or the pricing program that_airlines use).

In strategic trade models a government can manipulate the supply function of domestic firms with tariffs and subsidies. Laussel (1992) considers a market with linear demand and constant marginal costs where firms compete in a common foreign market with the help of domestic tax-subsidy schemes. The domestic government imposes a quadratic export tax and a linear subsidy. The quadratic tax makes steeper the slope of the effective marginal cost schedule of a firm softening competition. The subsidy allows the domestic firm to capture a larger share of the profits. If marginal costs are random and private information to the firms or the amount of subsidy uncertain (with the domestic firm

40 See Section 10.1 in Talluri and Van Ryzin (2004) for a description of airline pricing. For example, the authors state (p. 523): "A typical booking process proceeds as follows. An airline posts availability in each fare class to the reservation systems stating the availability of seats in each fare class." This is indeed like a supply function.

41 See Vickers (1985), Fersthman and Judd (1987), Sklivas (1987), and Faulí-Oller and Giralt (1995). 
receiving a noisy signal about the cost/subsidy level) we can conclude from our model that introducing more noise in the signals also softens competition. In the case of subsidies this could be achieved with the disclosure policy of the government towards national firms (which are supposed to know more than foreign firms about the subsidies of their government). The opaqueness of subsidies may soften competition. ${ }^{42}$

\section{Reverse auctions}

In the initial Paulson plan of October 2008 reverse auctions were suggested as mechanisms to extract toxic assets from banks' balance sheets. ${ }^{43}$ In a reverse auction the buyer, the US Treasury, would announce a buying schedule relating prices and quantities a certain class of securities (say Residential Mortgage Backed Securities out of California property of a certain face value, vintage and type). ${ }^{44}$ The buying schedule could be vertical (inelastic demand) or have some elasticity. Those securities are in the hands of multiple banks and the Treasury wants to buy a certain proportion of them. The value of the securities to bank $\mathrm{i}$ is $\theta_{\mathrm{i}}$, reflecting both the intrinsic value to the bank and the liquidity needs of the institution (both are correlated across institutions) and the bank has an imperfect estimate of $\theta_{i}$. The bank will sell first the securities with a lower probability of repayment of the underlying mortgages and will move on to better securities only if in need to sell more. This means that the marginal cost of selling securities will be increasing: $\lambda x_{i}$ for selling an amount $x_{i}$ of the securities. The parameter $\lambda$ reflects the quality heterogeneity of the securities, the larger it is the faster the securities of the bank improve as the lemons are sold. It is reasonable to think that in a crisis situation $\lambda$ will be higher since the quality heterogeneity of the securities will increase.

42 Grant and Quiggin (1997) study the case in which firms are competitive and governments try to manipulate their supply functions. In their model the competitive supply functions of the firms also depend on a shock. Whenever supply functions are linear the authors find an equilibrium in taxsubsidy schedules with quadratic trade revenue taxes. Again here the quadratic tax allows the government to manipulate the slope of the supply of the competitive domestic firms.

43 Emergency Economic Stabilization Act of 2008. The Federal Reserve is also considering reverse auctions to mop out excess liquidity in a post-crisis scenario.

44 Designs security-by-security and pooled auctions have been proposed with dynamic auctions (see Ausubel and Cramton (2008)) and for static auctions for substitute goods (Klemperer (2009)). 
The Treasury is uninformed about the value of the securities and the reverse auction will serve a price discovery purpose eliciting the average value $\tilde{\theta}$. Banks which value the security the least or have the higher liquidity needs will sell more. Market power is definitely a potential concern in this type of auction given the potentially few bidders. This means that with high correlation competition will be softened and the Treasury will pay much more than the competitive price for the securities. It is worth noting that the Treasury has no incentive to release any public information it may have since this would only increase the distortion. Introducing an elastic demand function would alleviate the market power problem and reduce the distortion. This also avoids any potential market breakdown when demand is inelastic and the combination of the number of bidders and the degree of adverse selection makes the linear equilibrium collapse.

\subsection{Demand schedule competition}

The model can be restated in terms of competition among buyers of an asset of unknown ex-post average value $\tilde{\theta} \equiv\left(\sum_{\mathrm{i}=1}^{\mathrm{n}} \theta_{\mathrm{i}}\right) / \mathrm{n}$. The value for agent i is $\theta_{\mathrm{i}}=\tilde{\theta}+\eta_{\mathrm{i}}$, where $\operatorname{cov}\left[\eta_{i}, \tilde{\theta}\right]=0$. With a change of variables $z_{i} \equiv-x_{i}$ we have the results for demand competition. The (inverse) supply of the asset is given by $p=\alpha+\beta \sum_{i} z_{i}$ (with $\beta>0$ ) where $\sum_{i} z_{i}$ is the total quantity demanded. The equilibrium demand is $\mathrm{Z}\left(\mathrm{s}_{\mathrm{i}}, \mathrm{p}\right)=\left(\mathrm{E}\left[\theta_{\mathrm{i}} \mid \mathrm{s}_{\mathrm{i}}, \mathrm{p}\right]-\mathrm{p}\right) /(\mathrm{d}+\lambda)=-\mathrm{b}+\mathrm{as}_{\mathrm{i}}-\mathrm{cp}$ (with the endogenous parameters as in Proposition 1). The case of inelastic supply where an auctioneer supplies $\mathrm{k}$ units of the good is easily accommodated letting $\beta \rightarrow \infty$ and $-\alpha / \beta \rightarrow \mathrm{k}>0$. The marginal benefit of buying $z_{i}$ units of the asset for agent $i$ is $\theta_{i}-\lambda z_{i}$, where $\theta_{i}$ is the value with a private component and $\lambda z_{\mathrm{i}}$ a transaction or opportunity cost, or risk aversion component. ${ }^{45}$ The profits of agent $i$ are given by $\pi_{i}=\left(\theta_{i}-p\right) z_{i}-\lambda z_{i}^{2} / 2$. A real market example would be

45 Note that the adjustment cost is exogenous while with CARA preferences, for example, it would be endogenous and would depend, in expectation, on the degree of risk aversion times the variance of $\theta$ conditional on the information of the trader. 
firms purchasing labor of unknown average productivity $\tilde{\theta}$ because of technological uncertainty, and facing an inverse linear labor supply and quadratic adjustment costs in the labor stock.

A first application of the model is to legacy loans auctions which were envisioned in the Public-Private Investment Program of March 2009 to remove those bad loans from the balance sheet of banks. ${ }^{46}$ Basically, the banks nominate pools of legacy loans that meet certain criteria and that they wish to sell. Approved private investors bid for the pools of loans and receive a non-recourse loan having as collateral the same securities to be acquired. The winning bid for each pool then is either accepted or rejected by the bank. ${ }^{47}$ In terms of our model the marginal valuation of a bidder will depend on the collateral that it can post. Using the same securities as collateral of the non-recourse loan to finance the purchase is equivalent to providing a subsidy to bidders that decreases the slope of their marginal valuation. Our model would rationalize then the subsidy scheme of the Treasury since it would reduce the discount of the auction price.

We turn now to applications to Treasury auctions or open market central bank operations (to provide liquidity to the banking system).

\section{Financial market auctions}

In an open market operation the supply of funds is given by the central bank (usually inelastically). The ECB conducts typically weekly repo auctions (main refinancing operations) and the Federal Reserve holds daily ones (presently both have a discriminatory format). The US Treasury auctions are uniform price format exclusively since 1998.

Each bank bids for funds with a demand function. Ewerhart et al. (2009) argue that the marginal valuations of bidders in the open market operations should be declining. For

46 See www.financialstability.gov.

47 Ausubel and Cramton (2009) propose to combine the forward auction with a reverse auction as in the Paulson plan. 
example, $\tilde{\theta}$ is related to the interest rate/price in the secondary interbank market and $\lambda$ reflects the structure of counterparty i's pool of collateral. A bank (bidder) prefers to provide the central bank illiquid collateral in exchange for funds. However, with an increased allotment the bidder must forward more liquid types of collateral which have a higher opportunity cost and this explains the declining marginal valuation. The marginal value $\theta_{\mathrm{i}}$ for funds of bank $\mathrm{i}$ is idiosyncratic and is only assessed imperfectly by the own bank (for example, due to uncertainty about future liquidity needs). Those values are correlated among banks.

Our results imply the following predictions for the case of an inelastic supply k: (i) there is a discount with respect to the expectation of the secondary market or average value $\mathrm{E}\left[\tilde{\theta}[\tilde{\mathrm{s}}]\right.$ since $\mathrm{p}=\mathrm{E}[\tilde{\theta} \mid \tilde{\mathrm{s}}]-(\mathrm{d}+\lambda) \mathrm{k} / \mathrm{n}$; (ii) as fundamentals' volatility $\sigma_{\theta}^{2}$ increases the discount decreases; (iii) when the liquidity of collateral high (low $\lambda$ ) bids schedules are very flat; (iv) increasing the size of the auction (k) or providing more public information (higher $1 / \sigma_{\theta}^{2}$ ) leads to an increased discount. All these are documented features of the ECB euro auctions (Ewerhart et al. (2009)). ${ }^{48}$

Our model also illustrates the impact of a crisis situation. The more severe the information problem (a larger $\rho$ or $\sigma_{\varepsilon}^{2} / \sigma_{\theta}^{2}$ ) or the more costly to part with more liquid collateral (higher $\lambda)^{49}$, the steeper demand functions are, the larger the equilibrium margin and the amount of bid shading, and the inefficiency in funds allocation (in the extreme the linear equilibrium may break down due to severe adverse selection coupled with market power).$^{50}$ Note that when a bank sees a high price for funds it infers that the values of other banks are high and therefore its own value also high. Cassola et al. (2009) study ECB auctions and show that after the subprime crisis in August 2007

48 Note however that the ECB auctions in the period studied are discriminatory while our model is uniform price.

49 Note also that if we interpret $\lambda$ as proxy for risk aversion then in a crisis situation it is usually thought that risk aversion increases.

50 Flannery (1996) builds an adverse selection model of the secondary market for bank assets where there is a fire-sale penalty which, it is argued, should be higher in a crisis situation because of increased uncertainty about the signals received by institutions. 
marginal valuations for funds of banks increased and the aggregate bid curve was steeper with increased bid shading. These authors also find evidence of strategic effects. In our model the level effect on valuations would be represented by an increase in $\bar{\theta}$.

What has been the response of central banks to the crisis? The central bank has two main objectives in the liquidity auctions. The first is to inject the right amount of money so that the short term rate stays close to the target level. The second is to provide appropriate liquidity to the banks (enough in particular to cover their reserve requirements). A fixedquantity auction controls the aggregate amount of money injected exactly and elicits the values for liquidity of the banks (price discovery). However, there is an inefficiency in the distribution of liquidity which can be substantial when $\rho$ and/or $\sigma_{\varepsilon}^{2} / \sigma_{\theta}^{2}$ are large. A first way to reduce the inefficiency in the allocation is accepting lower quality collateral from the banks in the repo auctions. This is equivalent to provide a quadratic subsidy to the banks that lowers effectively $\lambda$. The amount of the subsidy will be increasing with $\rho$ and $\sigma_{\varepsilon}^{2} / \sigma_{\theta}^{2}$ and decreasing with $\mathrm{n}$. Central banks have enlarged acceptable collateral and some the qualifying participants in the auctions. For example, the Federal Reserve established the TAF auction facility (with a single-price format) to broaden the range of counterparties and the range of collateral in relation to regular open market operations.

A second way is to modify the auction procedure. The inelastic supply auction may generate a lot of inefficiency when $\rho$ and/or $\sigma_{\varepsilon}^{2} / \sigma_{\theta}^{2}$, as well as $\lambda$, are large. It may pay then to introduce some elasticity in the supply to control market power and reduce inefficiency. In the extreme the central bank could set a fixed-price tender (an horizontal supply schedule with $\beta=0$ ). The trade-offs are the following. The inelastic auction provides price discovery and tight quantity control but the allocation may be very distortionary. The fixed-price tender controls the amount of money injected only indirectly, and does not elicit the liquidity value from the banks, but eliminates any inefficiency in the distribution of liquidity since banks bid competitively. This may be precisely the case in a crisis situation where a fixed-price full-allotment tender may be preferable. A fixed-price tender controls the amount of money injected only indirectly, and does not elicit the liquidity value from the banks, but eliminates any inefficiency in 
the distribution of liquidity since banks bid competitively. Noting that in a crisis situation the control of the total amount of liquidity comes second to making enough liquidity available to the banks helps to explain what the ECB has done after the collapse of Lehman Brothers by accepting the banks' demands in full at a fixed rate instead of the usual auction where banks would bid for money and set the interest rate in the process.

It is worth noting that the central bank should have no incentive to release public information (i.e. increase $1 / \sigma_{\theta}^{2}$ ) since this would increase bid shading and the distortion in the allocation of liquidity.

In the Treasury auction interpretation the sources of private information could be different expectations about the future resale value of securities $\tilde{\theta}$ (for instance, bidders have different forecast of inflation and securities are denominated in nominal terms), and as before bidders may have different liquidity needs due to idiosyncratic shocks. There is evidence of private information in Treasury auctions, which prices feature a discount from secondary market prices, increasing with the noise in the signal of the bidders, as well as of auctions prices aggregating information (Cammack (1991), Nyborg et al. (2002)). ${ }^{51}$ Bindseil et al. (2005) argue that the common value component in T-bill auctions is much more important than in the case of central bank auctions. US Treasury auctions are exclusively uniform price since October 1998, and only a limited number of primary dealers can submit competitive bids. ${ }^{52}$ Gordy (1999) argues that bidders in Treasury auctions submit demand schedules to protect against the winner's curse and he associates larger bid dispersion with increased incidence of the winner's curse in Treasury auctions in Portugal. Bid dispersion in our model can be associated with the slope of the demand schedule with a steeper slope when the information problem is more severe.

51 Hortaçsu and Kastl (2008) cannot reject the hypothesis that bidders in Canadian 3-months T-Bill auctions have private values.

52 Similarly in Treasury auctions in Sweden the range of participants is from 6 to 15 (Nyborg et al. (2002)). 
Underpricing is thought to be a serious problem in uniform price auctions. ${ }^{53}$ Keloharju et al. (2005) find underpricing but little support for market power effects in uniform price Finnish Treasury auctions and they attribute it to the fact that the Treasury acts strategically manipulating supply after observing the bids. There are also worries that in the present financial crisis margins and profits of (Wall Street) dealers have grown dramatically at the expense of the Treasury and the Fed (part of the story may come from a decrease in the number of participants in the auctions). ${ }^{54}$ The Treasury could profit also from using an elastic supply schedule in its auctions. Supposedly its objective may be revenue minus an adjustment cost of a quantity target. If this is the case our results would indicate that the optimal schedule should be more elastic the more severe the adverse selection problem is. A lower $\beta$ would reduce underbidding but would increase the departures from the quantity target and underbidding increases when adverse selection worsens. .55

\section{Concluding remarks}

In a model with private and common value uncertainty and no exogenous noise we have found a privately revealing equilibrium where the incentives to acquire information are preserved. Several testable implications derive from the equilibrium. Price-cost margins and bid shading are increasing in cost correlation and in the noise in the signals, and decreasing with the size of the market. Note, however, that information on the slope of marginal costs/benefits will be needed to disentangle the effect of this parameter from the distortion introduced by private information. Price volatility is increasing with noise in the signals and prior volatility. The results may help explain pricing patterns arising in electricity markets, revenue management and auctions. For example, it explains how the Treasury may overpay in reverse auctions for toxic assets. It may also explain how in a financial crisis loosening collateral requirements in central bank liquidity auctions may be part of an optimal subsidy scheme to banks and how a central bank may respond

53 Kandel et al. (1999) provide underpricing evidence for IPO (initial public offering) uniform-price auctions in Israel.

54 See Financial Times, August 3, 2009: "Wall St. profits from Fed role" and Wall St. gets its cut from the Fed and Treasury".

55 LiCalzi and Pavan (2005) advocate this in a model with no adverse selection to control market power. 
optimally by changing the liquidity facility from an auction to a fixed rate tender. Finally, the model also characterizes the biases introduced by a Cournot model when competition is in fact in supply or demand schedules. 


\section{Appendix I: Proofs of Propositions 1, 4 and 6.}

Proof of Proposition 1: Suppose that sellers other than $i$ use the strategy $X\left(s_{i}, p\right)=b-a s_{i}+c p$. Form the market clearing equation and from the point of view of seller $\mathrm{i}$ (provided $\mathrm{a}>0$ ) the price is informationally equivalent to $\mathrm{h}_{\mathrm{i}} \equiv\left(\beta \mathrm{b}(\mathrm{n}-1)-\alpha+(1+\beta(\mathrm{n}-1) \mathrm{c}) \mathrm{p}+\beta \mathrm{x}_{\mathrm{i}}\right) / \beta \mathrm{a}=\sum_{\mathrm{j} \neq \mathrm{s}} \mathrm{s}_{\mathrm{j}}$. The pair $\left(\mathrm{s}_{\mathrm{i}}, \mathrm{p}\right)$ is informationally equivalent to the pair $\left(\mathrm{s}_{\mathrm{i}}, \mathrm{h}_{\mathrm{i}}\right)$, hence

$$
\mathrm{E}\left[\theta_{\mathrm{i}} \mid \mathrm{s}_{\mathrm{i}}, \mathrm{p}\right]=\mathrm{E}\left[\theta_{\mathrm{i}} \mid \mathrm{s}_{\mathrm{i}}, \mathrm{h}_{\mathrm{i}}\right] \text {. }
$$

Because of the assumed information structure we have

$$
\left(\begin{array}{c}
\theta_{\mathrm{i}} \\
\mathrm{s}_{\mathrm{i}} \\
\mathrm{h}_{\mathrm{i}}
\end{array}\right) \sim \mathrm{N}\left(\left(\begin{array}{c}
\bar{\theta} \\
\bar{\theta} \\
(\mathrm{n}-1) \bar{\theta}
\end{array}\right),\left(\begin{array}{ccc}
\sigma_{\theta}^{2} & \sigma_{\theta}^{2} & (\mathrm{n}-1) \rho \sigma_{\theta}^{2} \\
\sigma_{\theta}^{2} & \sigma_{\theta}^{2}+\sigma_{\varepsilon}^{2} & (\mathrm{n}-1) \rho \sigma_{\theta}^{2} \\
(\mathrm{n}-1) \rho \sigma_{\theta}^{2} & (\mathrm{n}-1) \rho \sigma_{\theta}^{2} & (\mathrm{n}-1)\left(\sigma_{\theta}^{2}+\sigma_{\varepsilon}^{2}\right)+(\mathrm{n}-1)(\mathrm{n}-2) \rho \sigma_{\theta}^{2}
\end{array}\right)\right),
$$

We obtain

$$
\begin{aligned}
& \mathrm{E}\left[\theta_{\mathrm{i}} \mid \mathrm{s}_{\mathrm{i}}, \mathrm{h}_{\mathrm{i}}\right]=\mathrm{E}\left[\theta_{\mathrm{i}} \mid \mathrm{s}_{\mathrm{i}}, \frac{\mathrm{h}_{\mathrm{i}}}{\mathrm{n}-1}\right]=\frac{\sigma_{\varepsilon}^{2}}{\sigma_{\theta}^{2}(1+(\mathrm{n}-1) \rho)+\sigma_{\varepsilon}^{2}} \bar{\theta}+ \\
& \frac{\sigma_{\theta}^{2}\left(\sigma_{\theta}^{2}(1-\rho)(1+(\mathrm{n}-1) \rho)+\sigma_{\varepsilon}^{2}\right)}{\left(\sigma_{\theta}^{2}(1-\rho)+\sigma_{\varepsilon}^{2}\right)\left(\sigma_{\theta}^{2}(1+(\mathrm{n}-1) \rho)+\sigma_{\varepsilon}^{2}\right)} \mathrm{s}_{\mathrm{i}}+\frac{\sigma_{\theta}^{2} \sigma_{\varepsilon}^{2} \rho}{\left(\sigma_{\theta}^{2}(1-\rho)+\sigma_{\varepsilon}^{2}\right)\left(\sigma_{\theta}^{2}(1+(\mathrm{n}-1) \rho)+\sigma_{\varepsilon}^{2}\right)} \mathrm{h}_{\mathrm{i}} .
\end{aligned}
$$

We are looking for strategies of the form $X\left(s_{i}, p\right)=b-a s_{i}+c p$. Using the F.O.C. $\mathrm{p}-\mathrm{E}\left[\theta_{\mathrm{i}} \mid \mathrm{s}_{\mathrm{i}}, \mathrm{p}\right]=\left(\frac{\beta}{1+\beta(\mathrm{n}-1) \mathrm{c}}+\lambda\right) \mathrm{x}_{\mathrm{i}}$ and the expression for $\mathrm{h}_{\mathrm{i}}$ we obtain the following

$$
\begin{aligned}
& -\frac{\sigma_{\varepsilon}^{2}\left(\sigma_{\varepsilon}^{2}+(1-\rho) \sigma_{\theta}^{2}\right) \bar{\theta}+\left(\sigma_{\theta}^{2} \sigma_{\varepsilon}^{2} \rho(\beta \mathrm{nb}-\alpha) / \beta \mathrm{a}\right)}{\left(\sigma_{\varepsilon}^{2}+(1-\rho) \sigma_{\theta}^{2}\right)\left(\sigma_{\varepsilon}^{2}+(1+(\mathrm{n}-1) \rho) \sigma_{\theta}^{2}\right)}-\frac{(1-\rho) \sigma_{\theta}^{2}\left(\sigma_{\varepsilon}^{2}+(1+(\mathrm{n}-1) \rho) \sigma_{\theta}^{2}\right)}{\left(\sigma_{\varepsilon}^{2}+(1-\rho) \sigma_{\theta}^{2}\right)\left(\sigma_{\varepsilon}^{2}+(1+(\mathrm{n}-1) \rho) \sigma_{\theta}^{2}\right)} \mathrm{s}_{\mathrm{i}} \\
& +\left(1-\frac{\sigma_{\theta}^{2} \sigma_{\varepsilon}^{2} \rho((1+\beta \mathrm{nc}) / \beta \mathrm{a})}{\left(\sigma_{\varepsilon}^{2}+(1-\rho) \sigma_{\theta}^{2}\right)\left(\sigma_{\varepsilon}^{2}+(1+(\mathrm{n}-1) \rho) \sigma_{\theta}^{2}\right)}\right) \mathrm{p}=\left(\frac{\beta}{1+\beta(\mathrm{n}-1) \mathrm{c}}+\lambda\right)\left(\mathrm{b}-\mathrm{as}_{\mathrm{i}}+\mathrm{cp}\right)
\end{aligned}
$$


Identifying coefficients, letting $M \equiv \frac{\rho \sigma_{\varepsilon}^{2} \mathrm{n}}{(1-\rho)\left(\sigma_{\varepsilon}^{2}+(1+(n-1) \rho) \sigma_{\theta}^{2}\right)}$, we obtain a,b,c by solving the following system of equations

$$
\left\{\begin{array}{c}
\frac{(1-\rho) \sigma_{\theta}^{2}}{\left(\sigma_{\varepsilon}^{2}+(1-\rho) \sigma_{\theta}^{2}\right)}=\left(\frac{\beta}{1+\beta(\mathrm{n}-1) \mathrm{c}}+\lambda\right) \mathrm{a} \\
-\frac{\sigma_{\varepsilon}^{2}}{\left(\sigma_{\varepsilon}^{2}+(1+(\mathrm{n}-1) \rho) \sigma_{\theta}^{2}\right)} \bar{\theta}\left(\frac{\beta}{1+\beta(\mathrm{n}-1) \mathrm{c}}+\lambda\right)^{-1}-\frac{\mathrm{M}(\beta \mathrm{nb}-\alpha)}{\beta \mathrm{n}}=\mathrm{b} \\
\left(1-\frac{\mathrm{M}(1+\beta \mathrm{nc})}{\beta \mathrm{n}}\left(\frac{\beta}{1+\beta(\mathrm{n}-1) \mathrm{c}}+\lambda\right)\right)=\left(\frac{\beta}{1+\beta(\mathrm{n}-1) \mathrm{c}}+\lambda\right) \mathrm{c}
\end{array}\right.
$$

This characterizes linear equilibria. We have that

$$
\begin{aligned}
& \mathrm{a}=\frac{(1-\rho) \sigma_{\theta}^{2}}{\left(\sigma_{\varepsilon}^{2}+(1-\rho) \sigma_{\theta}^{2}\right)}(\mathrm{d}+\lambda)^{-1} \\
& \mathrm{~b}=\frac{1}{1+\mathrm{M}}\left(\frac{\alpha}{\beta} \mathrm{M}-\frac{\sigma_{\varepsilon}^{2}}{\left(\sigma_{\varepsilon}^{2}+(1+(\mathrm{n}-1) \rho) \sigma_{\theta}^{2}\right)}(\mathrm{d}+\lambda)^{-1} \bar{\theta}\right)
\end{aligned}
$$

with $d=\frac{\beta}{1+\beta(n-1) c}$. The last equation in the curved bracket is quadratic in $c$ of the form $\mathrm{g}(\mathrm{c})=0$ with

$$
g(c)=\lambda \beta(n-1)(1+M) c^{2}+\left((\beta+\lambda)(1+M)+(n-1)\left(\lambda \frac{M}{n}-\beta\right)\right) c+(\beta+\lambda) \frac{M}{\beta n}-1 .
$$

For $\mathrm{n}=1$ there is a unique solution to the quadratic equation. Otherwise, it can be checked that the determinant of the quadratic equation is positive and therefore the equation has two real roots. Furthermore, only the largest root $\mathrm{c}$ is compatible with the second order condition.

It is easily checked also that $\mathrm{g}(-\mathrm{M} /(1+\mathrm{M}) \beta \mathrm{n})<0$ and therefore for the largest root we have $\mathrm{c}>-\mathrm{M} /(1+\mathrm{M}) \beta \mathrm{n}$ because of convexity of the parabola $\mathrm{g}(\cdot)$. It follows also that 
$c>-M /(1+M) \beta n>-1 / \beta n$ and therefore $1+\beta n c>0$. Since $\beta n c>-1$ it follows that $1+\beta(n-1) c>0$ either for $c>0$ or $c<0$. Furthermore, $a>0$. This is so since from the expression for $a$ in the system of equations, $\operatorname{sgn}(a)=\operatorname{sgn}\left(\frac{\beta}{1+\beta(n-1) c}+\lambda\right)$. To see that $\mathrm{c}<1 / \lambda$ note the following:

$$
\mathrm{c}=\left(\frac{\beta}{1+\beta(\mathrm{n}-1) \mathrm{c}}+\lambda\right)^{-1}-\frac{\mathrm{M}(1+\beta \mathrm{nc})}{\beta \mathrm{n}}<\frac{1}{\lambda} .
$$

The largest root decreases with $M$ since $\partial g / \partial M>0$ for $c>-1 / \beta n$. This is so since it can be checked that $\partial \mathrm{g} / \partial \mathrm{M}$ is a convex parabola in $\mathrm{c}$ with largest root $-1 / \beta \mathrm{n}$. It follows that for $\mathrm{c}>-1 / \beta \mathrm{n}$ we have that $\partial \mathrm{g} / \partial \mathrm{M}>0$. Similarly, we have that $\partial \mathrm{g} / \partial \lambda>0$ at any candidate equilibrium $\mathrm{c}$. This is so since it can be checked that $\partial \mathrm{g} / \partial \lambda$ is a convex parabola in $\mathrm{c}$ with largest root $-\mathrm{M} /(1+\mathrm{M}) \beta \mathrm{n}$ for $\mathrm{n}>1$ and we know that $\mathrm{g}(-\mathrm{M} /(1+\mathrm{M}) \beta \mathrm{n})<0$. This means that since $\mathrm{g}(\cdot)$ is a convex parabola in $\mathrm{c}$, in equilibrium we have that $\mathrm{c}>-\mathrm{M} /(1+\mathrm{M}) \beta \mathrm{n}$ and the result that $\partial \mathrm{g} / \partial \lambda>0$ follows. We conclude that the largest root decreases with $\lambda$. When $M=0$ we have that $c>0$. In this case we have that $\mathrm{c}$ increases in $\mathrm{n}$ since $\partial \mathrm{g} / \partial \mathrm{n}=\beta \mathrm{c}(\lambda \mathrm{c}-1)<0$ for $\lambda^{-1}>\mathrm{c}>0$. Finally, it is possible to check that

$$
\frac{\partial \mathrm{c}}{\partial \mathrm{n}}=-\frac{\partial \mathrm{g} / \partial \mathrm{n}}{\partial \mathrm{g} / \partial \mathrm{c}}=-\frac{\beta^{-1}(\beta+\lambda(\beta \mathrm{c}(\mathrm{n}-1)+1))(\mathrm{cn} \beta+1)\left(\mathrm{Mn}^{-1}(1-\rho)-\rho\right)(\rho(\mathrm{n}-1)+1)^{-1} \mathrm{Mn}^{-1}+\mathrm{c}\left(\mathrm{Mn}^{-1} \beta-\beta+2 \mathrm{Mn}^{-1} \lambda+\mathrm{c}\left(\beta \lambda-\mathrm{Mn}^{-1} \beta \lambda+2 \mathrm{M} \beta \lambda\right)\right)}{2 \mathrm{c} \lambda \beta(\mathrm{n}-1)(\mathrm{M}+1)+\left(\left(-\beta(\mathrm{n}-1)+(\beta+\lambda)(\mathrm{M}+1)+\mathrm{Mn}^{-1} \lambda(\mathrm{n}-1)\right)\right)}
$$

It follows that

$$
\frac{\partial}{\partial \mathrm{n}}(\mathrm{c}(\mathrm{n}-1))=(\mathrm{n}-1) \frac{\partial \mathrm{c}}{\partial \mathrm{n}}+\mathrm{c}=\frac{(\beta+\lambda(\beta \mathrm{c}(\mathrm{n}-1)+1))\left(\mathrm{Mn}^{-1}(\mathrm{n}-1)\left(\rho-\mathrm{Mn}^{-1}(1-\rho)\right)+\mathrm{c} \beta(\mathrm{M}+1)\left(\rho(\mathrm{n}-1)+1+\mathrm{Mn}^{-1}(\mathrm{n}-1)(\rho-1)\right)\right)}{(\rho(\mathrm{n}-1)+1) \beta(\partial \mathrm{g} / \partial \mathrm{c})}>0
$$

when $c>0$ since $\partial g / \partial c>0,(\beta+\lambda(\beta c(n-1)+1)) \geq n^{-1}(\lambda+n \beta)>0$, and from $0 \leq \mathrm{Mn}^{-1}<\frac{\rho}{(1-\rho)} \quad, \quad$ both $\quad \rho(\mathrm{n}-1)+1+\mathrm{Mn}^{-1}(\mathrm{n}-1)(\rho-1)>0 \quad$ and $\operatorname{Mn}^{-1}(\mathrm{n}-1)\left(\rho-\mathrm{Mn}^{-1}(1-\rho)\right) \geq 0$ follow. 
Lemma. If $\mathrm{n}-\mathrm{M}-2 \geq 0$ then as $\lambda \rightarrow 0, \mathrm{c}(\lambda) \rightarrow \infty$. If $\mathrm{n}-\mathrm{M}-2<0$ then as $\lambda \rightarrow 0$, $\mathrm{c}(\lambda) \rightarrow-(\mathrm{n}-\mathrm{M}) /(\mathrm{n}-\mathrm{M}-2) \beta \mathrm{n}$ (in this case $\lim _{\lambda \rightarrow 0} \mathrm{c}<0$ if and only if $\frac{\sigma_{\theta}^{2}}{\sigma_{\varepsilon}^{2}}<\frac{(2 \rho-1)}{(1-\rho)(\rho(\mathrm{n}-1)+1)}$ or $\mathrm{n}<\mathrm{M}$ ).

Proof: From the implicit expression determining $\mathrm{c}$ in the proof of Proposition 1

$$
\mathrm{c}=\frac{1-\frac{(\beta+\lambda(1+\beta \mathrm{c}(\mathrm{n}-1))) \sigma_{\varepsilon}^{2} \rho}{\left(\sigma_{\theta}^{2}((\mathrm{n}-1) \rho+1)+\sigma_{\varepsilon}^{2}\right)(1-\rho) \beta}}{\frac{\beta}{1+\beta(\mathrm{n}-1) \mathrm{c}}+\lambda+\frac{(\beta+\lambda(1+\beta \mathrm{c}(\mathrm{n}-1))) \sigma_{\varepsilon}^{2} \rho}{\left(\sigma_{\theta}^{2}((\mathrm{n}-1) \rho+1)+\sigma_{\varepsilon}^{2}\right)(1-\rho)(1+\beta \mathrm{c}(\mathrm{n}-1))}}
$$

and operating we obtain

$$
\mathrm{c} \lambda=\frac{1-\frac{(\beta+\lambda(1+\beta \mathrm{c}(\mathrm{n}-1))) \sigma_{\varepsilon}^{2} \rho}{\left(\sigma_{\theta}^{2}(\rho(\mathrm{n}-1)+1)+\sigma_{\varepsilon}^{2}\right)(1-\rho) \beta}}{\left(\frac{\beta}{(1+\beta(\mathrm{n}-1) \mathrm{c}) \lambda}+1+\frac{(\beta+\lambda(1+\beta \mathrm{c}(\mathrm{n}-1))) \sigma_{\varepsilon}^{2} \rho}{\left(\sigma_{\theta}^{2}(\rho(\mathrm{n}-1)+1)+\sigma_{\varepsilon}^{2}\right)(1-\rho)(1+\beta \mathrm{c}(\mathrm{n}-1)) \lambda}\right)} .
$$

Let $\lim _{\lambda \rightarrow 0} \mathrm{c} \lambda=v$. Then, taking limits in the previous equality we obtain

$$
v=\frac{1-\frac{(1+v(\mathrm{n}-1)) \sigma_{\varepsilon}^{2} \rho}{\left(\sigma_{\theta}^{2}(\rho(\mathrm{n}-1)+1)+\sigma_{\varepsilon}^{2}\right)(1-\rho)}}{\left(\frac{\beta}{\beta(\mathrm{n}-1) v}+1+\frac{(1+v(\mathrm{n}-1)) \sigma_{\varepsilon}^{2} \rho}{\left(\sigma_{\theta}^{2}(\rho(\mathrm{n}-1)+1)+\sigma_{\varepsilon}^{2}\right)(1-\rho)(v(\mathrm{n}-1))}\right)} .
$$

Solving for $v$, we have $v=0$ and

$$
v=\frac{\sigma_{\theta}^{2}(\mathrm{n}-2)(1-\rho)(\rho(\mathrm{n}-1)+1)-\sigma_{\varepsilon}^{2}(2 \rho(\mathrm{n}-1)-\mathrm{n}+2)}{(\mathrm{n}-1)\left(\sigma_{\theta}^{2}(1-\rho)+\sigma_{\varepsilon}^{2}\right)(\rho(\mathrm{n}-1)+1)} .
$$

Denote by $\hat{\mathrm{c}}=\lim _{\lambda \rightarrow 0} \mathrm{c}$. In case that $v=0$, using the implicit expression determining $\mathrm{c}$ we get that

$$
\overline{\mathrm{c}}=-\frac{1}{\beta \mathrm{n}}-\frac{2\left(\sigma_{\theta}^{2}((\mathrm{n}-1) \rho+1)+\sigma_{\varepsilon}^{2}\right)(1-\rho)}{\beta \mathrm{n}\left(\sigma_{\theta}^{2}(\mathrm{n}-2)(1-\rho)((\mathrm{n}-1) \rho+1)-\sigma_{\varepsilon}^{2}(2 \rho(n-1)-n+2)\right)}=-\frac{(\mathrm{n}-\mathrm{M})}{(\mathrm{n}-\mathrm{M}-2) \beta \mathrm{n}} .
$$


In equilibrium we have that $(1+\mathrm{c}(\mathrm{n}-1) \beta)>0$. This inequality evaluated at $\hat{\mathrm{c}}$ is equivalent to

$$
\left(\sigma_{\theta}^{2}(\mathrm{n}-2)(1-\rho)((\mathrm{n}-1) \rho+1)-\sigma_{\varepsilon}^{2}(2 \rho(\mathrm{n}-1)-\mathrm{n}+2)\right)<0
$$

If $\sigma_{\theta}^{2}(n-2)(1-\rho)(\rho(n-1)+1)-\sigma_{\varepsilon}^{2}(2 \rho(n-1)-n+2)>0$, then necessarily $\quad v>0$ and $\begin{array}{llll}\text { therefore } \quad \hat{\mathrm{c}}=+\infty & \text { (and } \quad(1+\overline{\mathrm{c}}(\mathrm{n}-1) \beta)>0 \quad \text { When }\end{array}$ $\sigma_{\theta}^{2}(n-2)(1-\rho)(n \rho-\rho+1)-\sigma_{\varepsilon}^{2}(2 \rho(n-1)-n+2)<0$, the condition $(1+\widehat{c}(n-1) \beta)>0$ does not hold for $v>0$. Finally, when $\sigma_{\theta}^{2}=\frac{\sigma_{\varepsilon}^{2}(2 \rho(n-1)-n+2)}{(n-2)(1-\rho)(n \rho-\rho+1)}$ direct computation of c yields a quadratic equation which larger solution tends to $\hat{\mathrm{c}}=+\infty$ as $\lambda$ converges to zero. Note that

$$
\left(\sigma_{\theta}^{2}(\mathrm{n}-2)(1-\rho)((\mathrm{n}-1) \rho+1)-\sigma_{\varepsilon}^{2}(2 \rho(\mathrm{n}-1)-\mathrm{n}+2)\right)=(1-\rho)\left(\sigma_{\varepsilon}^{2}+(1+(\mathrm{n}-1) \rho) \sigma_{\theta}^{2}\right)(\mathrm{n}-\mathrm{M}-2) .
$$

In summary: If $(1-\rho)(n-M-2) \geq 0$, then $\lim _{\lambda \rightarrow 0} c=+\infty$. If $(1-\rho)(n-M-2)<0$, then $\lim _{\lambda \rightarrow 0} \mathrm{c}=-(\mathrm{n}-\mathrm{M}) /(\mathrm{n}-\mathrm{M}-2) \beta \mathrm{n}$. (In this case, $\lim _{\lambda \rightarrow 0} \mathrm{c}<0$ if and only if $\frac{\sigma_{\theta}^{2}}{\sigma_{\varepsilon}^{2}}<\frac{(2 \rho-1)}{(1-\rho)(\rho(n-1)+1)}$ or $\left.\mathrm{n}<\mathrm{M}\right)$.

Proof of Proposition 4: Similarly as in the proof of Proposition 1 it can be checked that the coefficients of the equilibrium strategy $X^{c}\left(s_{i}, p\right)=b^{c}-a^{c} s_{i}+c^{c} p$ are given by the solution to the system of equations

$$
\left\{\begin{array}{c}
\frac{(1-\rho) \sigma_{\theta}^{2}}{\left(\sigma_{\varepsilon}^{2}+(1-\rho) \sigma_{\theta}^{2}\right)}=\lambda \mathrm{a} \\
-\frac{\sigma_{\varepsilon}^{2}}{\left(\sigma_{\varepsilon}^{2}+(1+(\mathrm{n}-1) \rho) \sigma_{\theta}^{2}\right)} \bar{\theta}-\frac{\mathrm{M}(\beta \mathrm{nb}-\alpha)}{\beta \mathrm{n}} \lambda=\lambda \mathrm{b} \\
\left(1-\frac{\mathrm{M}(1+\beta \mathrm{nc})}{\beta \mathrm{n}} \lambda\right)=\lambda \mathrm{c}
\end{array}\right.
$$


where $M \equiv \frac{\rho \sigma_{\varepsilon}^{2} \mathrm{n}}{(1-\rho)\left(\sigma_{\varepsilon}^{2}+(1+(n-1) \rho) \sigma_{\theta}^{2}\right)}$. The equilibrium coefficients are given by:

$$
\begin{aligned}
& \mathrm{a}^{\mathrm{c}}=\frac{(1-\rho) \sigma_{\theta}^{2}}{\left(\sigma_{\varepsilon}^{2}+(1-\rho) \sigma_{\theta}^{2}\right)} \lambda^{-1}, \mathrm{~b}^{\mathrm{c}}=\frac{1}{1+\mathrm{M}}\left(\frac{\alpha}{\beta} \mathrm{M}-\frac{\sigma_{\varepsilon}^{2}}{\left(\sigma_{\varepsilon}^{2}+(1+(\mathrm{n}-1) \rho) \sigma_{\theta}^{2}\right)} \lambda^{-1} \bar{\theta}\right), \\
& \text { and } \mathrm{c}^{\mathrm{c}}=\frac{\lambda^{-1}-(\beta \mathrm{n})^{-1} \mathrm{M}}{\mathrm{M}+1}
\end{aligned}
$$

It is immediate that $1 / \lambda>c^{c}>-1 / \beta n, a>0, c^{c}$ is strictly decreasing in $M$, and $c^{c}>0$ for $\mathrm{M}=0$.

Proof of Proposition 6: Recall that the $\mathrm{n}$ subscript denotes the n-replica market. Note first that from the equation $f_{n}(c)=0$ in the n-replica market defining $c_{n}$ (just replace $\beta$ by $\beta / n$ in $f(c)=0$ ) we have that $c_{n} \underset{n}{\longrightarrow} c_{\infty} \equiv \frac{\lambda^{-1}-\beta^{-1} M_{\infty}}{M_{\infty}+1}$ if $\rho>0$ where $M_{\infty} \equiv \frac{\sigma_{\varepsilon}^{2}}{(1-\rho) \sigma_{\theta}^{2}}\left(\right.$ and $\left.M_{n} \underset{n}{\longrightarrow} M_{\infty}\right)$, and $c_{n} \underset{n}{\longrightarrow} \lambda^{-1}$ if $\rho=0$. It is immediate then that the order of the distortion $d_{n}=\left(\beta^{-1} n+(n-1) c_{n}\right)^{-1}$ is $1 / n$ and the same holds for $c_{n}-c_{n}^{c}=\left(\left(d_{n}+\lambda\right)^{-1}-\lambda^{-1}\right) /\left(M_{n}+1\right)$ and $a_{n}^{c}-a_{n}=\left(\lambda^{-1}-\left(d_{n}+\lambda\right)^{-1}\right) /(M+1)>0$. (Note also that we have $\left.c_{n}=\left(\lambda+d_{n}\right)^{-1}-\left(\beta^{-1}+c_{n}\right) M_{n}\right)$.

Let us show first the order for the price difference $E\left[\left(p_{n}-p_{n}^{c}\right)^{2}\right]$. We know that $\mathrm{p}_{\mathrm{n}}-\mathrm{p}_{\mathrm{n}}^{\mathrm{c}}=\beta\left(\tilde{\mathrm{x}}_{\mathrm{n}}^{\mathrm{c}}-\tilde{\mathrm{x}}_{\mathrm{n}}\right)$ and that $\mathrm{E}\left[\left(\tilde{\mathrm{x}}_{\mathrm{n}}-\tilde{\mathrm{x}}_{\mathrm{n}}^{\mathrm{c}}\right)^{2}\right]=\left((\beta+\lambda)^{-1}-\left(\beta+\lambda+\mathrm{d}_{\mathrm{n}}\right)^{-1}\right)^{2} \mathrm{E}\left[\left(\alpha-\tilde{\mathrm{t}}_{\mathrm{n}}\right)^{2}\right]$, where $\quad \tilde{\mathrm{t}}_{\mathrm{n}}=\mathrm{E}\left[\tilde{\theta}_{\mathrm{n}} \mid \tilde{\mathrm{s}}_{\mathrm{n}}\right]=\xi_{\mathrm{n}} \tilde{\mathrm{s}}_{\mathrm{n}}+\left(1-\xi_{\mathrm{n}}\right) \bar{\theta} \quad$ and $\quad \xi_{\mathrm{n}} \equiv \operatorname{var}\left[\tilde{\theta}_{\mathrm{n}}\right] /\left(\operatorname{var}\left[\tilde{\theta}_{\mathrm{n}}\right]+\sigma_{\varepsilon}^{2} / \mathrm{n}\right)$, $\operatorname{var}\left[\tilde{\theta}_{n}\right]=(1+(n-1) \rho) \sigma_{\theta}^{2} / n$. It follows that $\tilde{\theta}_{n} \rightarrow \tilde{\theta}_{\infty}$ in mean square as $n$ tends to infinity where $\tilde{\theta}_{\infty}$ is normally distributed with mean $\bar{\theta}$ and variance $\rho \sigma_{\theta}^{2}$. In consequence, 
$\tilde{\mathrm{s}}_{\mathrm{n}}=\left(\sum_{\mathrm{i}} \mathrm{s}_{\mathrm{i}}\right) / \mathrm{n}=\tilde{\theta}_{\mathrm{n}}+\left(\sum_{\mathrm{i}} \varepsilon_{\mathrm{i}}\right) / \mathrm{n}$ will converge also in mean square to $\tilde{\theta}_{\infty}$ (since $\left(\sum_{\mathrm{i}} \varepsilon_{\mathrm{i}}\right) / \mathrm{n} \underset{\mathrm{n}}{\longrightarrow} 0$ in mean square). $\quad$ Since $\xi_{\mathrm{n}} \stackrel{\mathrm{n}}{\longrightarrow} 1$ it follows that $\tilde{\mathrm{t}}_{\mathrm{n}} \longrightarrow \tilde{\theta}_{\infty}$ in mean square and therefore $E\left[\left(\tilde{\mathfrak{t}}_{\mathrm{n}}\right)^{2}\right]$ and $E\left[\left(\alpha-\tilde{\mathfrak{t}}_{\mathrm{n}}\right)^{2}\right]$ are of the order of a constant. The order of $E\left[\left(p_{n}-p_{n}^{c}\right)^{2}\right]$ and of $E\left[\left(\tilde{x}_{n}-\tilde{x}_{n}^{c}\right)^{2}\right]$ is the order of $\left((\beta+\lambda)^{-1}-\left(\beta+\lambda+d_{n}\right)^{-1}\right)^{2}$ which is $1 / n^{2}$ since $d_{n}=\left(\beta^{-1} n+(n-1) c_{n}\right)^{-1}$ is of the order of $1 / n$.

We know also that $E\left[\left(u_{i n}-u_{i n}^{c}\right)^{2}\right]=\left(\lambda^{-1}-\left(\lambda+d_{n}\right)^{-1}\right)^{2} E\left[\left(t_{i}-\tilde{t}_{n}\right)^{2}\right]$ where $\mathrm{t}_{\mathrm{i}} \equiv \mathrm{E}\left[\theta_{\mathrm{i}} \mid \mathrm{s}\right]=\mathrm{E}\left[\theta_{\mathrm{i}} \mid \mathrm{s}_{\mathrm{i}}, \sum_{\mathrm{j} \neq \mathrm{i}} \mathrm{s}_{\mathrm{j}}\right]$. From the expression for $\mathrm{E}\left[\theta_{\mathrm{i}} \mid \mathrm{s}_{\mathrm{i}}, \sum_{\mathrm{j} \neq \mathrm{i}} \mathrm{s}_{\mathrm{j}}\right]$, and the fact that $\mathrm{M}_{\mathrm{n}} \longrightarrow \mathrm{n} \mathrm{M}_{\infty}$ and $\tilde{\mathrm{s}}_{\mathrm{n}} \longrightarrow \mathrm{n} \tilde{\theta}_{\infty}$ in mean square, it follows that $\mathrm{t}_{\mathrm{i}} \rightarrow \mathrm{E}\left[\theta_{\mathrm{i}} \mid \mathrm{s}_{\mathrm{i}}, \tilde{\theta}_{\infty}\right]=\left(1+\mathrm{M}_{\infty}\right)^{-1} \mathrm{~s}_{\mathrm{i}}+\mathrm{M}_{\infty}\left(1+\mathrm{M}_{\infty}\right)^{-1} \tilde{\theta}_{\infty}$ in mean square as $\mathrm{n}$ tends to infinity, and $E\left[\left(t_{i}-\tilde{t}_{n}\right)^{2}\right]$ is of the order of a constant. It follows that $E\left[\left(u_{i n}-u_{i n}^{c}\right)^{2}\right]$ is of order $1 / \mathrm{n}^{2}$ since $\left(\lambda^{-1}-\left(\lambda+d_{n}\right)^{-1}\right)^{2}$ is. We conclude that $\left(\mathrm{ETS}^{\mathrm{c}}-\mathrm{ETS}\right) / \mathrm{n}=\left((\beta+\lambda) \mathrm{E}\left[\left(\mathrm{x}_{\mathrm{n}}-\mathrm{x}_{\mathrm{n}}^{\mathrm{c}}\right)^{2}\right]+\lambda \mathrm{E}\left[\left(\mathrm{u}_{\mathrm{in}}-\mathrm{u}_{\mathrm{in}}^{\mathrm{c}}\right)^{2}\right]\right) / 2$ is of order $1 / \mathrm{n}^{2}$.

\section{Appendix II: Information acquisition}

In this Appendix we characterize the equilibrium with costly information acquisition. Consider the model of Section 2 and suppose now that private signals have to be purchased at a cost, increasing and convex in the precision $\tau_{\varepsilon}$ of the signal, according to a smooth function $H(\cdot)$ that satisfies $H(0)=0, H^{\prime}>0$ for $\tau_{\varepsilon}>0$, and $H^{\prime \prime} \geq 0$. There are, thus, nonincreasing returns to information acquisition. A strategy for seller $\mathrm{i}$ is a pair $\left(\tau_{\varepsilon_{\mathrm{i}}}, \mathrm{X}_{\mathrm{i}}(.,).\right)$ determining the precision purchased and the supply function strategy. We 
analyze the symmetric equilibria of the game. Note that in order for $\left(\left(\frac{1}{\sigma_{\varepsilon_{1}}^{2}}\right), X_{i}(\cdot, \cdot)\right)_{i=1, \ldots n}$ to be a pure equilibrium of the game, $\left(X_{i}(\cdot, \cdot)\right)_{i=1, \ldots n}$ needs to be the equilibrium of a game for a given precision tuple $\left(\left(\frac{1}{\sigma_{\varepsilon_{\mathrm{i}}}^{2}}\right)\right)_{\mathrm{i}=1, \ldots \mathrm{n}}$. Since we are interested in studying a symmetric equilibrium, we assume that any seller $\mathrm{j} \neq \mathrm{i}$ has the same precision, denoted by $\frac{1}{\sigma_{\varepsilon}^{2}}$, and the same coefficients, denoted by $(b, a, c)$, for the candidate equilibrium supply function $X\left(s_{j}, p\right)=b-a s_{j}+c p, j \neq i$. Provided that $1+\beta(n-1) c>0$ and exactly as in Section 2 we obtain a supply function for seller $\mathrm{i}$

$$
X_{i}\left(s_{i}, p\right)=\left(p-E\left[\theta_{i} \mid s_{i}, p\right]\right) /(d+\lambda)
$$

with $d=\left(\beta^{-1}+(n-1) c\right)^{-1}$. Now, as in the proof of Proposition 1 from the point of view of seller $\mathrm{i}$ and provided $\mathrm{a}>0$ the price is informationally equivalent to $\mathrm{h}_{\mathrm{i}} \equiv\left(\beta \mathrm{b}(\mathrm{n}-1)-\alpha+(1+\beta(\mathrm{n}-1) \mathrm{c}) \mathrm{p}+\beta \mathrm{x}_{\mathrm{i}}\right) / \beta \mathrm{a}=\sum_{\mathrm{j} \neq \mathrm{i}} \mathrm{s}_{\mathrm{j}}$, and applying standard Gaussian theory we obtain

$$
\mathrm{E}\left(\theta_{\mathrm{i}} \mid \mathrm{s}_{\mathrm{i}}, \mathrm{h}_{\mathrm{i}}\right)=\bar{\theta}+\frac{\sigma_{\theta}^{2}\left(\sigma_{\theta}^{2}+(\mathrm{n}-2) \rho \sigma_{\theta}^{2}+\sigma_{\varepsilon}^{2}\right)-(\mathrm{n}-1)\left(\rho \sigma_{\theta}^{2}\right)^{2}}{\Delta_{\mathrm{i}}}\left(\mathrm{s}_{\mathrm{i}}-\bar{\theta}\right)+\frac{\rho \sigma_{\theta}^{2} \sigma_{\varepsilon_{\mathrm{i}}}^{2}}{\Delta_{\mathrm{i}}}\left(\mathrm{h}_{\mathrm{i}}-(\mathrm{n}-1) \bar{\theta}\right)
$$

Where $\Delta_{\mathrm{i}} \equiv\left(\sigma_{\theta}^{2}+\sigma_{\varepsilon_{\mathrm{i}}}^{2}\right)\left((1+(\mathrm{n}-2) \rho) \sigma_{\theta}^{2}+\sigma_{\varepsilon}^{2}\right)-(\mathrm{n}-1) \sigma_{\theta}^{4} \rho^{2}$.

Using the expression for the demand function of $i$ and $h_{i}$ and identifying coefficients with $\mathrm{X}_{\mathrm{i}}\left(\mathrm{s}_{\mathrm{i}}, \mathrm{p}\right)=\mathrm{b}_{\mathrm{i}}-\mathrm{a}_{\mathrm{i}} \mathrm{s}_{\mathrm{i}}+\mathrm{c}_{\mathrm{i}} \mathrm{p}$ we obtain

$$
\mathrm{a}_{\mathrm{i}}=\frac{\frac{\sigma_{\theta}^{2}\left(\sigma_{\theta}^{2}+(\mathrm{n}-2) \rho \sigma_{\theta}^{2}+\sigma_{\varepsilon}^{2}\right)-(\mathrm{n}-1)\left(\rho \sigma_{\theta}^{2}\right)^{2}}{\Delta_{\mathrm{i}}}}{\frac{\beta}{1+\beta(\mathrm{n}-1) \mathrm{c}}+\lambda+\frac{\rho \sigma_{\theta}^{2} \sigma_{\varepsilon_{\mathrm{i}}}^{2}}{a \Delta_{\mathrm{i}}}}, \mathrm{b}_{\mathrm{i}}=\frac{-\frac{\left((1-\rho) \sigma_{\theta}^{2}+\sigma_{\varepsilon}^{2}\right) \sigma_{\varepsilon_{\mathrm{i}}}^{2} \bar{\theta}}{\Delta_{\mathrm{i}}}-\frac{\rho \sigma_{\theta}^{2} \sigma_{\varepsilon_{\mathrm{i}}}^{2}\left((\mathrm{n}-1) \mathrm{b}-\frac{\alpha}{\beta}\right)}{\mathrm{a} \Delta_{\mathrm{i}}}}{\frac{\beta}{1+\beta(\mathrm{n}-1) \mathrm{c}}+\lambda+\frac{\rho \sigma_{\theta}^{2} \sigma_{\varepsilon_{\mathrm{i}}}^{2}}{\mathrm{a} \Delta_{\mathrm{i}}}}, \text { and } \mathrm{c}_{\mathrm{i}}=\frac{1-\frac{\rho \sigma_{\theta}^{2} \sigma_{\varepsilon_{\mathrm{i}}}^{2}}{\Delta_{\mathrm{i}} \mathrm{a}}\left(\frac{1+\beta(\mathrm{n}-1) \mathrm{c}}{\beta}\right)}{\frac{\beta}{1+\beta(\mathrm{n}-1) \mathrm{c}}+\lambda+\frac{\rho \sigma_{\theta}^{2} \sigma_{\varepsilon_{\mathrm{i}}}^{2}}{\Delta_{\mathrm{i}} \mathrm{a}}} \text {. }
$$

The expected profits of seller i from trading are given by

$$
\mathrm{E}\left[\pi_{\mathrm{i}}\right]=\left(\frac{\beta}{1+\mathrm{c} \beta(\mathrm{n}-1)}+\frac{\lambda}{2}\right) \mathrm{E}\left[\left(\mathrm{X}_{\mathrm{i}}\left(\mathrm{s}_{\mathrm{i}}, \mathrm{p}\right)\right)^{2}\right] \text {. }
$$


After some lengthy manipulations it can be checked that $E\left[\pi_{\mathrm{i}}\right]=$ $\frac{\frac{\sigma_{\theta}^{2}\left(\sigma_{\theta}^{2}(1-\rho)(\rho(\mathrm{n}-1)+1)+\sigma_{\varepsilon}^{2}\right)\left(\sigma_{\theta}^{2}\left(\mathrm{a} \beta \rho(\mathrm{n}-1)-(1+c \beta((\mathrm{n}-1)))^{2}+\mathrm{a}^{2} \beta^{2}(\mathrm{n}-1)\left(\sigma_{\theta}^{2}(1-\rho)\right)(\rho(\mathrm{n}-1)+1)+\sigma_{\varepsilon}^{2}\right)\right)+\sigma_{\varepsilon_{\mathrm{i}}}^{2}(\mathrm{n}-1)\left(\sigma_{\theta}^{2} \rho(1+\mathrm{c} \beta(\mathrm{n}-1))-\mathrm{a} \beta\left(\sigma_{\theta}^{2}(\rho(\mathrm{n}-2)+1)+\sigma_{\varepsilon}^{2}\right)\right)^{2}}{\left(\sigma_{\theta}^{4}(1-\rho)(\rho(\mathrm{n}-1)+1)+\sigma_{\theta}^{2} \sigma_{\varepsilon}^{2}+\sigma_{\varepsilon_{\mathrm{i}}}^{2}\left(\sigma_{\theta}^{2}(\rho(\mathrm{n}-2)+1)+\sigma_{\varepsilon}^{2}\right)\right)}+((\alpha-\bar{\theta})-(\mathrm{b}+\bar{\theta}(\mathrm{c}-\mathrm{a})) \beta(\mathrm{n}-1))^{2}}{2(1+\mathrm{c} \beta(\mathrm{n}-1))(2 \beta+\lambda(1+\mathrm{c} \beta(\mathrm{n}-1)))}$.

The marginal benefit of acquiring precision $\tau_{\varepsilon_{\mathrm{i}}} \equiv 1 / \sigma_{\varepsilon_{\mathrm{i}}}^{2}, \partial \mathrm{E}\left[\pi_{\mathrm{i}}\right] / \partial \tau_{\varepsilon_{\mathrm{i}}}$, evaluated at a symmetric solution $\tau_{\varepsilon_{\mathrm{i}}}=\tau_{\varepsilon}$ is given by

$$
\psi\left(\tau_{\varepsilon}\right) \equiv \frac{1}{2\left(2 \beta(1+(\mathrm{n}-1) \beta \mathrm{c})^{-1}+\lambda\right)} \frac{\left(\tau_{\varepsilon}(1-\rho)(1+\rho(\mathrm{n}-1))+\tau_{\theta}\right)^{2}}{\left(\tau_{\varepsilon}(1-\rho)+\tau_{\theta}\right)^{2}\left(\tau_{\varepsilon}(1+\rho(\mathrm{n}-1))+\tau_{\theta}\right)^{2}}
$$

(note that it is decreasing in $\tau_{\varepsilon}$ for a given $\mathrm{c}$ ). Interior symmetric equilibria are characterized by the solution of $\psi\left(\tau_{\varepsilon}\right)-\mathrm{H}^{\prime}\left(\tau_{\varepsilon}\right)=0$ with $\mathrm{c}\left(\tau_{\varepsilon}\right)$ given by the largest solution to the quadratic equation $\mathrm{g}(\mathrm{c})=0$ for a given $\tau_{\varepsilon} \cdot{ }^{56}$ Let $\mathrm{c}(0+) \equiv \lim _{\tau_{\varepsilon} \rightarrow 0} \mathrm{c}\left(\tau_{\varepsilon}\right)$. This is well defined and is a function of $\beta, \lambda, \rho$ and $n$ since as $\tau_{\varepsilon} \rightarrow 0$ we have that $\mathrm{M} \rightarrow \rho \mathrm{n} /(1-\rho)$. Then $\psi(0) \equiv \lim _{\tau_{\varepsilon} \rightarrow 0} \psi\left(\tau_{\varepsilon}\right)=\frac{1}{2\left(2 \beta(1+(\mathrm{n}-1) \beta \mathrm{c}(0+))^{-1}+\lambda\right) \tau_{\theta}^{2}}>0$, and $\psi\left(\tau_{\varepsilon}\right) \rightarrow 0$ as $\tau_{\varepsilon} \rightarrow \infty$.

If $\mathrm{H}^{\prime}(0)<\psi(0)$ for $\rho<1$ there is an interior solution $\tau_{\varepsilon}^{*}>0$ to the equation

$$
\phi\left(\tau_{\varepsilon}\right) \equiv \psi\left(\tau_{\varepsilon}\right)-\mathrm{H}^{\prime}\left(\tau_{\varepsilon}\right)=0
$$

since $\phi(0)>0, \phi(\infty)<0$ and $\phi(\cdot)$ is continuous. With considerable work, one can show that the solution is unique at least if $\mathrm{n}=2$ or if $\rho$ is close to 0 or 1 .

If $\mathrm{H}^{\prime}(0) \geq \psi(0)$ then there can not be any information acquisition in a symmetric equilibrium and in fact there is no equilibrium (with $\mathrm{H}^{\prime}(0)$ not too high). We have that

56 It can be checked that $\mathrm{E}\left[\pi_{\mathrm{i}}\right]$ is strictly concave in $\tau_{\varepsilon_{\mathrm{i}}}$. 
$\tau_{\varepsilon}^{*}=0$ at a candidate equilibrium but this can not be an overall equilibrium since if other sellers do not purchase information then the price contains no additional information for a seller and it will pay a single seller to get information (with $\mathrm{H}^{\prime}(0)$ not too high). As parameters $\beta, \lambda, \rho$ and n move in such a way that $\psi(0) \downarrow \mathrm{H}^{\prime}(0)$, then $\tau_{\varepsilon}^{*} \rightarrow 0$ and the linear supply function equilibrium collapses.

In summary:

Proposition A.1. Let $\psi(0) \equiv \frac{1}{2\left(2 \beta(1+(n-1) \beta c(0+))^{-1}+\lambda\right) \tau_{\theta}^{2}}$. There is a symmetric equilibrium in the game with costly information acquisition provided that $\mathrm{H}^{\prime}(0)<\psi(0)$ and $\rho<1$. At equilibrium sellers buy a positive precision of information $\tau_{\varepsilon}^{*}>0$. This is so in particular if $\mathrm{H}^{\prime}(0)=0$ or the prior is diffuse enough $\left(\tau_{\theta}\right.$ small) (even if the number of sellers is large and/or $\rho$ close to 1$)$. As $\rho \rightarrow 1$ we have that $\psi(0) \rightarrow \frac{1}{2(2 \beta n+\lambda) \tau_{\theta}^{2}}$ since $\mathrm{c}(0+) \rightarrow-1 / \beta \mathrm{n}$.

In the replica economy (Section 6) we have to replace $\beta$ by $\beta / \mathrm{n}$ and we have that $\psi_{\mathrm{n}}(0) \equiv \frac{1}{2\left(2 \beta\left(\mathrm{n}+(\mathrm{n}-1) \beta \mathrm{c}_{\mathrm{n}}(0+)\right)^{-1}+\lambda\right) \tau_{\theta}^{2}}>0$. Proposition A.1 applies with $\psi_{\mathrm{n}}(0)$ instead of $\psi(0)$. Now, as $\rho \rightarrow 1$ we have that $\psi_{\mathrm{n}}(0) \rightarrow \frac{1}{2(2 \beta+\lambda) \tau_{\theta}^{2}}$ since $c_{n}(0+) \rightarrow-1 / \beta$. For $\rho$ close to 1 for any number of sellers we will need the same degree of diffusion of the prior in order to have positive precision acquisition.

\section{Appendix III: Cournot competition}

Consider the market exactly as in Section 2 in the replica version (section 4) but now seller i sets a quantity contingent on its information $\left\{\mathrm{s}_{\mathrm{i}}\right\} .57$ The seller has no other source

57 See Vives (2002) for related results when cost parameters are i.i.d. and Vives (1988) for the common value case. 
of information and, in particular, does not condition on the price. The expected profits of seller $\mathrm{i}$ conditional on receiving signal $\mathrm{s}_{\mathrm{i}}$ and assuming seller $\mathrm{j}, \mathrm{j} \neq \mathrm{i}$, uses strategy $\mathrm{X}_{\mathrm{j}}\left(\mathrm{s}_{\mathrm{j}}\right)$, are

$$
E\left[\pi_{i} \mid s_{i}\right]=x_{i}\left(P_{n}\left(\sum_{j \neq i} X_{j}\left(s_{j}\right)+x_{i}\right)-E\left[\theta_{i} \mid s_{i}\right]\right)-\frac{\lambda}{2} x_{i}^{2}
$$

From the F.O.C. of the optimization of a seller we obtain

$$
\mathrm{p}-\left(\mathrm{E}\left[\theta_{\mathrm{i}} \mid \mathrm{s}_{\mathrm{i}}\right]+\lambda \mathrm{x}_{\mathrm{i}}\right)=\frac{\beta}{\mathrm{n}} \mathrm{x}_{\mathrm{i}}
$$

(Note that given that the profit function is strictly concave and the information structure symmetric, equilibria will be symmetric.) It follows that

$$
\frac{\mathrm{p}-\mathrm{E}\left[\mathrm{MC}_{\mathrm{n}}\right]}{\mathrm{p}}=\frac{1}{\mathrm{n} \eta_{\mathrm{n}}}
$$

where $E_{n}\left[M C_{n}\right] \equiv \frac{1}{n} \sum_{i=1}^{n}\left(E\left[\theta_{i} \mid s_{i}\right]+\lambda x_{i}\right)=\frac{1}{n} \sum_{i=1}^{n} E\left[\theta_{i} \mid s_{i}\right]+\lambda \tilde{x}_{n}$ and $\eta_{n}=p /\left(\beta \tilde{x}_{n}\right)$. The margins are larger or smaller than in the supply function equilibrium case depending on whether the slope of supply $c_{n}$ is positive or negative since in the Cournot case they correspond to the case of $c_{n}=0$.

The following proposition characterizes the Bayesian Cournot equilibrium and the pricetaking Bayesian Cournot equilibrium (denoted by a superscript c). Both equilibria are different from their supply function counterparts (except in the knife-edge case for which $\left.\mathrm{c}_{\mathrm{n}}=0\right)$ since there is no conditioning in the market price. We will abuse somewhat notation and we will use the same notation for parameters at the Cournot equilibrium than at the supply function one.

Proposition A.4. There is a unique equilibrium and a unique price-taking Bayesian Cournot equilibrium. They are symmetric, and affine in the signals. Letting $\xi \equiv \sigma_{\theta}^{2} /\left(\sigma_{\theta}^{2}+\sigma_{\varepsilon}^{2}\right)$ the strategies of the sellers are given (respectively) by: 


$$
\begin{aligned}
& X_{n}\left(s_{i}\right)=b_{n}(\alpha-\bar{\theta})-a_{n}\left(s_{i}-\bar{\theta}\right), \text { where } a_{n}=\frac{\xi}{\frac{2 \beta}{n}+\lambda+\beta \frac{n-1}{n} \rho \xi}, \text { and } b_{n}=\frac{1}{\lambda+\beta\left(\frac{1+n}{n}\right)} \\
& X_{n}^{c}\left(s_{i}\right)=b_{n}^{c}(\alpha-\bar{\theta})-a_{n}^{c}\left(s_{i}-\bar{\theta}\right), \text { where } a_{n}^{c}=\frac{\xi}{\frac{\beta}{n}+\lambda+\beta \frac{n-1}{n} \rho \xi}, \text { and } b_{n}^{c}=\frac{1}{\lambda+\beta} .
\end{aligned}
$$

Proof: Drop the subscript $\mathrm{n}$ labeling the replica market and let $\beta=1$. We consider first the Bayesian Cournot equilibrium. We check that the candidate strategies form an equilibrium. The expected profits of seller $\mathrm{i}$ conditional on receiving signal $\mathrm{s}_{\mathrm{i}}$ and assuming seller $\mathrm{j}, \mathrm{j} \neq \mathrm{i}$, uses strategy $\mathrm{X}_{\mathrm{j}}(\cdot)$, are

$$
E\left[\pi_{i} \mid s_{i}\right]=x_{i}\left(\alpha-E\left[\theta_{i} \mid s_{i}\right]-\frac{1}{n} \sum_{j \neq i} E\left[X_{j}\left(s_{j}\right) \mid s_{i}\right]-\left(\frac{1}{n}+\frac{\lambda}{2}\right) x_{i}\right) .
$$

Then first order conditions (F.O.C.) yield for $i=1, \ldots, n$ :

$$
\alpha-E\left[\theta_{i} \mid s_{i}\right]-\frac{1}{n} \sum_{j \neq i} E\left[X_{j}\left(s_{j}\right) \mid s_{i}\right]=2\left(\frac{1}{n}+\frac{\lambda}{2}\right) X_{i}\left(s_{i}\right)
$$

Plugging in the candidate equilibrium strategy and using the formulae for the conditional expectations for $E\left[\theta_{i} \mid s_{i}\right]$ and $E\left[s_{j} \mid s_{i}\right]$,

$$
\mathrm{E}\left[\theta_{\mathrm{i}} \mid \mathrm{s}_{\mathrm{i}}\right]=\xi \mathrm{s}_{\mathrm{i}}+(1-\xi) \bar{\theta} \text { and } \mathrm{E}\left[\mathrm{s}_{\mathrm{j}} \mid \mathrm{s}_{\mathrm{i}}\right]=\mathrm{E}\left[\theta_{\mathrm{j}} \mid \mathrm{s}_{\mathrm{i}}\right]=\xi \rho \mathrm{s}_{\mathrm{i}}+(1-\xi \rho) \bar{\theta}
$$

it is easily checked that they satisfy the F.O.C. (which are also sufficient in our model). To prove uniqueness we show that the Bayesian Cournot equilibria of our game are in one-to-one correspondence with the (person-by-person) optimization of an appropriately defined concave quadratic team function $G$. A team decision rule $\left(X_{1}\left(s_{1}\right), \ldots, X_{n}\left(s_{n}\right)\right)$ is (person-by-person) optimal if it can not be improved upon by changing only one 
component $\mathrm{X}_{\mathrm{i}}(\cdot)$ (i.e. each agent maximizes the team objective conditional on his information and taking as given the strategies of the other agents.) Let $\mathrm{G}(\mathrm{x})=\pi_{\mathrm{i}}(\mathrm{x})+\mathrm{f}_{\mathrm{i}}\left(\mathrm{x}_{-\mathrm{i}}\right)$ where

$$
f_{i}\left(x_{-i}\right)=\sum_{j \neq i}\left(\alpha-\theta_{j}\right) x_{j}-\left(\frac{1}{n}+\frac{\lambda}{2}\right) \sum_{j \neq i} x_{j}^{2}-\frac{1}{2 n} \sum_{\substack{k \neq j \\ k, j \neq i}} x_{k} x_{j} .
$$

This yields

$$
G(x)=\sum_{j}\left(\alpha-\theta_{j}\right) x_{j}-\left(\frac{1}{n}+\frac{\lambda}{2}\right) \sum_{j} x_{j}^{2}-\frac{1}{2 n} \sum_{i \neq j} x_{i} x_{j}
$$

We obtain the same outcome by solving either $\max _{x_{i}} E\left[\pi_{i} \mid s_{i}\right]$ or $\max _{x_{i}} E\left[G \mid s_{i}\right]$ since $f_{i}\left(x_{-i}\right)$ does not involve $x_{i}$. Note now that person-by-person optimization is equivalent in our context to the global optimization of the team function (since the random term does not affect the coefficients of the quadratic terms and the team function is concave in actions, Radner (1962, Theorem 4)). Invoke the result by Radner (1962, Theorem 5)), which implies that in our model, the components of the unique Bayesian team decision function of the equivalent team problem are affine. Based on the above three observations conclude that the affine Bayesian Cournot equilibrium is the unique equilibrium.

A similar argument establishes the result for the Bayesian price-taking equilibrium. Then the F.O.C. for seller $\mathrm{i}$ is given by

$$
\alpha-E\left[\theta_{i} \mid s_{i}\right]-\frac{1}{n} \sum_{j} E\left[X_{j}\left(s_{j}\right) \mid s_{i}\right]=\lambda X_{i}\left(s_{i}\right)
$$

and the solution is a (person-by-person) maximum of a team problem with an objective function which is precisely the ETS.

We consider, as before, convergence to price taking and its speed as the economy is replicated. The following proposition characterizes the convergence of the Bayesian 
Cournot equilibrium to a price-taking equilibrium. ETS $\left(\operatorname{ETS}_{n}^{c}\right)$ denotes here the expected total surplus at the (price-taking) Bayesian Cournot equilibrium.

Proposition A.5. As the market grows large the market price $\mathrm{p}_{\mathrm{n}}$ at the Bayesian Cournot equilibrium converges in mean square to the price-taking Bayesian Cournot price $\mathrm{p}_{\mathrm{n}}^{\mathrm{c}}$ at the rate of $1 / n$. (That is, $E\left[\left(p_{n}-p_{n}^{c}\right)^{2}\right]$ tends to 0 at the rate of $1 / n^{2}$.) The difference $\left(\operatorname{ETS}_{\mathrm{n}}^{\mathrm{c}}-\mathrm{ETS}_{\mathrm{n}}\right) / \mathrm{n}$ is of the order of $1 / \mathrm{n}^{2}$.

Proof: Let us show first the order for the price difference $E\left[\left(p_{n}-p_{n}^{c}\right)^{2}\right]$. We know that $\mathrm{p}_{\mathrm{n}}-\mathrm{p}_{\mathrm{n}}^{\mathrm{c}}=\beta\left(\tilde{\mathrm{x}}_{\mathrm{n}}^{\mathrm{c}}-\tilde{\mathrm{x}}_{\mathrm{n}}\right)$ and, letting $\mathrm{r}_{\mathrm{i}} \equiv \mathrm{E}\left[\theta_{\mathrm{i}} \mid \mathrm{s}_{\mathrm{i}}\right]$ and $\tilde{\mathrm{r}}_{\mathrm{n}}=\left(\sum_{\mathrm{i}=1}^{\mathrm{n}} \mathrm{r}_{\mathrm{i}}\right) / \mathrm{n}$ it is easily checked that

$$
E\left[\left(\tilde{x}_{n}-\tilde{x}_{n}^{c}\right)^{2}\right]=\left((\beta+\lambda)^{-1}-(\beta+\lambda+\beta / n)^{-1}\right)^{2} E\left[\left(\alpha-\tilde{r}_{n}\right)^{2}\right],
$$

where $\tilde{\mathrm{r}}_{\mathrm{n}}=\xi \tilde{\mathrm{s}}_{\mathrm{n}}+(1-\xi) \bar{\theta}$ and $\xi \equiv \sigma_{\theta}^{2} /\left(\sigma_{\theta}^{2}+\sigma_{\varepsilon}^{2}\right)$. From this it follows that $\tilde{r}_{n} \rightarrow \xi \tilde{\theta}+(1-\xi) \bar{\theta}$ in mean square and therefore $E\left[\left(\alpha-\tilde{r}_{n}\right)^{2}\right]$ is of the order of a constant. The order of $E\left[\left(p_{n}-p_{n}^{c}\right)^{2}\right]$ and of $E\left[\left(\tilde{x}_{n}-\tilde{x}_{n}^{c}\right)^{2}\right]$ is the order of $\left((\beta+\lambda)^{-1}-(\beta+\lambda+\beta / \mathrm{n})^{-1}\right)^{2}$ which is $1 / \mathrm{n}^{2}$.

It is easily checked also that $E\left[\left(u_{\text {in }}-u_{\text {in }}^{c}\right)^{2}\right]=\left(\lambda^{-1}-(\lambda+\beta / n)^{-1}\right)^{2} E\left[\left(r_{i}-\tilde{r}_{n}\right)^{2}\right]$. The order of $E\left[\left(r_{i}-\tilde{r}_{n}\right)^{2}\right]$ will be the same as $\xi^{2} E\left[\left(s_{i}-\tilde{s}_{n}\right)^{2}\right]$ which is the order of a constant. Since the order of $\left(\lambda^{-1}-(\lambda+\beta / n)^{-1}\right)^{2}$ is $1 / n^{2}$, it follows that the order of 


$$
\begin{aligned}
& \mathrm{E}\left[\left(\mathrm{u}_{\mathrm{in}}-\mathrm{u}_{\mathrm{in}}^{\mathrm{c}}\right)^{2}\right] \quad \text { is } \quad \text { also } 1 / \mathrm{n}^{2} \quad \text { We conclude that } \\
& \left(\mathrm{ETS}^{\mathrm{c}}-\mathrm{ETS}\right) / \mathrm{n}=\left((\beta+\lambda) \mathrm{E}\left[\left(\mathrm{x}_{\mathrm{n}}-\mathrm{x}_{\mathrm{n}}^{\mathrm{c}}\right)^{2}\right]+\lambda \mathrm{E}\left[\left(\mathrm{u}_{\mathrm{in}}-\mathrm{u}_{\mathrm{in}}^{\mathrm{c}}\right)^{2}\right]\right) / 2 \text { is of order } 1 / \mathrm{n}^{2} .
\end{aligned}
$$




\section{References}

Alba, J., I. Otero-Novas, C. Meseguer and C. Batlle (1999), "Competitor Behavior and Optimal Dispatch: Modelling Techniques for Decision-Making", The New Power Markets: Corporate Strategies for Risk and Reward. ed. R. Jameson, London: Risk Publications.

Allen, B. (1981), "Generic Existence of Completely Revealing Equilibria for Economies with Uncertainty when Prices Convey Information”, Econometrica, 49, 1173-1119.

Andersson, B. and L. Bergman (1995), "Market Structure and the Price of Electricity: An Ex Ante Analysis of the Deregulated Swedish Electricity Market", The Energy Journal, 16, 97-130.

Angeletos, G. M. and A. Pavan (2007), "Efficient Use of Information and Social Value of Information", Econometrica, 75, 4, 1103-1142.

Angeletos, G. M. and A. Pavan (2009), "Policy with Dispersed Information”, Journal of the European Economic Association, 7, 1, 1-50.

Ausubel, L. (2004), “An Efficient Ascending-Bid Auction for Multiple Objects", American Economic Review, 94, 1452-1475.

Ausubel, L. and P. Cramton (2008), “A Troubled Asset Reverse Auction”, mimeo.

Ausubel, L. and P. Cramton (2009), “A Two-Sided Legacy Loan Auction”, mimeo.

Back, K., and J. F. Zender (1993), "Auctions of Divisible Goods: On the Rationale for the Treasury Experiment", Review of Financial Studies, 6, 733-764.

Back, K., and J. Zender (2001), “Auctions of Divisible Goods with Endogenous Supply”, Economics Letters, 73, 29-34.

Baldick, R., Grant, R. and E. Kahn (2004), "Theory of an Application of Linear Supply Function Equilibrium in Electricity Markets”, Journal of Regulatory Economics, 25, 143-167.

Baldick, R. and W. Hogan (2006), "Stability of Supply Function Equilibria: Implications for Daily versus Hourly Bids in a Poolco Market", Journal of Regulatory Economics, 30, 119-139. 
Battacharya, U. and R. Spiegel (1991), "Insiders, Outsiders, and Market Breakdowns", Review of Financial Studies, 4, 2, 119-139.

Biais, B., D. Martimort and J. C. Rochet (2000), "Competing Mechanisms in a Common Value Environment”, Econometrica, 68, 4, 799-837.

Bindseil U., K. Nyborg, and I. Strebulaev (2005), "Bidding and Performance in Repo Auctions: Evidence from ECB Open Market Operations", Discussion Papers 2005/13, Department of Finance and Management Science, Norwegian School of Economics and Business Administration.

Borenstein, S. and J. Bushnell (1999), "An Empirical Analysis of the Potential for Market Power in California's Electricity Industry", Journal of Industrial Economics, 47, 285-323.

Borenstein, S., J. Bushnell and F. Wolak (2002), "Measuring Market Inefficiencies in California's Restructured Wholesale Electricity Market”, American Economic Review, 92, 1376-1405

Bushnell, J., E. Mansur and C. Saravia (2008), "Vertical Arrangements, Market Structure, and Competition: An Analysis of Restructured U.S. Electricity Markets", American Economic Review, 98, 1, 237-266.

Cammack, E. (1991), "Evidence on Bidding Strategies and the Information in Treasury Bill Auctions", Journal of Political Economy, 99, 1 100-130.

Cassola, N., A. Hortaçsu and J. Kastl (2009), “The 2007 Subprime Market Crisis Through the Lens of ECB Auctions for Short-Term Funds", NBER Working Papers 15158 .

Crampes C. and N. Fabra (2005), "The Spanish Electricity Industry: Plus Ça Change...", The Energy Journal, 26, 127-154.

Cripps, M. and J. Swinkels (2006), "Efficiency of Large Double Auctions", Econometrica, 74, 1, 47-92.

Ewerhart, C., N. Cassola and N. Valla (2009), "Declining Valuations and Equilibrium Bidding in Central Bank Refinancing Operations", ECB Working Paper Series \#668, forthcoming in International Journal of Industrial Organization.

Faulí-Oller, R. and M. Giralt (1995), "Competition and Cooperation within a Multidivisional Firm", Journal of Industrial Economics, 43, 77-99. 
Fershtman, Ch. and K. Judd (1987), "Equilibrium Incentives in Oligopoly", American Economic Review, 77, 927-940.

Flannery, M. J. (1996). "Financial Crises, Payment Systems Problems, and Discount Window Lending.” Journal of Money, Credit and Banking 28(4), 804-824.

Gordy, M. (1999), “Hedging Winner's Curse with Multiple Bids: Evidence from the Portuguese Treasury Bill Auction", Review of Economics and Statistics, 81, 448465.

Grant, S. and Quiggin, J. (1997), "Strategic Trade Policy under Uncertainty: Sufficient Conditions for the Optimality of Ad Valorem, Specific and Quadratic Trade Taxes”, International Economic Review, 38, 187-203.

Green, R. and D. Newbery (1992), "Competition in the British Electricity Spot Market", Journal of Political Economy, 100, 929-953.

Green, R. (1996), "Increasing Competition in the British Electricity Spot Market", Journal of Industrial Economics, 44, 205-216.

Green, R. (1999), “The Electricity Contract Market in England and Wales”, Journal of Industrial Economics, 47, 1, 107-124.

Grossman, S. (1981), "Nash Equilibrium and the Industrial Organization of Markets with Large Fixed Costs", Econometrica, 49, 5, 1149-1172.

Hart, O. (1985), "Imperfect Competition in General Equilibrium: An Overview of Recent Work" in Frontiers of Economics, ed. by K. Arrow and S. Honkapohja. Oxford: Basil Blackwell.

Holmberg, P., D. Newbery and D. Ralph (2008), "Supply Function Equilibria: Step Functions and Continuous Representations", Electricity Policy Research Group WP \# EPRG0829. Cambridge: University of Cambridge.

Hortaçsu, A. and S. Puller (2008), "Understanding Strategic Bidding in Multi-Unit Auctions: A Case Study of the Texas Electricity Spot Market", RAND Journal of Economics, 39, 1, 86-114.

Hortaçsu, A. and J. Kastl (2008), "Do Bidders in Canadian Treasury Bill Auctions Have Private Values?", mimeo. 
Jackson, M. (1991), "Equilibrium, Price Formation, and the Value of Private Information", Review of Financial Studies, 4, 1, 1-16.

Palfrey, T. (1985), "Uncertainty Resolution, Private Information Aggregation and the Cournot Competitive Limit”, Review of Economic Studies, 52, 168, 69-74.

Kandel, S., O. Sarig and A. Wohl (1999), "The Demand for Stocks: An Analysis of IPO Auctions", Review of Financial Studies, 12, 227-248.

Keloharju, M., K. Nyborg and K. Rydqvist (2005), "Strategic Behavior and Underpricing in Uniform Price Auctions: Evidence from Finnish Treasury Auctions", Journal of Finance, 60, 4, 1865-1902.

Klemperer, P. and M. Meyer (1989), "Supply Function Equilibria in Oligopoly under Uncertainty", Econometrica, 57, 1243-1277.

Klemperer, P. (2009), “A New Auction for Substitutes: Central-Bank Liquidity Auctions, "Toxic Asset" Auctions, and Variable Product-Mix Auctions", mimeo.

Kuhn, K-U. and M. Machado (2004), "Bilateral Market Power and Vertical Integration in the Spanish Electricity Spot Market”, CEPR Discussion Paper 4590.

Kremer, I. and K. Nyborg (2004), "Underpricing and Market Power in Uniform Price Auctions", Review of Financial Studies, 17, 849-877.

Kyle, A. S. (1989), "Informed Speculation with Imperfect Competition", Review of Economic Studies, 56, 317-355.

Laussel, D. (1992), "Strategic Commercial Policy Revisited: A Supply-Function Equilibrium Model”, American Economic Review, 82, 84-99.

LiCalzi, M. and A. Pavan (2005), "Tilting the Supply Schedule to Enhance Competition in Uniform-price Auctions", European Economic Review, 49, 227-250.

Mansur, E. and M. White (2009), "Market Organization and Efficiency in Electricity Markets", Yale School of Management Working Paper.

McAfee, P. and V. te Velde (2006), "Dynamic Pricing in the Airline Industry", forthcoming in Handbook on Economics and Information Systems, Ed: T.J. Hendershott, Elsevier. 
Milgrom, P.R. and R.J. Weber (1982), "A Theory of Auctions and Competitive Bidding”, Econometrica, 50, 1089-1122.

Morris, S. and H. Shin (2002), "The Social Value of Public Information", American Economic Review, 92, 1521-1534.

Niu, H., R. Baldick, and G. Zhu (2005), "Supply Function Equilibrium Bidding Strategies With Fixed Forward Contracts”, IEEE Transactions on Power Systems, 20, 4, 1859-1867.

Nyborg, K., K. Rydqvist and S. Sundaresan (2002), "Bidder Behavior in Multiunit Auctions: Evidence from Swedish Treasury Auctions", Journal of Political Economy, 110, 2, 394-424.

Perry, M. and P. Reny (1999), "On the Failure of the Linkage Principle in Multi-Unit Auctions", Econometrica, 67, 4, 895-900.

Radner, R. (1962), “Team Decision Problems”, Annals of Mathematical Statistics, 33, 857-888.

Ramos, A., M. Ventosa, and M. Rivier (1998), "Modeling Competition in Electric Energy Markets by Equilibrium Constraints”, Utilities Policy, 7, 223-242.

Reece, D. (1978), “Competitive Bidding for Offshore Petroleum Leases”, Bell Journal of Economics, 9, 2, 369-384.

Rudkevich, A. (2005). "On the Supply Function Equilibrium and its Applications in Electricity Markets", Decision Support Systems, 40, 409-425.

Sioshansi, R. and S. Oren (2007), "How Good are Supply Function Equilibrium Models: An Empirical Analysis of the ERCOT Balancing Market”, Journal of Regulatory Economics, 31, 1, 1-35.

Sklivas, S. (1987), “The Strategic Choice of Managerial Incentives”, RAND Journal of Economics, 18, 452-458.

Talluri, K. and G. Van Ryzin (2004), The Theory and Practice of Revenue Management. Dordrecht: Kluwer Academic Publishers. 
Vickers, J. (1985), "Delegation and the Theory of the Firm", Economic Journal Supplement, 95, 138-147.

Vives, X. (1986), “Commitment, Flexibility and Market Outcomes", International Journal of Industrial Organization, 4, 217-229.

Vives, X. (1988), "Aggregation of Information in Large Cournot Markets", Econometrica, 56, 4, 851-876.

Vives, X. (1999), Oligopoly Pricing: Old Ideas and New Tools, Cambridge: MIT Press.

Vives, X. (2002), "Private Information, Strategic Behavior, and Efficiency in Cournot Markets", RAND Journal of Economics, 33, 361-376.

Vives, X. (2009), "Endogenous public information and welfare”, mimeo.

von der Fher, N.H. and D. Harbord (1993), "Spot Market Competition in the U.K. Electricity Industry", Economic Journal, 103, 531-546.

Wang, J,. and J. Zender (2002), "Auctioning Divisible Goods", Economic Theory, 19, 673-705.

Wilson, R. (1979), “Auctions of Shares”, The Quarterly Journal of Economics, 93, 675689.

Wolfram, C. (1998), "Strategic Bidding in a Multiunit Auction: An Empirical Analysis of Bids to Supply Electricity in England and Wales", RAND Journal of Economics, $29,703-725$. 